LAW RENCE LIVERMORE N A T IO N A L LABORATORY

Becky Butlin

February 9, 2007 
This document was prepared as an account of work sponsored by an agency of the United States Government. Neither the United States Government nor the University of California nor any of their employees, makes any warranty, express or implied, or assumes any legal liability or responsibility for the accuracy, completeness, or usefulness of any information, apparatus, product, or process disclosed, or represents that its use would not infringe privately owned rights. Reference herein to any specific commercial product, process, or service by trade name, trademark, manufacturer, or otherwise, does not necessarily constitute or imply its endorsement, recommendation, or favoring by the United States Government or the University of California. The views and opinions of authors expressed herein do not necessarily state or reflect those of the United States Government or the University of California, and shall not be used for advertising or product endorsement purposes.

This work was performed under the auspices of the U.S. Department of Energy by University of California, Lawrence Livermore National Laboratory under Contract W-7405-Eng-48. 


\title{
Mirror Sub-Assembly End-Effector Design
}

\author{
By: \\ Becky Butlin
}

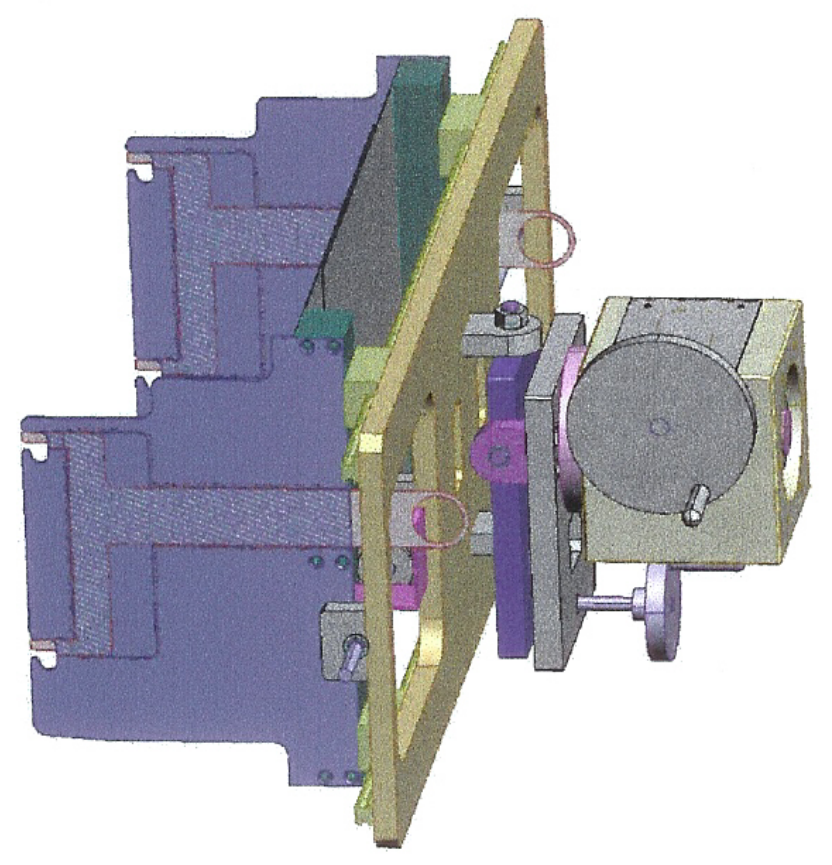

MS Plan II - Technical Report for Professor Michael Hill University of California, Davis

$12 / 29 / 06$ 


\section{Table of Contents}

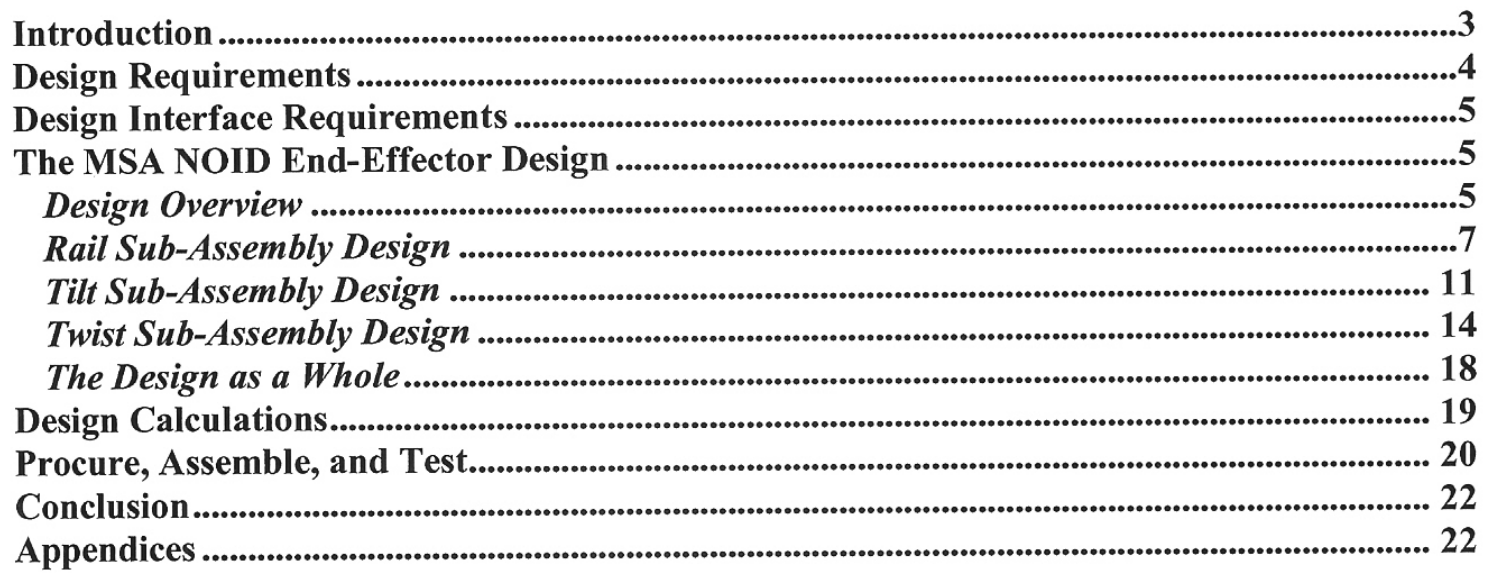

\section{Table of Figures}

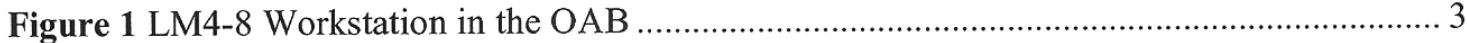

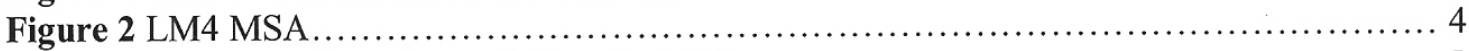

Figure 3 MSA Handling Fixture lifting the MSA ……........................................................... 5

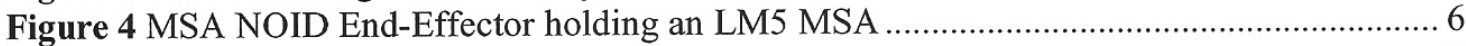

Figure 5 Three Sub-Assemblies of the MSA NOID End-Effector ............................................. 7

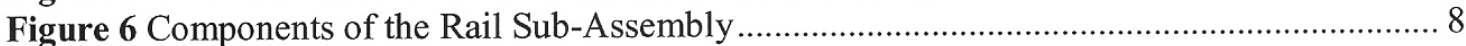

Figure 7 Additional components of the Rail Sub-Assembly ...................................................... 10

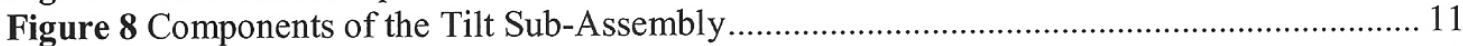

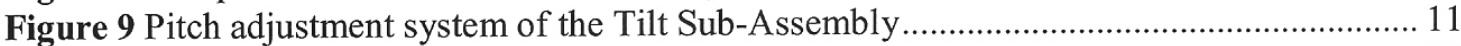

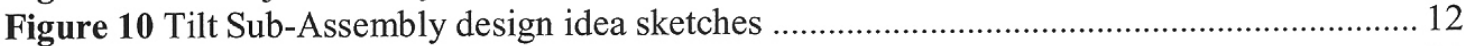

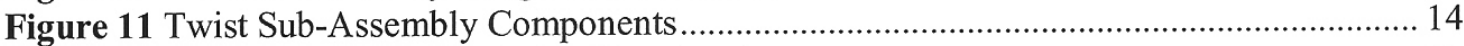

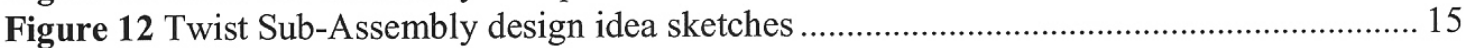

Figure 13 Twist mechanism of the Twist Sub-Assembly ............................................................ 17

Figure 14 MSA NOID End-Effector installed on the NOID arm ............................................ 18

Figure 15 MSA NOID End-Effector interface with an LM4 (upper) and an LM7 (lower)........ 19

Figure 16 Load test of the MSA NOID End-Effector.......................................

Figure 17 Fit and function test of the MSA NOID End-Effector with an LM5 Practice optic.... 21 


\section{Introduction}

The Optic Assembly Building (OAB) is a facility where large optical mirror units are assembled and installed into Line Replaceable Units (LRUs) for deployment into the National Ignition Facility (NIF) laser system. The New Optics Insertion Device (NOID), shown in Figure 1, is a powered jib crane specially designed to handle large optical assemblies. The NOID arm has three degrees of freedom. It can rotate about the vertical boom, travel up and down the boom, and extend away from and retract in towards the boom. The NOID is used to assist in the assembly of five types of Laser Mirror (LM) LRUs. These five LMs have been creatively named, LM4, LM5, LM6, LM7, and LM8. The LM4 and LM5 LRUs each contain four Mirror Sub-Assemblies (MSAs). The LM6, LM7, and LM8 LRUs each contain 2 MSAs. The MSAs are assembled apart from the LRU and are then installed in the LRU at the LM4-8 workstations shown in Figure 1.

An MSA NOID End-Effector is required to interface with the MSAs and install them into the LRUs. The End-Effector must attach to the Robo-hand on the end of the NOID arm. At the time the MSA NOID End-Effector was being designed the NOID, the LM4-5 workstation, and the LM6-8 workstation were already installed in the OAB. The LRUs and the MSAs designs were also complete. The MSA NOID End-Effector design had to work with the assembly equipment and LRU designs that were already in place.

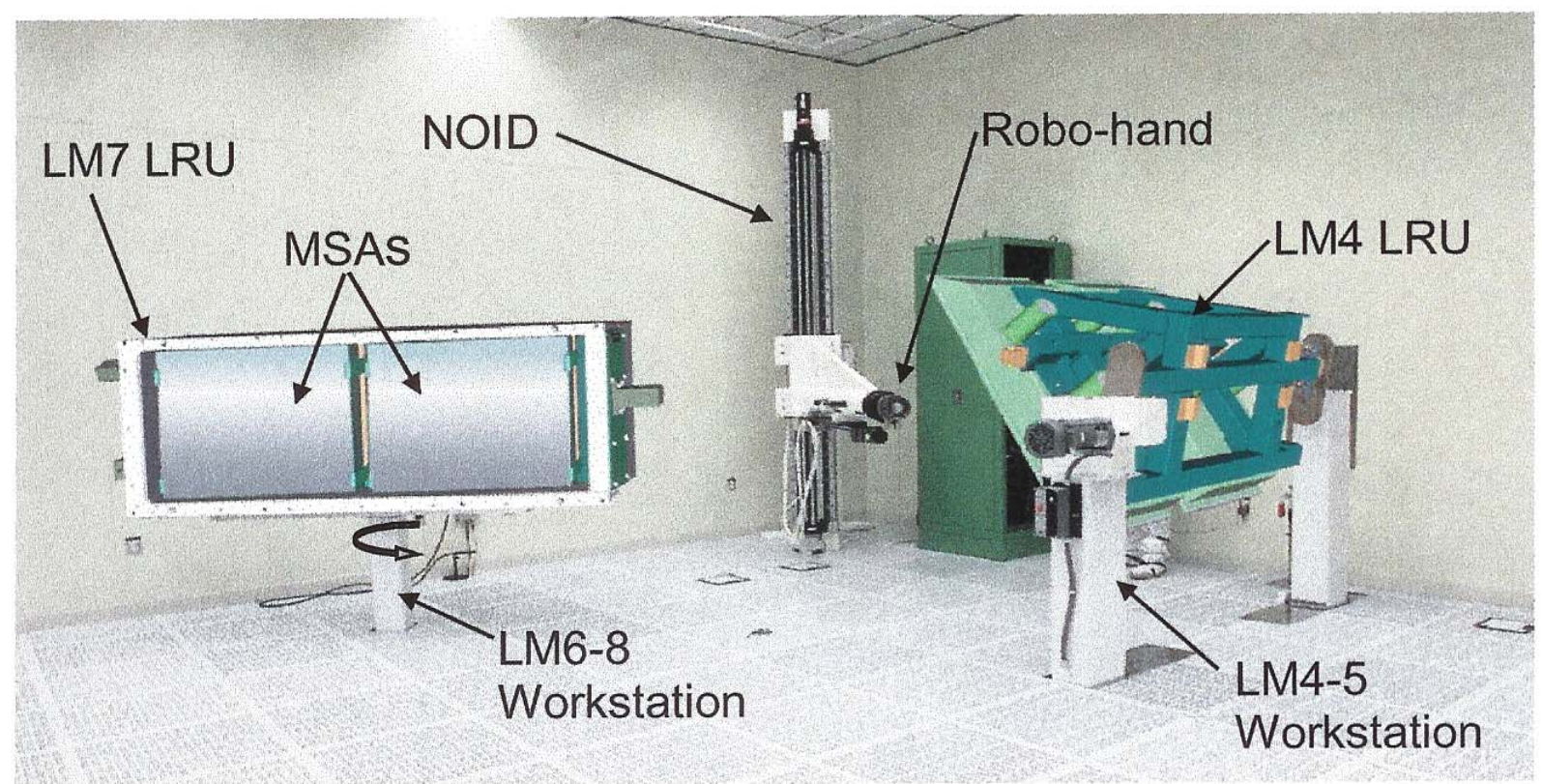

Figure 1 LM4-8 Workstation in the $\mathrm{OAB}$ 


\section{Design Requirements}

The most general, but most important design requirement is that the MSA NOID End-Effecter must be able to engage the MSAs and place them in the LM4-8 LRUs in the correct orientation. The MSA design for each LM4-8 LRU is very similar but varies in size. The widths of the MSAs range from $440 \mathrm{~mm}$ to $685 \mathrm{~mm}$. The MSA NOID End-Effector must be able to handle all sizes. All the MSAs have four mounting lugs on the sides as shown in Figure 2. These mounting lugs were added to the MSA design with the intent that they would be used to handle the MSAs in the OAB.

When the MSA is installed in the LRU, there is very little clearance between the MSA and the LRU frame, which creates a space constraint for the End-Effector design. In addition to this space constraint there is also restraint on the length of the End-Effector. The length of the MSA NOID End-Effector has to be less than $495 \mathrm{~mm}$ or the MSA will interfere with the LRU during installation.

In order to install the MSA into the LRU the MSA NOID End-Effector has to have several degrees of freedom. The EndEffector must be able to manipulate the MSA so that the bolt holes on the back of the MSA can be aligned with the clearance holes in the LRU. The MSA must also be oriented so that it is parallel to the mating surface on the LRU. In order for this to be accomplished the End-Effector has to have a minimum of $\pm 5^{\circ}$ twist rotation, $\pm 5^{\circ}$ pitch rotation, and $\pm 20^{\circ}$ yaw rotation.

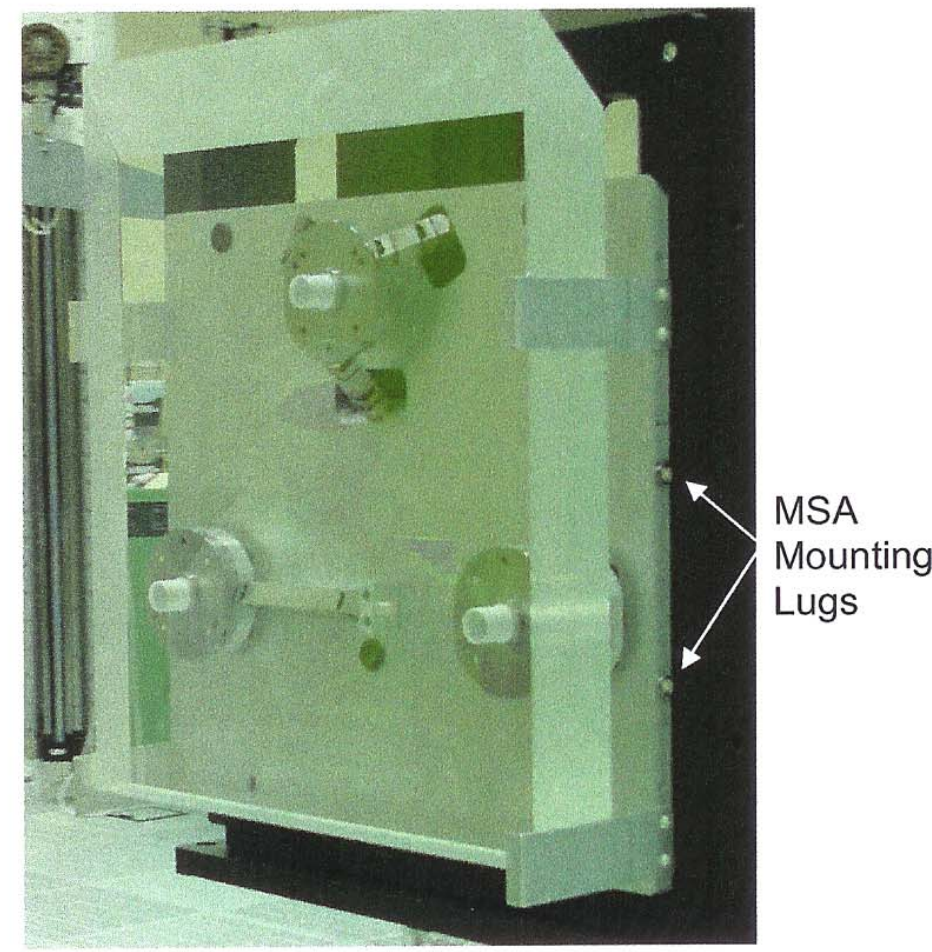

Figure 2 LM4 MSA

The MSA NOID End-Effector must maneuver the MSAs safely and comply with LLNL design standards for lifting devices. To maneuver the MSAs safely, the degrees of freedom of the EndEffector must be controlled to some degree so that the End-Effector is not free to rotate. The End-Effector must be able to hold and maneuver the heaviest MSA which weighs $270 \mathrm{lbs}$. To comply with the LLNL design standards the static safety factor on each component must be equal to or greater than 3 on yield or 4 on ultimate. Seismic load calculations require a minimum safety factor of 1 on yield or 1.25 on ultimate. There is also a maximum allowable bending moment on the NOID Robo-hand of 6000 in-lbs.

The MSA NOID End-Effector will be used in the OAB, which is a class 100 cleanroom. All exposed materials of the End-Effector must be cleanroom compatible and approved by the NIF cleanliness steering committee. The End-Effector should also be designed in such a way that particle generation is minimized when the End-Effector is used. 
The last design requirement is that the final cost of the MSA NOID End-Effector should be minimal. There was no set value, just a requirement to keep the cost down.

\section{Design Interface Requirements}

As previously discussed, the MSA NOID End-Effector has to attach to the Robo-hand on the NOID arm and interface with each LM4-8 LRU assembly. The End-Effector must install the MSAs into the appropriate LRUs without interfering with the LRU frame. The last piece of equipment the End-Effector must interface with is the MSA Handling Fixture shown in Figure 3. The MSA Handling Fixture is what is used to rotate the MSA from a horizontal to a vertical orientation. The End-Effector must accept the MSA from the MSA Handling Fixture while it is in the vertical orientation.

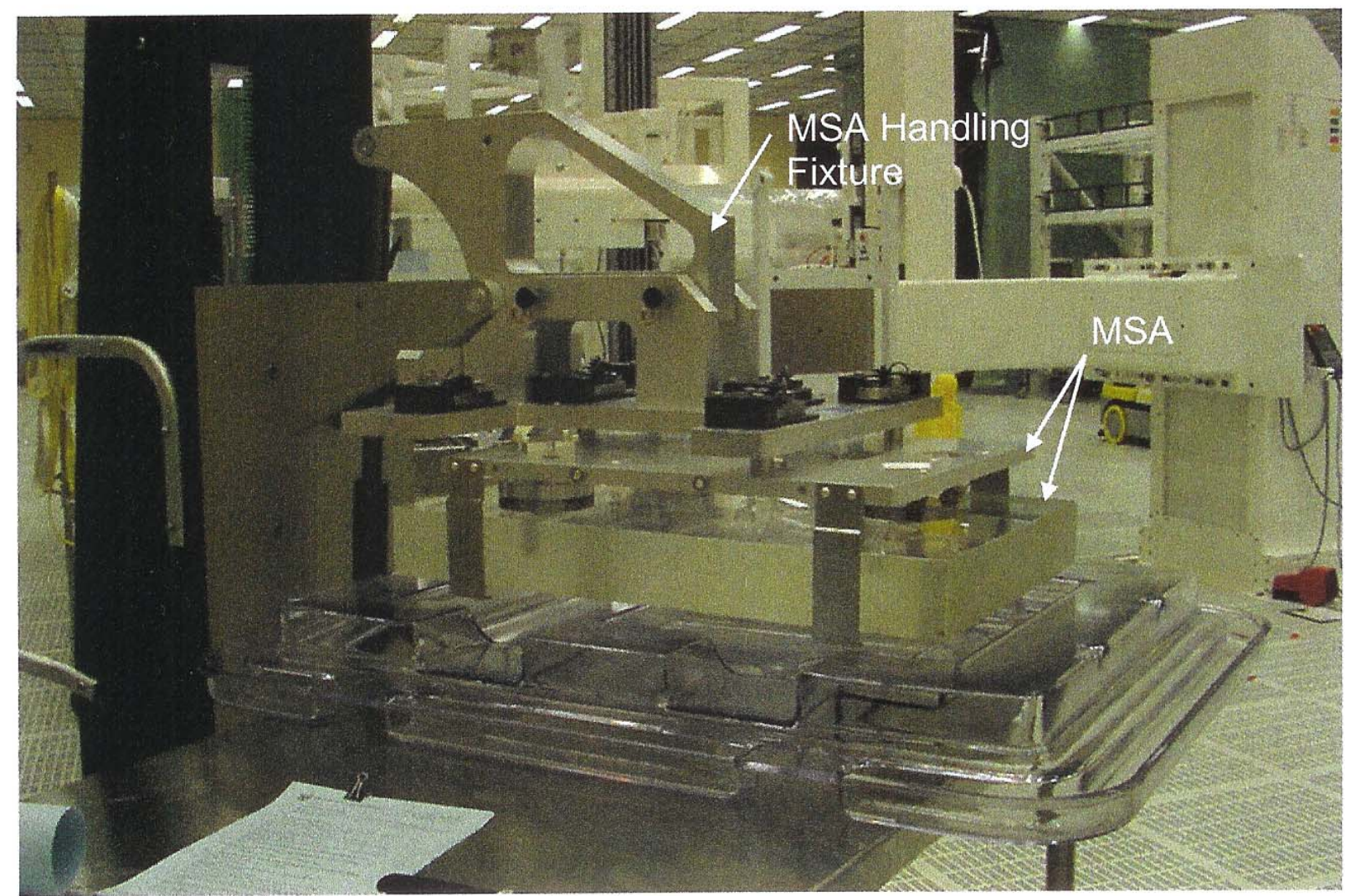

Figure 3 MSA Handling Fixture lifting the MSA

\section{The MSA NOID End-Effector Design}

\section{Design Overview}

The purpose of the MSA NOID End-Effector is to remove an assembled Mirror Sub-Assembly (MSA) from the MSA Handling Fixture and place it into the LRU. It was a challenge to obtain all the required degrees of freedom in such a compact system. For each degree of freedom, I came up with several conceptual designs. With each conceptual design, I made several sketches 
and created a decision matrix to determine which of the design concepts best met the design requirements. I also shared some of the design concepts with the assembly technicians that would be using the End-Effector to gather their thoughts. Once a design concept was chosen, I modeled the design in Pro/DESKTOP and created detailed drawings for each component. The drawings can be found in Appendix A. Great care was taken to make sure the dimensions and tolerances for each part were correct so that the parts would fit together as designed. Once the design was complete a Final Design Review was held. I presented the design to a large group of NIF engineers, mechanical technicians, $\mathrm{OAB}$ operations personnel, cleanliness and materials personnel, and safety personnel. The design review was a success and I was given permission to procure the MSA NOID End-Effector.

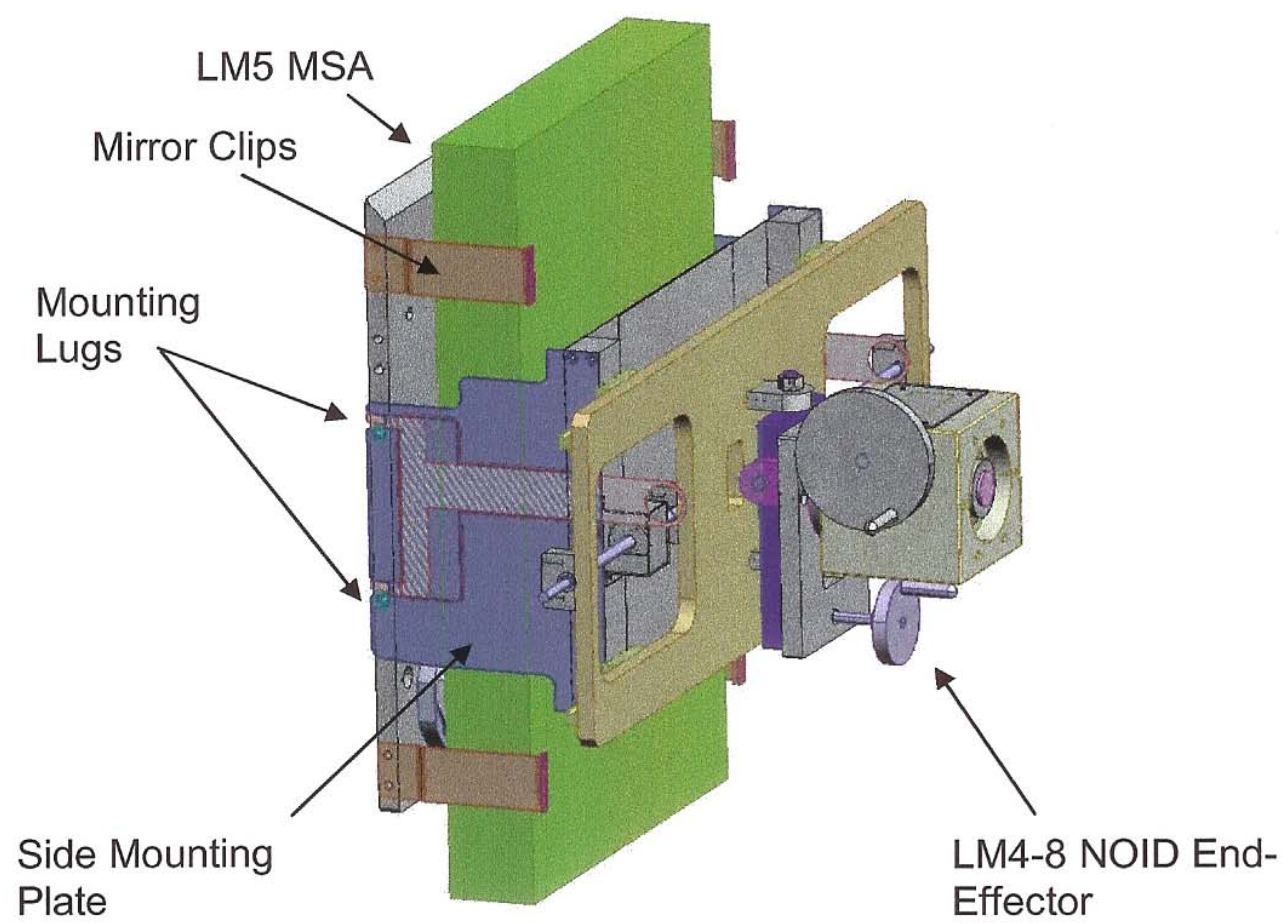

Figure 4 MSA NOID End-Effector holding an LM5 MSA

The final End-Effector design is shown in Figure 4. The MSA NOID End-Effector is a mechanical device, which approaches the MSA from the front and holds the MSA using the four mounting lugs on the MSA. A hook and latch mechanism is incorporated into the Side Mounting Plates so that a positive capture of the MSA is assured. The NOID can then lift the MSA from the MSA Handling Fixture and place it into the LRU.

The MSA NOID End-Effector design consists of three Sub-Assemblies as shown in Figure 5. The main function of the Rail Sub-Assembly is to interface with each of the MSAs. The distance between the Side Mounting Plates is adjustable to accommodate the varying widths of the MSAs. The main function of the Tilt Sub-Assembly is to provide Y-axis (yaw) and Z-axis (pitch) rotation. Rotation about the $\mathrm{Y}$-axis is only allowed when a friction nut has been loosened. Rotation about the $\mathrm{Z}$-axis is adjusted manually by turning a hand wheel. The main 
function of the Twist Sub-Assembly is to provide rotation about the X-axis (twist). The rotation about the $\mathrm{X}$-axis is also manually adjusted by turning a hand wheel. In this case, turning the hand wheel causes a shaft to rotate, which in turn causes the first two Sub-Assemblies to rotate about the $\mathrm{X}$-axis. The following three sub-sections give more details about the each SubAssembly and discuss the conception of the designs.

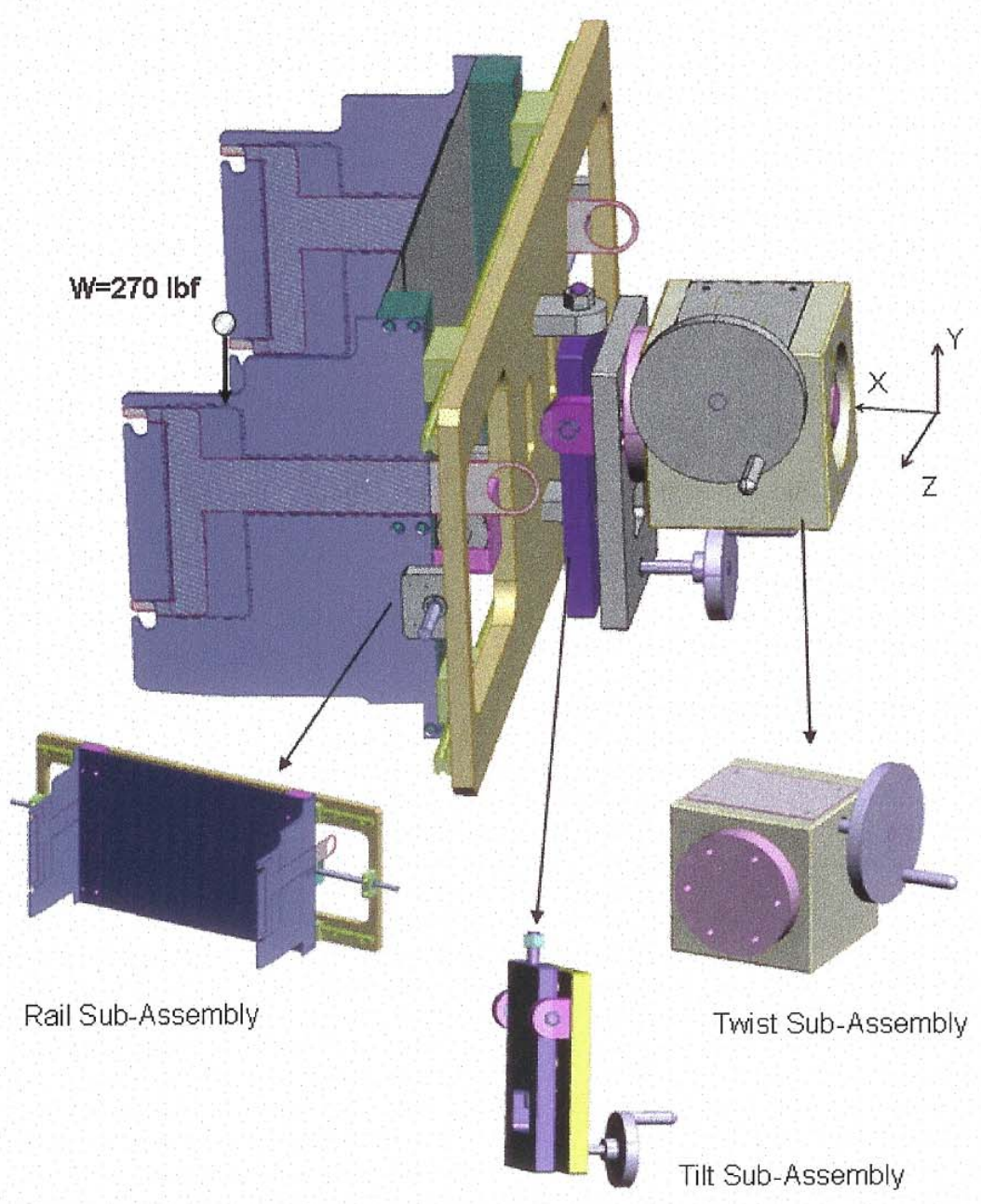

Figure 5 Three Sub-Assemblies of the MSA NOID End-Effector

\section{Rail Sub-Assembly Design}

As mentioned earlier, the main function of the Rail Sub-Assembly is to interface with all the MSAs. It has to safely hold the MSAs and protect the optics from particles the End-Effector may generate. The main design constraint of the Rail Sub-Assembly was the size because there is very little clearance between the MSAs and the LRU frames. 
There were two main conceptual designs considered for the Rail Sub-Assembly, which will be discussed later in this section. The final design is shown in Figure 6. The main components of the Rail Sub-Assembly are the side mounting plates, the protecting shields, the rail system and ACME rod, and the rail plate.

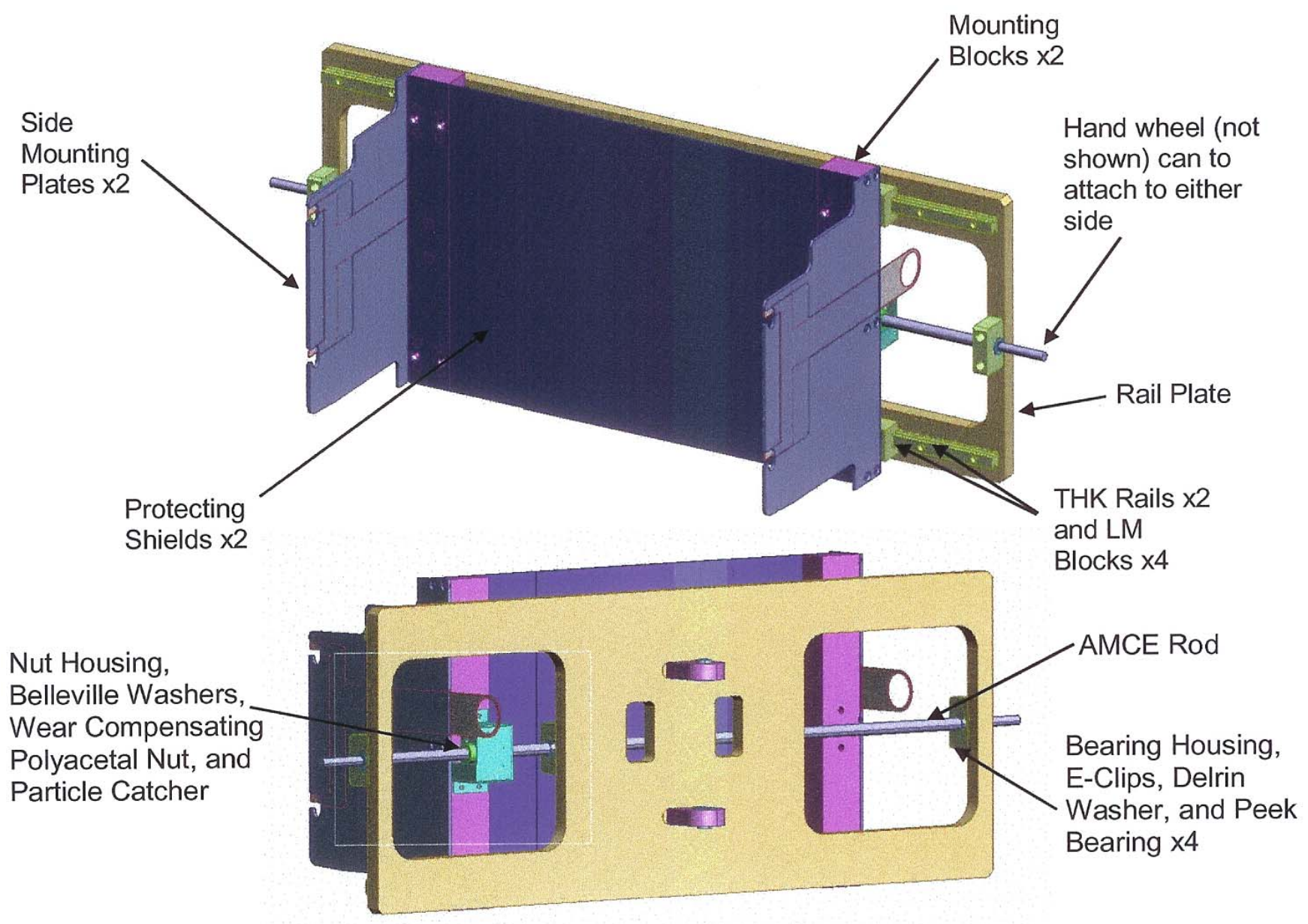

Figure 6 Components of the Rail Sub-Assembly

(Additional components shown in figure 7)

Vacuum grippers are often used to handle optical assemblies, but this was not an option for the End-Effector design because of the 4 Mirror Clips on the MSA (shown in Figure 4). The gasket of the vacuum gripper is only allowed to touch the optic outside of the clear aperture (where the NIF laser beam will not hit). In the case of the LM4-8 optics, there is only $14 \mathrm{~mm}$ around the edge of the optic that is outside of the clear aperture. The Mirror Clips on the MSA would interfere with a vacuum gripper design. Also, since there are several different MSA optic sizes, there would need to be different vacuum plates for each optic size. It was clear that using the 4 mounting lugs on the sides of the MSAs was the best choice. The mounting lugs for each MSA are in the same location. The design constraints did not leave too many options for the design of the side mounting plates. The plate geometry was completely driven by the tight clearances 
between the MSAs and the LRU frames. Stainless Steel was chosen as the plate material primarily because of its strength and durability over aluminum. Stainless steel also particulates less than aluminum. A latching mechanism was incorporated into the side mounting plates so that a positive capture of the MSA is assured. The side mounting plates consist of three pieces sandwiched together. The two outer pieces are welded together and the middle piece is free to slide in an out. This middle piece is pulled back while engaging the MSA and then pushed forward to lock the MSA in the plate hooks while the End-Effector is handling the MSA.

Because the MSAs vary in width, the distance between the plates needs to be adjustable. There were two conceptual designs considered. The first design concept was to have two parallel rods that the side mounting plates could slide freely on. The side mounting plates would attach to a block that would have a bearing sleeve in them. The rods would be placed through the bearing sleeves and the side plates could simply be pushed or pulled along the rods into the correct position. In order to keep an MSA from moving once it was engaged, clamps would be placed on the rails. The second design considered was a rail and lead screw design. With this design, the side mounting plates could slide in and out on a set of linear rails. A lead screw would be used to drive one of the side plates and the other one would be able to slide freely. A decision matrix was used to choose the best design. This matrix can be found in Table 1.

Table 1 Decision matrix for the mechanism to adjust the width of the side mounting plates (Each criterion was given $a$ value between 1 and 5 , with 1 being the lowest and 5 being the highest. The design with the highest total was deemed the best overall design.)

\begin{tabular}{|c|c|c|c|}
\hline \multirow[b]{2}{*}{ Design Criterion } & \multirow{2}{*}{$\begin{array}{l}\% \text { Weight } \\
\text { of Each } \\
\text { Criterion }\end{array}$} & \multicolumn{2}{|c|}{ Criterion Value } \\
\hline & & $\begin{array}{c}\text { Rod and } \\
\text { Clamp design }\end{array}$ & $\begin{array}{l}\text { Rail and Lead } \\
\text { Screw design }\end{array}$ \\
\hline Cost & $10 \%$ & 5 & 3 \\
\hline Safety / Risk to the optic and personnel & $40 \%$ & 2 & 4 \\
\hline Ease to operate and control the motion & $30 \%$ & 2 & 4 \\
\hline Particle generation / need for lubrication & $10 \%$ & 3 & 3 \\
\hline Wear over time & $10 \%$ & 3 & 4 \\
\hline Total (Sum of $\%$ weight $x$ the criterion value) & & 2.5 & 3.8 \\
\hline
\end{tabular}

As shown in the decision matrix, the rail and lead screw concept was the better design choice. I chose to use THK stainless steel linear rails and mounts. I was able to work with the vendor to have them use Krytox LVP grease, which is a cleanroom approved lubricant. In choosing the lead screw I needed to find a screw and nut combination that would require little to no lubrication, would last a long time, and would be made out of the acceptable cleanroom materials. This was much harder task than I had expected. I wanted to find something off the shelf because it would most likely be less expensive than designing and fabricating something from scratch. I finally found a Precision Modified-ACME Lead screw and nut combination from McMaster-Carr. The screw is made of 303 stainless steel and the nut is a polyacetal, self lubricating, wear-compensating nut. The material of the nut had not been approved for use in the OAB. I worked with the NIF materials group and received approval for the use of this material for my application. To use the nut, they required that I put a particle catcher around the nut. I also added protective shields near the face of the optic to help mitigate contamination on the mirror surface. 
The rail plate of the Rail Sub-Assembly was designed to hold the THK rails and the lead screw as well as interface with the Tilt Sub-Assembly. The width of the plate was chosen based on the widest MSA. The height of the plate was chosen based on the appropriate spacing of the THK rails. As the distance between the rails increases, the load on each rail decreases, but the overall weight of the plate increases. The plate height selected resulted in safety factors well above the required value and an acceptable weight for the Rail Sub-Assembly. Aluminum was chosen as the material for the rail plate to help keep the weight of the End-Effector down. Large cutouts were also placed in the plate to reduce the weight.

There are 4 aluminum blocks that attach to the rail plate to hold the lead screw. These are called the bearing housings and are shown in Figures 6 and 7. The thread of the lead screw was turned down at the location of the four blocks. Peek bushings were placed in each block to lower the friction between the lead screw and the block and to reduce the particle generation. Peek was chosen over other bearing materials because of its low coefficient of friction and durability. Eclips were placed at the two end blocks to prevent the lead screw from translating. There is one other block that holds the lead screw nut. This aluminum block is called the nut housing and is shown in Figure 6. It is important that a majority of the MSA weight is transferred to the THK rails and not onto the lead screw. To transfer the load correctly, the nut needs to be perfectly aligned with the lead screw both when the End-Effector is loaded and unloaded. To minimize the load transferred to the lead screw, Belleville washers were placed between the nut housing and the bar it is mounted to.

The last pieces of the Rail Sub-Assembly are the two hinges shown in Figure 7. These are used to interface with the Tilt Sub-Assembly and assist with the $\pm 20^{\circ}$ yaw rotation. This will be discussed further in the next section.

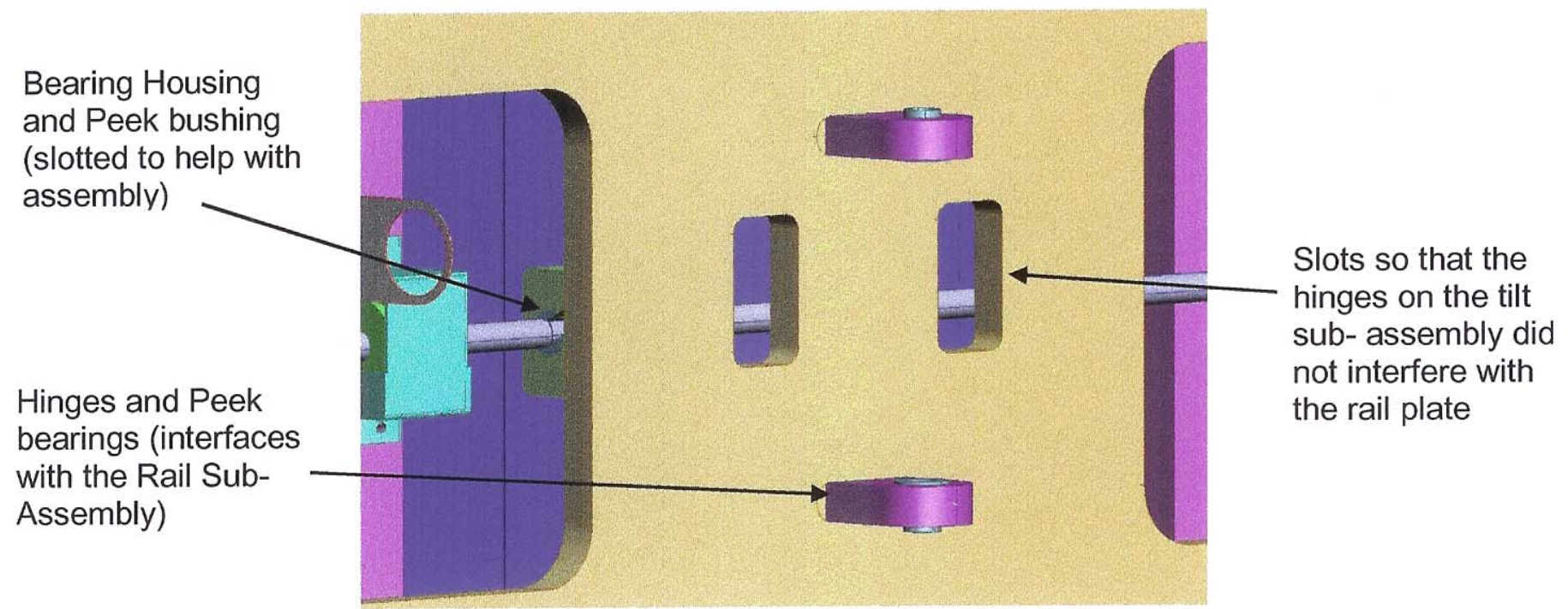

Figure 7 Additional components of the Rail Sub-Assembly 


\section{Tilt Sub-Assembly Design}

The main function of the Tilt Sub-Assembly is to safely rotate the MSA in pitch and yaw. Like the Rail Sub-Assembly, the main constraint of the Tilt Sub-Assembly design was the size. Since the total length of the End-Effector is limited to $495 \mathrm{~mm}$, the total length of the Tilt SubAssembly had to be minimal. The other constraint that played a large role in this part of the design was the requirement to be able to safely control the angular motion. Lastly, the weight was a consideration because of the maximum moment allowed on the NOID Robo-hand.

There were several conceptual designs considered for the Tilt Sub-Assembly, which will be discussed later in this section. The final design is shown in Figures 8 and 9. The main components of the Tilt Sub-Assembly are the two parallel aluminum plates, the rotating pins and hinges, the pitch adjustment system, and the yaw locking system.

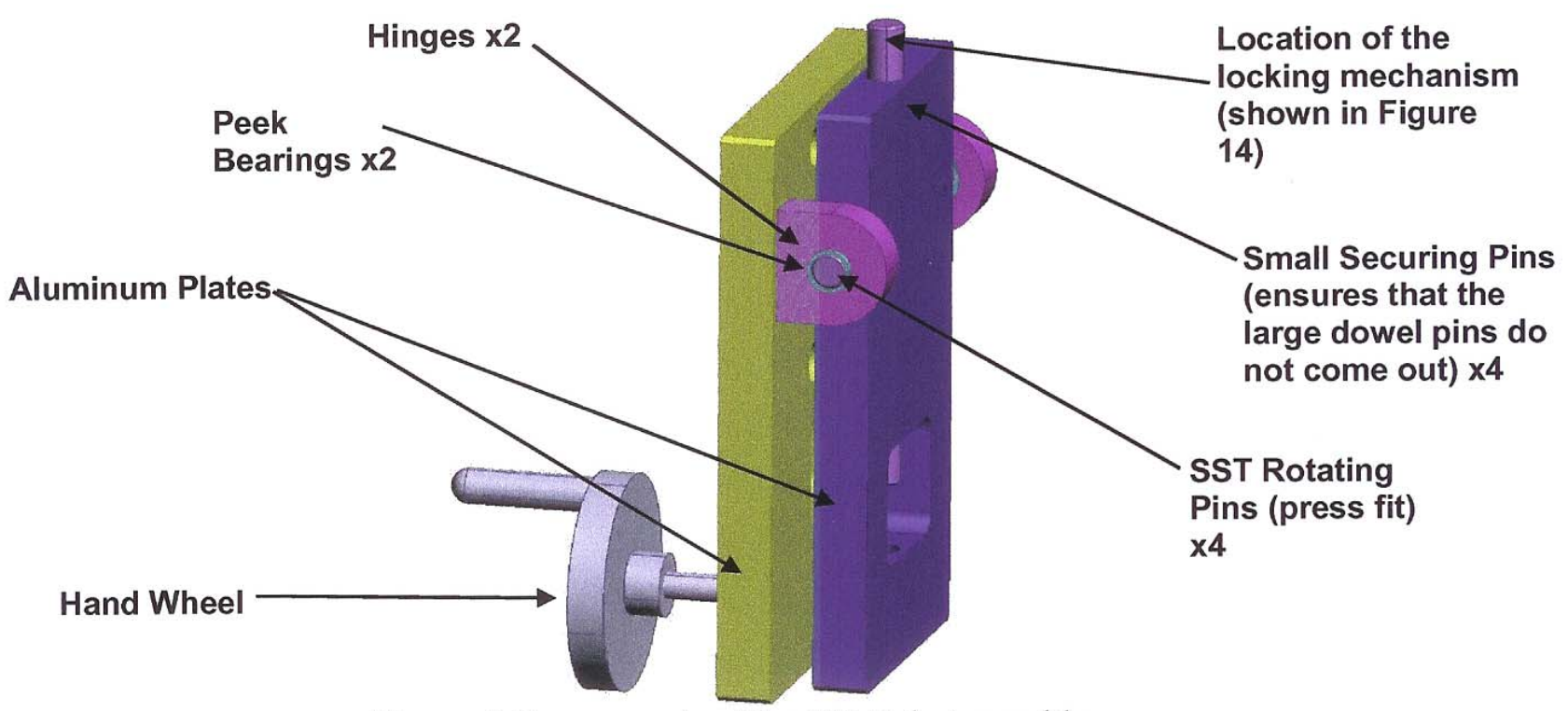

Figure 8 Components of the Tilt Sub-Assembly

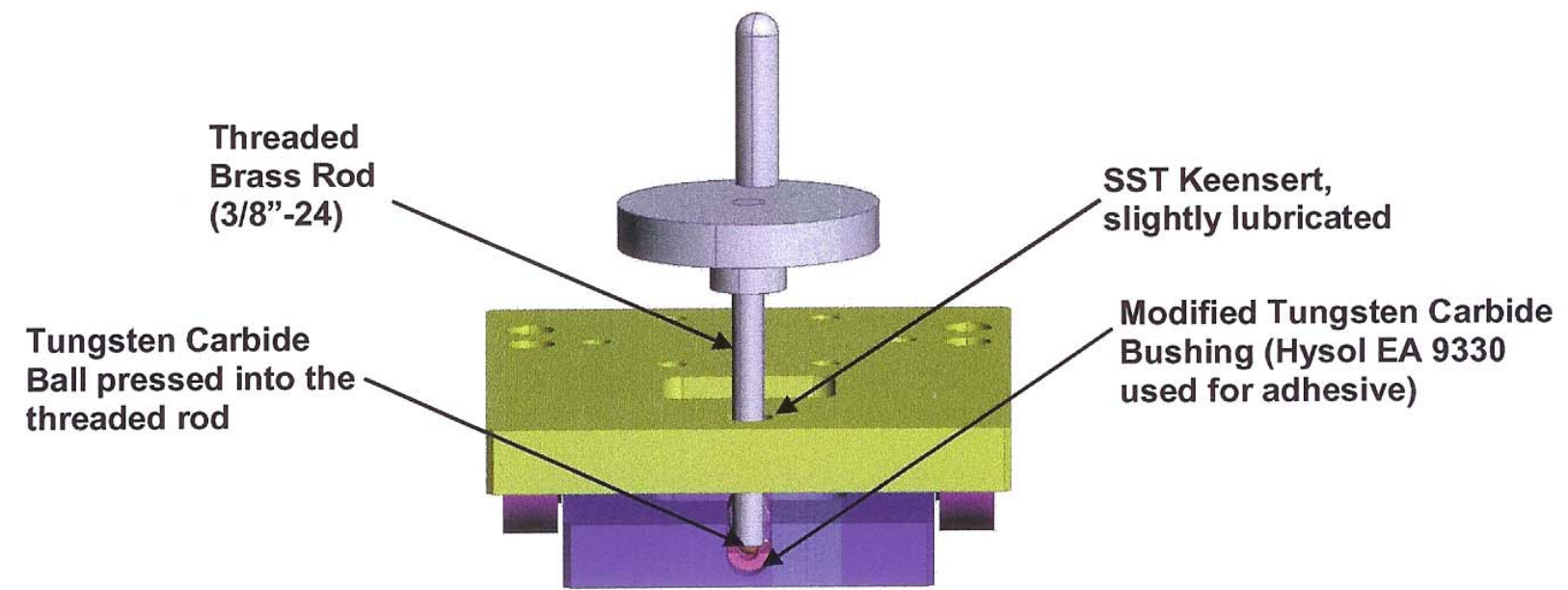

Figure 9 Pitch adjustment system of the Tilt Sub-Assembly 
When an MSA is being installed in an LRU, the MSA must be parallel to the mating surface on the LRU. In order for this to happen, the yaw orientation of the MSA relative to the NOID arm must continually be changing as the NOID arm is extended. For this reason, the yaw rotation of the End-Effector must be easy to control and adjust. The pitch rotation, on the other hand, only needs to be adjusted once or twice during the installation of an MSA.

To keep the design costs down, the first idea for this portion of the design was to see if there was anything commercially available that would meet the requirements. Unfortunately, I did not find anything that would meet the space, material, and load requirements of this system. The next idea was to use a combination of a commercially available joint with a custom design. There were two joint options: I could use a ball and socket joint, which would allow rotation in all directions or I could use a universal joint that would only allow pitch and yaw rotation. In both cases I would need to design mechanisms that would safely control the rotation. A sketch of this design idea is shown in Figure 10. The other idea was to design a mechanism that would control the pitch rotation while allowing the End-Effector to freely rotate in yaw about a vertical pin. I came up with several mechanisms that would adequately adjust and control the pitch motion. Two of the mechanisms considered are shown in Figure 10. A decision matrix was used to choose the best conceptual design, as shown in Table 2 .

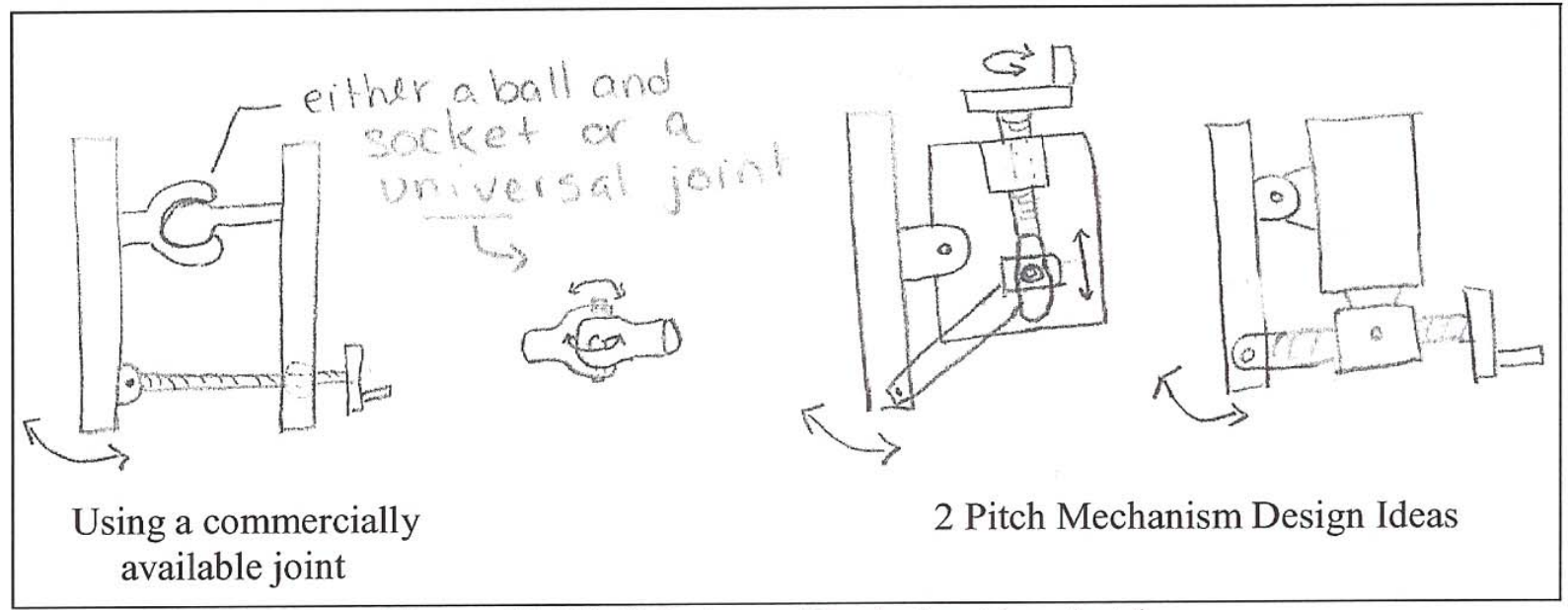

Figure 10 Tilt Sub-Assembly design idea sketches 
Table 2 Decision matrix for the mechanism to adjust the pitch and yaw (Each criterion was given a value between 1 and 5, with 1 being the lowest and 5 being the highest. The design with the highest total was deemed the best overall design.)

\begin{tabular}{|c|c|c|c|}
\hline \multirow[b]{2}{*}{ Design Criterion } & \multirow[b]{2}{*}{$\begin{array}{l}\% \text { Weight of } \\
\text { Each Criterion }\end{array}$} & \multicolumn{2}{|c|}{ Criterion Value } \\
\hline & & $\begin{array}{l}\text { Design using a } \\
\text { commercially } \\
\text { available joint }\end{array}$ & $\begin{array}{c}\text { Pitch } \\
\text { Mechanism } \\
\text { Design }\end{array}$ \\
\hline Total design and manufacturing cost & $15 \%$ & 4 & 2 \\
\hline Safety / Good motion control & $35 \%$ & 3 & 4 \\
\hline Particle generation / need for lubrication & $15 \%$ & 3 & 2 \\
\hline Wear over time & $10 \%$ & 3 & 3 \\
\hline Light weight desired & $10 \%$ & 4 & 2 \\
\hline Short length desired & $15 \%$ & 4 & 1 \\
\hline Total (Sum of $\%$ weight $x$ the criterion value) & & 3.4 & 2.8 \\
\hline
\end{tabular}

From the decision matrix it was clear that the joint design was best, however, after looking at the commercially available joints I decided that it would be better to design a custom universal joint that would better fit my application. The pitch and yaw plate assembly previously shown in Figure 8 is the universal joint that I designed. This design is significantly more compact than any of the designs I could come up with using a commercially available joint. The two vertically oriented pins interface with the hinges and flanged peak bearings on the Rail Sub-Assembly. These pins allow for the yaw rotation. I decided to leave the yaw rotation free so that the MSA could be easily adjusted by hand while the MSA is being installed in the LRU. I added a locking system to the top pin so that the yaw rotation could be held if desired. The locking system was added later and is therefore not shown in the model. It can be seen in Figure 14 on page 18. The top vertical pin was made longer and was threaded on the top end. The two threaded rings of the locking system were designed to act like two locking nuts. The friction of the bottom ring against the top hinge is what prevents the Rail Sub-Assembly from rotating in Yaw when the locking system is engaged.

The two horizontal pins allow for the pitch rotation of the End-Effector. The last part of the Tilt Sub-Assembly to be designed was the mechanism to adjust and control the pitch rotation. There were two options that were considered. The first idea was to use a threaded rod through one plate that would contact the second plate near the bottom. With this design gravity would push the second plate against the threaded rod. As the rod is threaded in or out, the plate would tilt up or down. The second idea also used a threaded rod through one plate, but this time the rod would be attached to the second plate. For this second design to work the threaded connection in the first plate would have to be able to rotate and the connection with the second plate would have to mimic a ball and socket joint. The second design is safer than the first because it would positively connect the threaded rod to both plates, but it is significantly more complicated. I ended up selecting the first design, because the added safety of the second design was not worth the extra design complications. The final pitch adjustment system is shown in Figure 9. The hand wheel is attached to a fine pitch threaded rod which is threaded through a stainless steel keensert in the aluminum plate. Since it is common for similar materials to gall together in a cleanroom, brass was selected for the threaded rod material. Cleanroom approved lubrication 
was also placed on the keensert to lower the friction and allow for easier turning of the handle. A lot of thought was put into the end of the threaded rod that would slide up and down the second plate as the threaded rod is turned. Particle generation, contact stresses, and friction were all factors in this part of the design. A Tungsten Carbide ball from McMaster-Carr was inserted into the end of the threaded rod. A modified Tungsten Carbide bushing from Reid Tool was chosen as the contact surface for the ball. The bushing was cut in half and glued to the second plate, providing a curved surface for the ball to slide against. A curve surface was selected over a flat surface to reduce the contact stresses. Tungsten Carbide was chosen because of its strength, low friction, and wear resistant properties. Other Tungsten Carbide designs were considered, but they would have required new parts to be designed and manufactured. The ball and modified Tungsten Carbide bushing design was chosen because the parts were commercially available and inexpensive.

\section{Twist Sub-Assembly Design}

The main function of the Twist Sub-Assembly is to provide a controlled twist rotation of the MSA. The other function of this sub-assembly is to attach the whole end-effector to the NOID Robo-hand. The main design considerations of the Twist Sub-Assembly design were the size, the load capacity, and safety. Since the Twist Sub-Assembly is furthest from the MSA, there is a large moment load it must withstand.

There were several conceptual designs considered for the Twist Sub-Assembly, which will be discussed later in this section. The final design is shown in Figure 11. The main components of the Twist Sub-Assembly are the aluminum shaft housing, the shaft, two roller bearings, a clamp collar, and the twist mechanism.
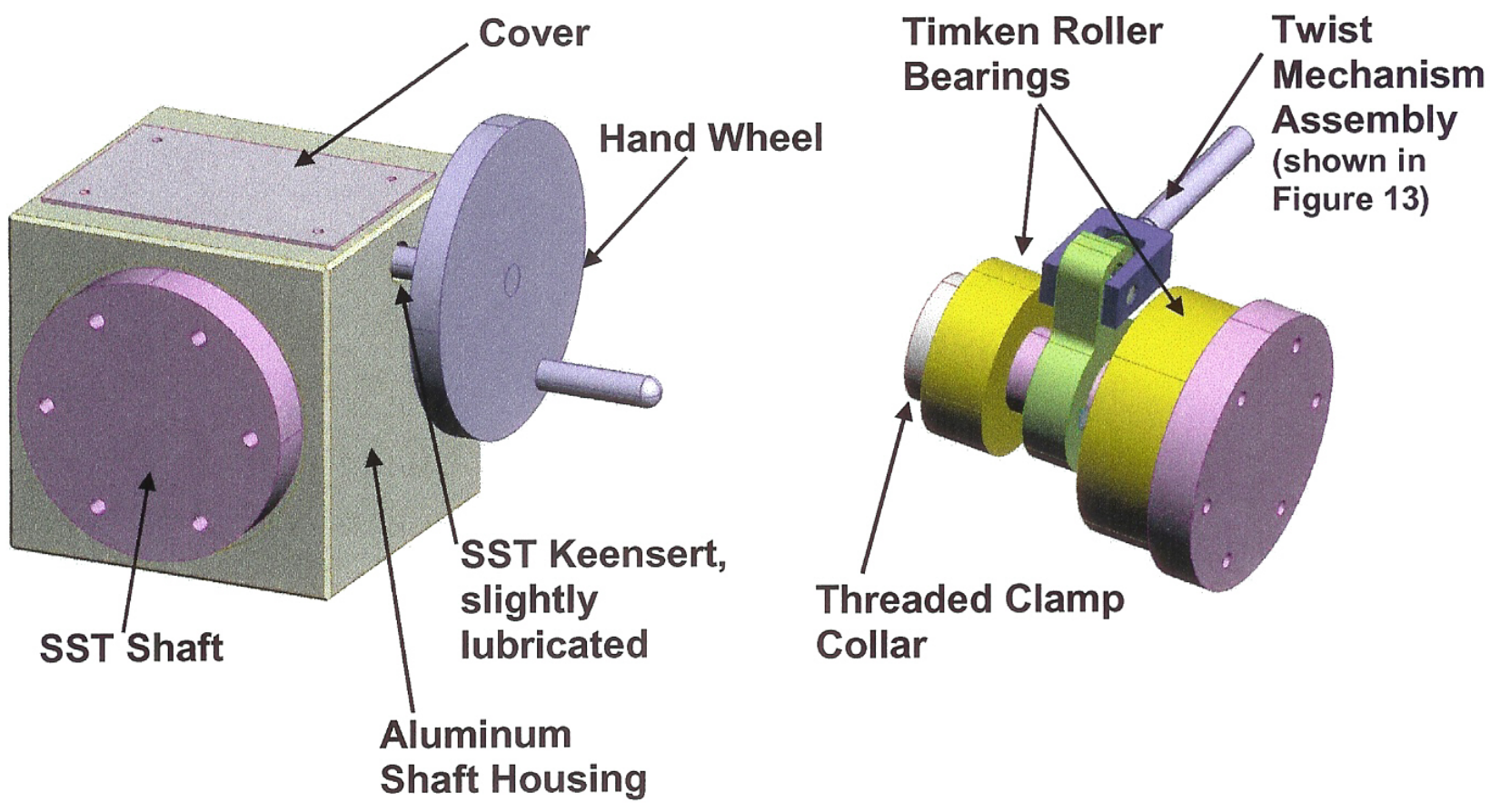

Figure 11 Twist Sub-Assembly Components 
There were four conceptual designs considered for the Twist Sub-Assembly. Sketches of the four concepts are shown in Figure 12. The first concept is the most simple. It simply uses bolts, washers, and a plate with arced slots. The bolts would always be tight until a twist adjustment is required, at which time the bolts would be slightly loosened and the End-Effector (with an MSA) would be rotated by hand. This design concept is simple, but it has some very apparent safety concerns. If the MSA was not centered on the Rail Sub-Assembly it is possible that the EndEffector would twist on its own if the bolts were not tight enough. Also, when the bolts are loose it is risky to have personnel control the twist by hand. The second design concept considered is also very simple. It uses a large threaded shaft that would turn inside a shaft housing as shown in Figure 12. There would be a locking nut to hold the shaft from rotating when twist rotation was not desired. When twist rotation is required, the nut would be loosened and then the EndEffector (with an MSA) would be rotated to the desired position and the nut would be tightened again. This design is simple, but the process could be cumbersome if several iterations were required to get the exact twist orientation required. The design also has safety issues when the locking nut is loosened. The third concept uses a worm gear assembly to rotate a shaft that is connected to the rest of the End-Effector, also shown in Figure 12. This design provides a safer and more controlled twist adjustment. The challenges with this design were to find gears that are cleanroom compatible, provide the fine adjustment required, and have minimal backlash. The last design concept consists of a shaft, a shaft housing, and a mechanism that will cause the shaft to rotate. At this point in the design, there were a few design ideas for the mechanism that would control the twist rotation, but nothing had been finalized. Once again the pros and cons of each concept were considered and a design was chosen. The pros and cons are summarized in the decision matrix found in Table 3.

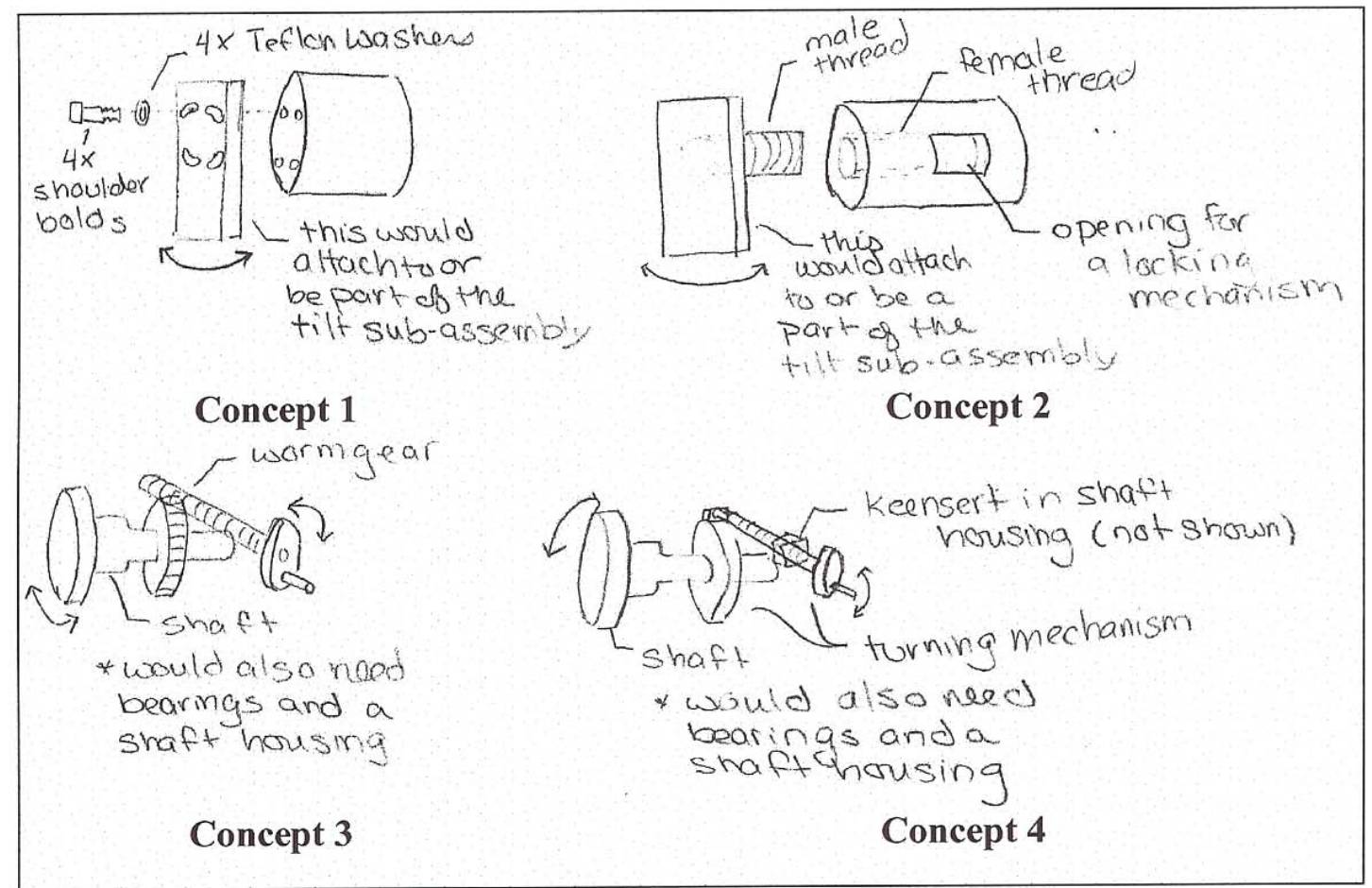

Figure 12 Twist Sub-Assembly design idea sketches 
Table 3 Decision matrix for the twist design concept

(Each criterion was given a value between 1 and 5, with 1 being the lowest and 5 being the highest. The design with the highest total was deemed the best overall design.)

\begin{tabular}{|c|c|c|c|c|c|}
\hline \multirow[b]{2}{*}{ Design Criterion } & \multirow[b]{2}{*}{$\begin{array}{l}\% \text { Weight } \\
\text { of Each } \\
\text { Criterion }\end{array}$} & \multicolumn{4}{|c|}{ Criterion Value } \\
\hline & & $\begin{array}{c}\text { Bolt in } \\
\text { slotted holes } \\
\text { design }\end{array}$ & $\begin{array}{c}\text { Threaded } \\
\text { shaft } \\
\text { design } \\
\end{array}$ & $\begin{array}{l}\text { Worm } \\
\text { gear } \\
\text { design } \\
\end{array}$ & $\begin{array}{c}\text { Twist } \\
\text { mechanism } \\
\text { design }\end{array}$ \\
\hline Total design and manufacturing cost & $10 \%$ & 5 & 4 & 3 & 2 \\
\hline $\begin{array}{l}\text { Safety / Risk to the optic and } \\
\text { personnel }\end{array}$ & $30 \%$ & 1 & 1 & 5 & 4 \\
\hline $\begin{array}{l}\text { Smooth and easy operation under a } \\
\text { large moment load }\end{array}$ & $20 \%$ & 2 & 2 & 5 & 5 \\
\hline Fine adjustment & $15 \%$ & 1 & 2 & 3 & 5 \\
\hline $\begin{array}{l}\text { Cleanliness: Particle generation / } \\
\text { need for lubrication }\end{array}$ & $5 \%$ & 4 & 3 & 2 & 3 \\
\hline Wear over time/ backlash & $10 \%$ & 3 & 5 & 3 & 4 \\
\hline Short length desired & $10 \%$ & 5 & 3 & 3 & 3 \\
\hline $\begin{array}{l}\text { Total (Sum of } \% \text { weight } x \text { the criterion } \\
\text { value) }\end{array}$ & & 2.35 & 2.35 & 3.95 & 4.00 \\
\hline
\end{tabular}

As shown in Table 3, the worm gear and twist mechanism designs were far superior. Even though the twist mechanism design required more design effort, it was the superior design concept because of the need for fine adjustment and minimal backlash. After that concept was chosen, the twist sub-assembly had to be designed. First, I focused on the shaft and the shaft housing. The shaft design was mostly driven by the moment load it would carry and the size of the bearings that would support the shaft. The detailed drawing of the shaft can be found in Appendix A. The face of the shaft is 4.5 inches in diameter and interfaces directly with the Tilt Sub-Assembly. This way, when the shaft is rotated the tilt and rail sub-assemblies will also rotate. The shaft diameter steps down twice, once to fit the inner diameter of the larger bearing and again to fit the inner diameter of the smaller bearing. A radius was added at each step down to reduce the stress concentrations in the shaft. The end of the shaft was threaded so that a threaded clamp collar could be placed at the end of the shaft to hold the bearings in place. The two bearings in the Twist Sub-Assembly are tapered roller bearings from Timken. These were lubricated with cleanroom approved lubrication. I chose tapered roller bearings because they can take both thrust and radial loads. The threaded clamp collar was from King Bearing. The bearings and the clamp collar are concealed in a shaft housing. The main functions of the shaft housing are to support the shaft bearings and to connect the whole End-Effector to the NOID Robo-hand. The detailed drawing of the shaft housing can be found in Appendix A. The length of the shaft housing was chosen to give the whole End-Effector the optimal length for installing the MSAs into the LRUs. The internal cut outs were sized to properly hold the bearings and to allow for easy assembly of the Twist Sub-Assembly. The last component needed for this SubAssembly was the mechanism that would be used to turn the shaft.

After a lot of brainstorming and several sketches I came up with the twist mechanism shown in Figure 13. The twist mechanism consists of a threaded brass rod that is threaded through a slightly lubricated keensert in the shaft housing. As the threaded rod is turned, it pushes/pulls a fork which then pushes/pulls the force ring, causing the shaft to rotate. 


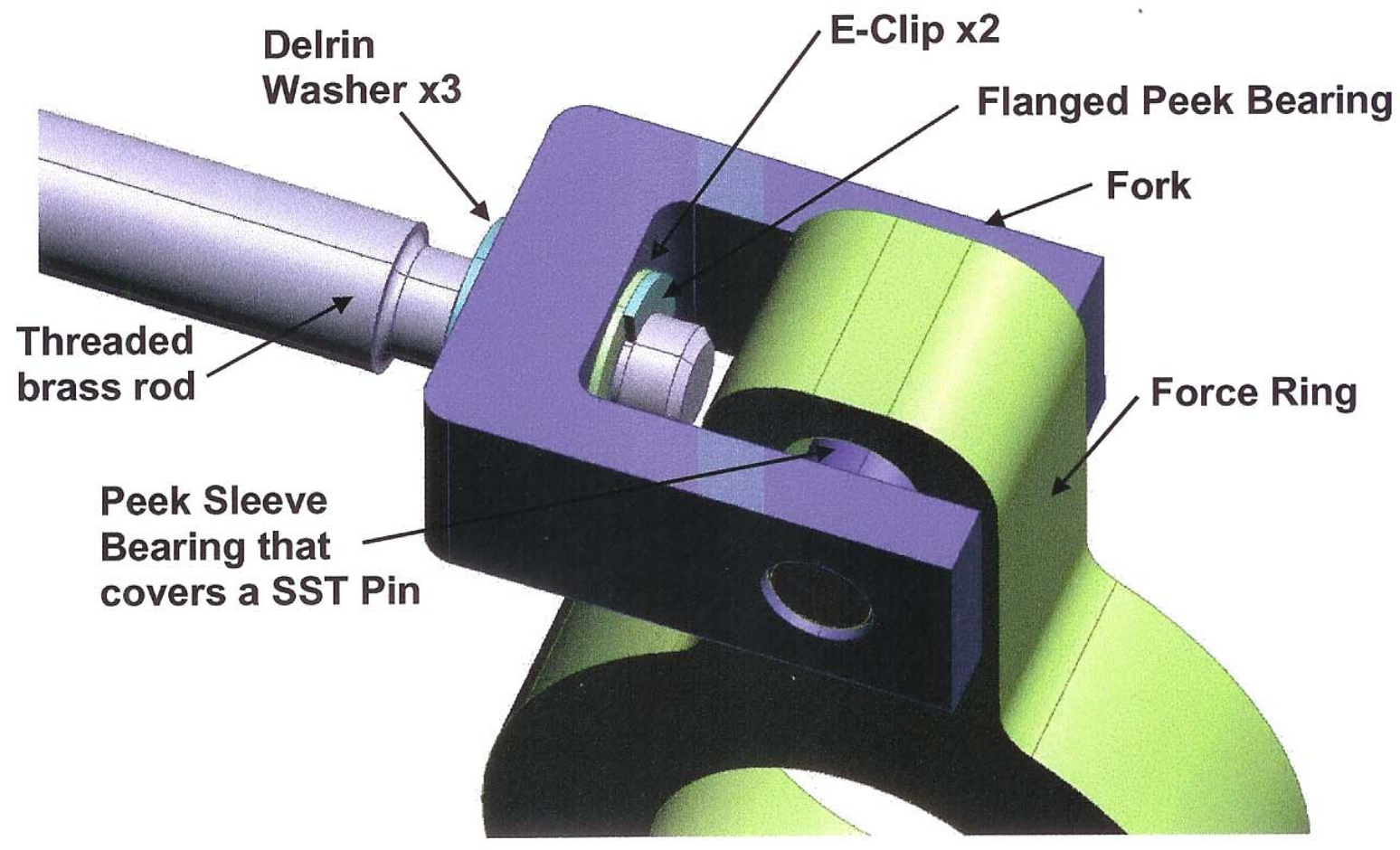

Figure 13 Twist mechanism of the Twist Sub-Assembly

The threaded rod is made from brass and has a $1 / 2-20$ fine pitch thread. Brass was chosen because it is unlikely to gall with the stainless steel keensert. The fine pitch thread was chosen to allow for fine adjustments of the twist rotation. The threaded rod is turned down where it connects to the aluminum fork as shown in Figure 13. There is a flanged peak bearing sleeve that goes through the fork and allows the rod to turn in the fork. Peek was chosen for the bearing sleeve because of its low friction and wear resistant properties. The rod is held in place with two Eclips. A Delrin washer was placed between the E-clip and the fork on the non-flanged side of the peak bearing. On the other end of the force ring there is a stainless steel dowel pin that is pressed into the fork and goes through the vertical slot in the force ring. This dowel pin has a peek bearing sleeve around it that allows for a low friction interaction between the dowel pin and the force ring as the pin moves up and down in the slot. The peek sleeve was selected so that inner diameter just fit over the dowel pin. The slot in the force ring was sized so that there was very little slop between it and the peek sleeve. This was carefully done to minimize the backlash in the twist mechanism assembly. There are also two Delrin washers on the dowel pin axel that were placed on each side of the force ring. These washers were placed there so that the aluminum force ring did not side against the aluminum fork and create particles. The last piece of the twist mechanism is the stainless steel key that locks the force ring in position against the shaft. 


\section{The Design as a Whole}

The last components to be selected were the hand wheels. The Rail Sub-Assembly, Tilt SubAssembly, and Twist Sub-Assembly each need one hand wheel. The hand wheel sizes were selected based on the clearance between the other components and on the estimated amount of force required to turn the wheel when the End-Effector is holding an MSA. All hand wheels were purchased from Carr Lane and are made of stainless steel. The hand wheel for the Rail Sub-Assembly is attached in such a way that it can easily be removed and moved to either side of the lead screw as required.

With the hand wheels in place and all three Sub-Assemblies mated together, the MSA NOID End-Effector design is complete and all design requirements have been met. The completed End-Effector is shown installed on the NOID in Figure 14.

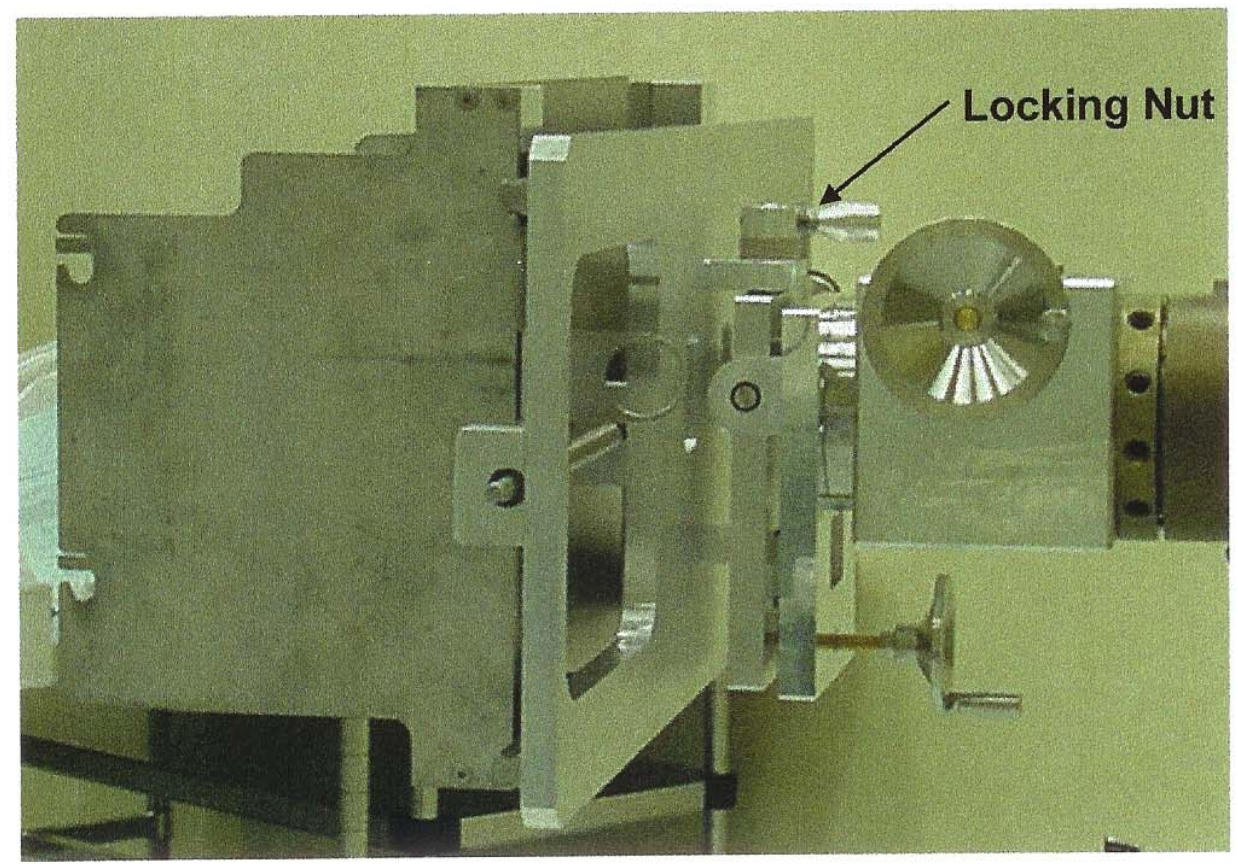

Figure 14 MSA NOID End-Effector installed on the NOID arm

As stated earlier, I modeled the MSA NOID End-Effector design in Pro/DESKTOP. I used the End-Effector assembly model to perform an interface study to make sure that in all cases the MSA NOID End-Effector could install the MSAs without interfering with the LRU frames. The clearance is tight in some cases, but the study showed that the appropriate MSAs can be installed in each LRU type. Figure 15 shows some of the tight clearances that were found in the study. As can be seen in the figure, the Rail Sub-Assembly hand wheel would have to be moved to a specific side of the lead screw in order for the MSA to be installed into an LM4 LRU. 

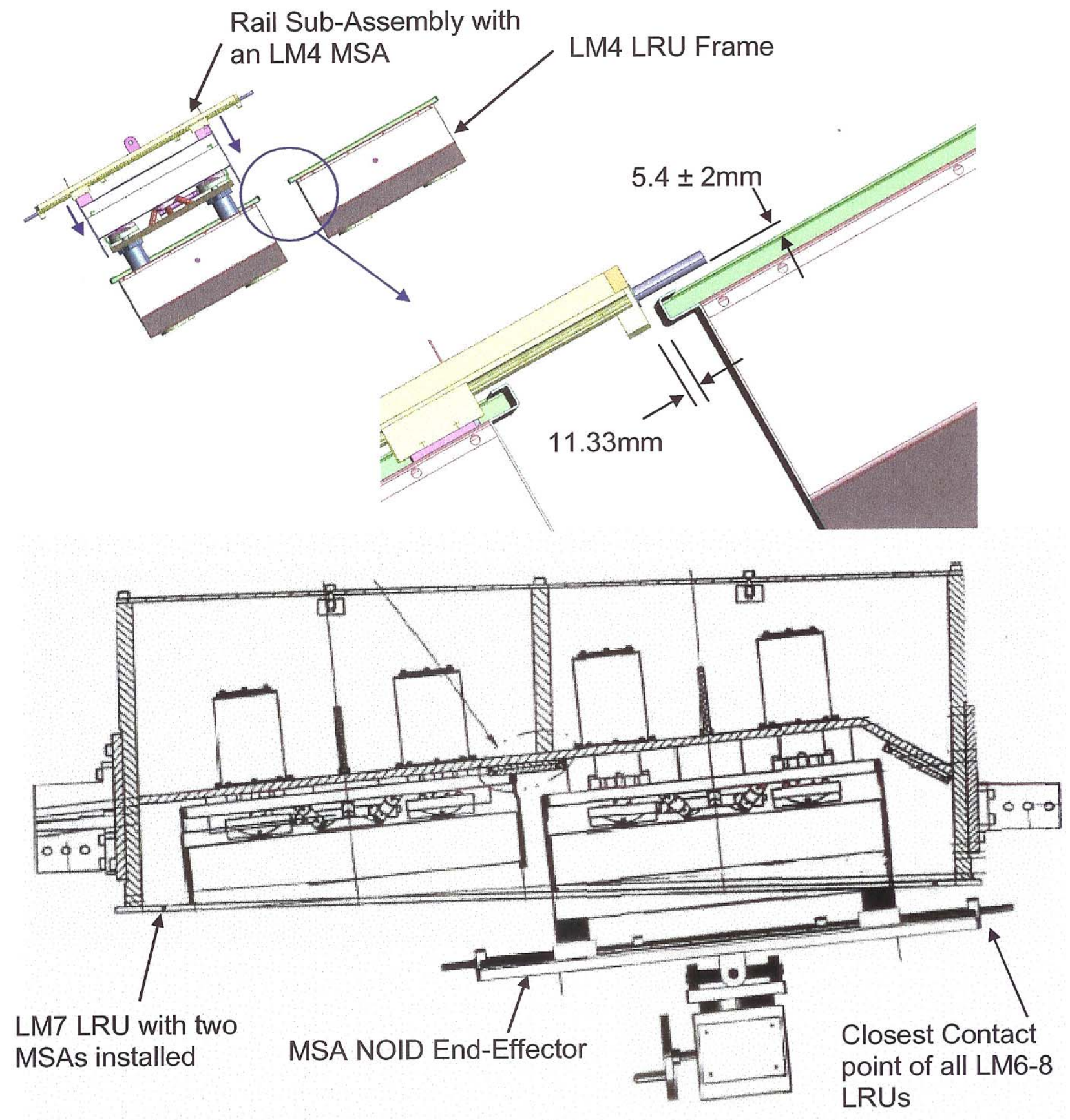

Figure 15 MSA NOID End-Effector interface with an LM4 (upper) and an LM7 (lower)

\section{Design Calculations}

Before the any equipment designed at Lawrence Livermore National Laboratory can be used, a safety note must be written and approved. The safety note for the MSA NOID End-Effector addresses the structural integrity of the End-Effector. The safety note calculations can be found in Appendix B. The End-Effector was designed per guidelines of the Lawrence Livermore National Laboratory Mechanical Engineering Design Safety Standards. In most cases the Design 
Safety Standards require a minimum safety factor of 3 on yield or 4 on ultimate for static loads and a minimum safety factor of 1 on yield or 1.25 on ultimate for seismic loads.

The largest MSA weight of $270 \mathrm{lbs}$ was used for the calculations. When the MSA is cantilevered off of the Side Mounting Plates, an over turning moment is created throughout the assembly. Overall, the machined components were considered very robust and the critical load path was assumed to be through the fasteners connecting the components and through the shaft of the Twist Sub-Assembly. It was also conservatively assumed that the MSA was rotated $20^{\circ}$ in yaw and was 4 inches off center along the THK rails on the Rail Sub-Assembly. This placed an additional shear load on most of the End-Effector components.

Both static and seismic calculations were performed on the End-Effector. For the seismic calculations it was assumed that the LM4-8 NOID End-Effector will be subject to $1.3 \mathrm{~g}$ vertical and $1.3 \mathrm{~g}$ horizontal loads during a seismic event. It is unrealistic to have $100 \%$ of the seismic load applied to all three directions (X, Y, and Z) at the same time. For this reason, NIF seismic guidance was applied to the calculations. That is, vertical seismic load $(\mathrm{Y})=100 \%$, horizontal seismic loads $(X$ and $Z)=40 \%$. Due to the free-swinging nature of the NOID arm around the center column, horizontal accelerations in "Z" were considered nil.

As can be seen in Table B1 of Appendix B, most of the MSA NOID End-Effector components met the Design Safety Standards. The few that did not meet the Design Safety Standards were accepted based on the improbability of occurrence or acceptable consequences of the component yielding. The worst case static moment load on the Robo-hand was calculated to be 5319 in-lb which is just under the manufactures rated load of $6000 \mathrm{in}-\mathrm{lb}$.

\section{Procure, Assemble, and Test}

The drawings found in Appendix A were sent to several machine shops for bidding. Lukas Machine, in Seattle Washington had the lowest bid at $\$ 4409.00$ and was awarded the job. When the cost of the machined components is totaled with the cost of the "off the shelf" items, the total manufacturing cost of the MSA NOID End-Effector was just under $\$ 6,000$, which met the low cost requirement of the design.

Once all the components were received, a dirty fit up was performed to make sure that all the pieces fit together as designed. At the time of the dirty fit up, a new yaw locking system was designed and fabricated. The parts were then disassembled and precision cleaned. The final assembly was performed in the OAB and the assembly was attached to the NOID as shown previously in Figure 14.

The final step before the MSA NOID End-Effector could be used for production was a load and function test. The load test was performed with $405 \mathrm{lbs}$ hung from the End-Effector at the location of the MSA's center of gravity, as shown in Figure 16. The $405 \mathrm{lbs}$ represented 150\% of the weight of the heaviest MSA. The test was performed with the End-Effector at the extreme twist and yaw angles and with the MSA weight off center by 4 inches on the Rail Sub-Assembly. The load was held for 10 minutes and then the End-Effector was inspected for yielding. During the inspection it was discovered that the E-clips that were used in the Twist Sub-Assembly were not strong enough to carry the load at the extreme angles. The E-clips were replaced with a set 
screw design and the assembly was reload tested. There were no signs of yielding during the second load test.

The function test of the End-Effector followed the load test. The function test was first performed using aluminum blanks for optics and installing the blank MSAs into an LM4 LRU frame. The second function test was performed using practice optics and installing the practice MSAs into an LM5 LRU frame. A picture of this function test is shown in Figure 17. Due to hardware restraints at the time a fit test was not performed with an LM6, LM7, or LM8 LRU. Since the designs are very similar, there is not expected to be any problems installing the MSAs into these LRUs.

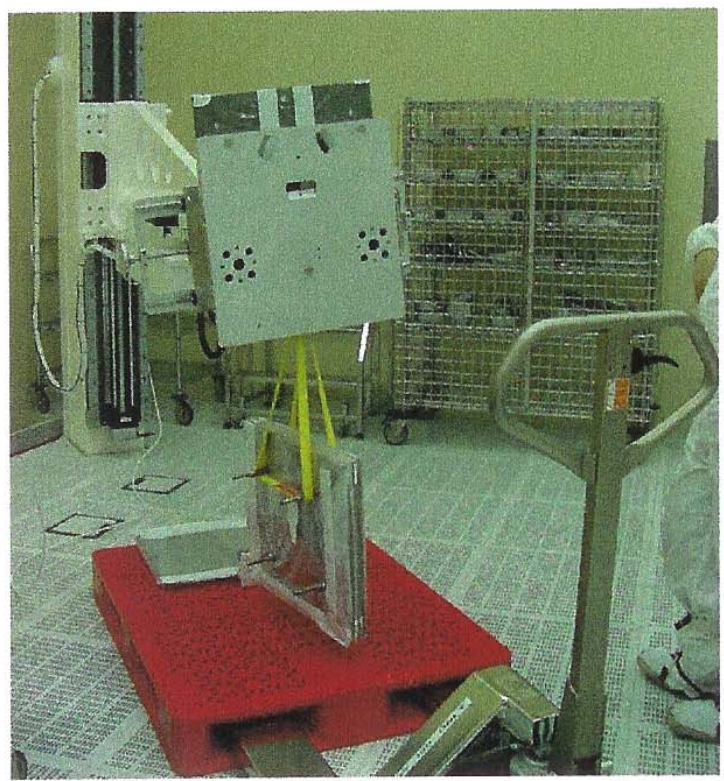

Figure 16 Load test of the MSA NOID EndEffector

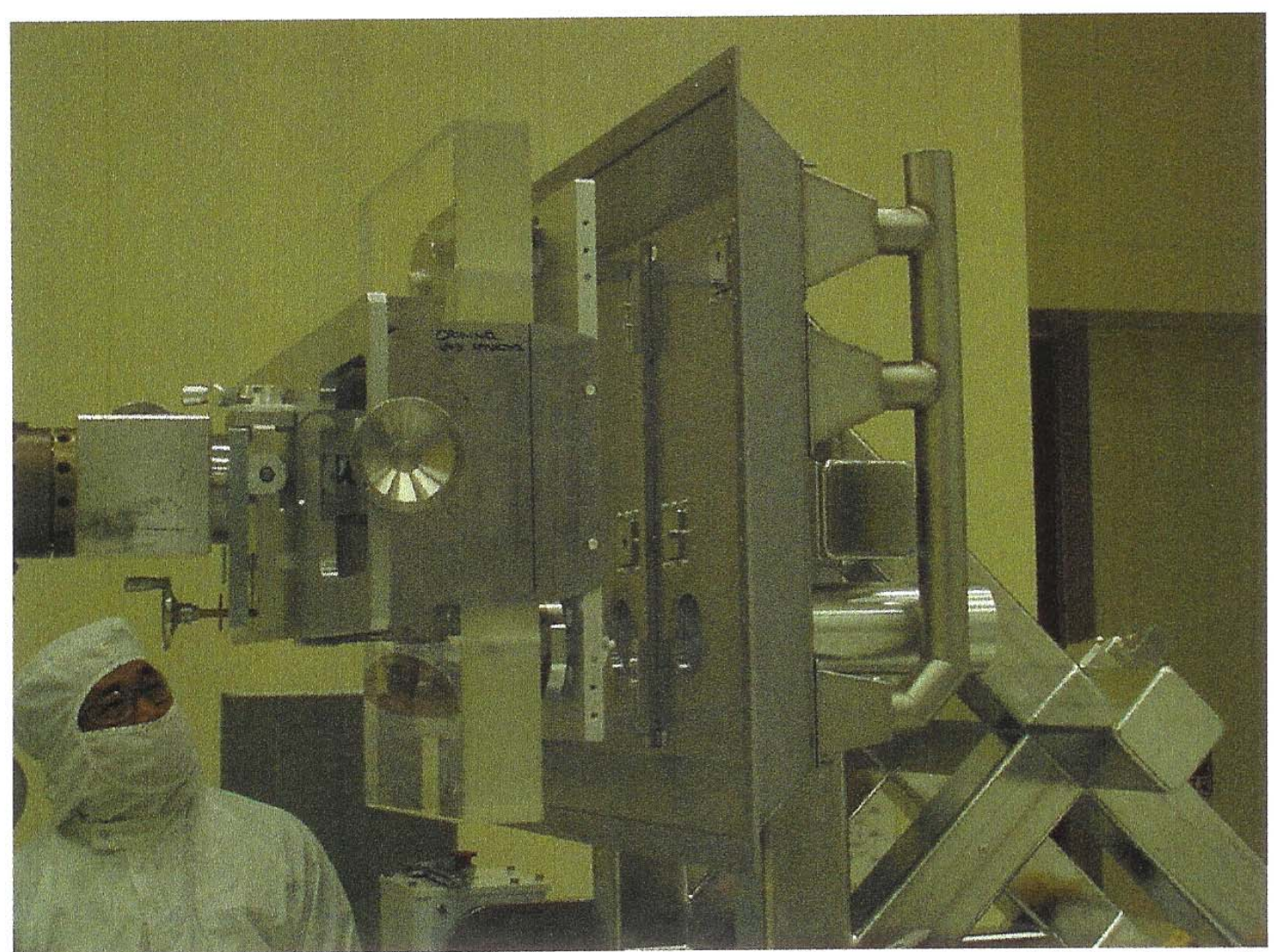

Figure 17 Fit and function test of the MSA NOID End-Effector with an LM5 Practice optic 


\section{Conclusion}

The final testing of the MSA NOID End-Effector was completed in June, 2004. Soon after the testing was complete, the LM4-8 LRU production was put on hold for a couple of years while other parts of the NIF laser were built. It was only in October, 2006 that the End-Effector was used to build its first production LM5 LRU. It is now December, 2006 and the End-Effector is currently being used to build a production LM4 LRU. So far the End-Effector has worked well and has been successful in installing 8 MSAs. LM6, LM7, and LM8 LRUs are scheduled to be assembled in January, 2007. I have no doubt that the MSA NOID End-Effector will effectively install the MSAs into these LRUs.

\section{$\underline{\text { Appendices }}$}

Appendix A: MSA NOID End-Effector component drawings.

Appendix B: MSA NOID End-Effector Safety Note Calculations 
Appendix A-Reference Drawings

26 attached pages 


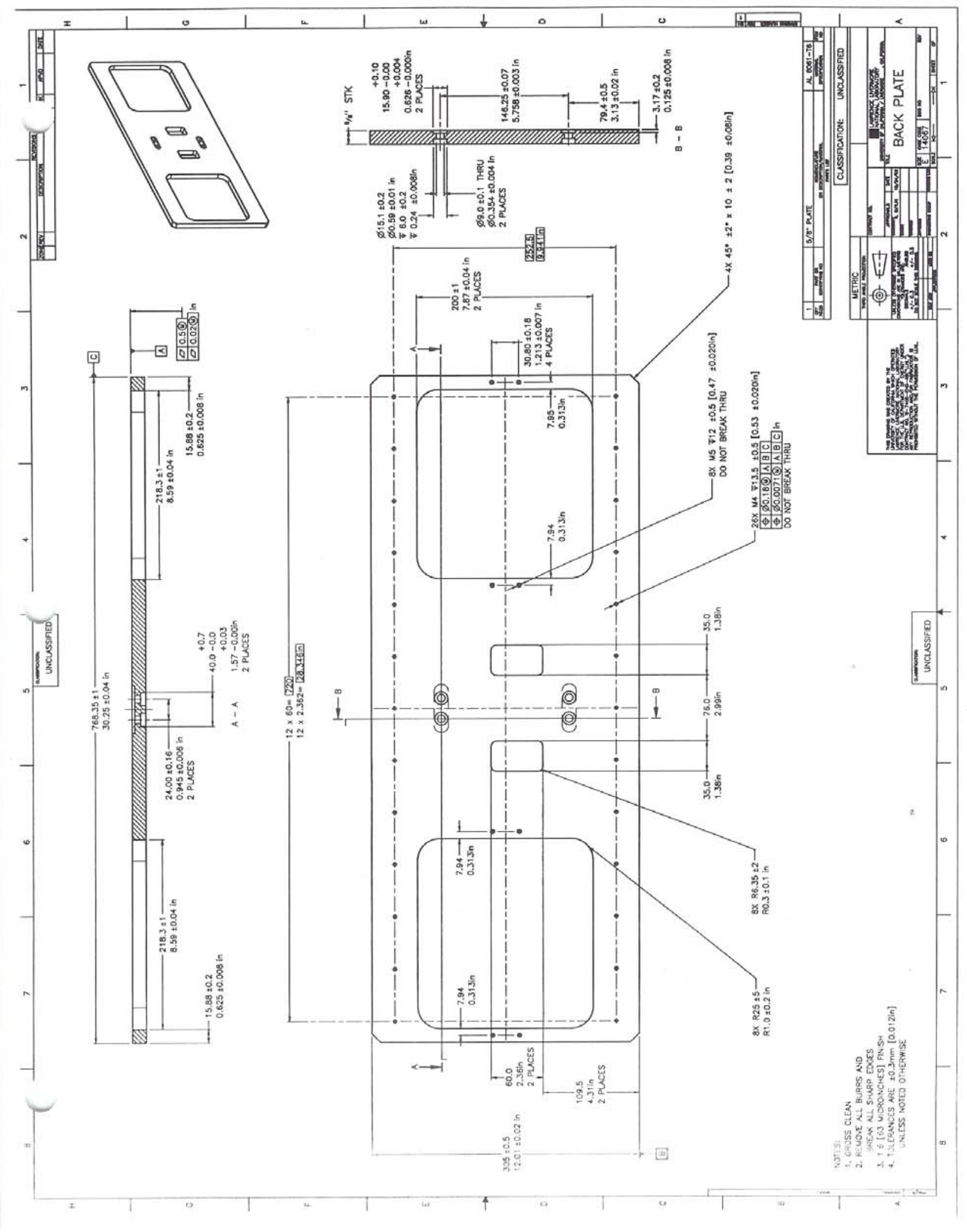




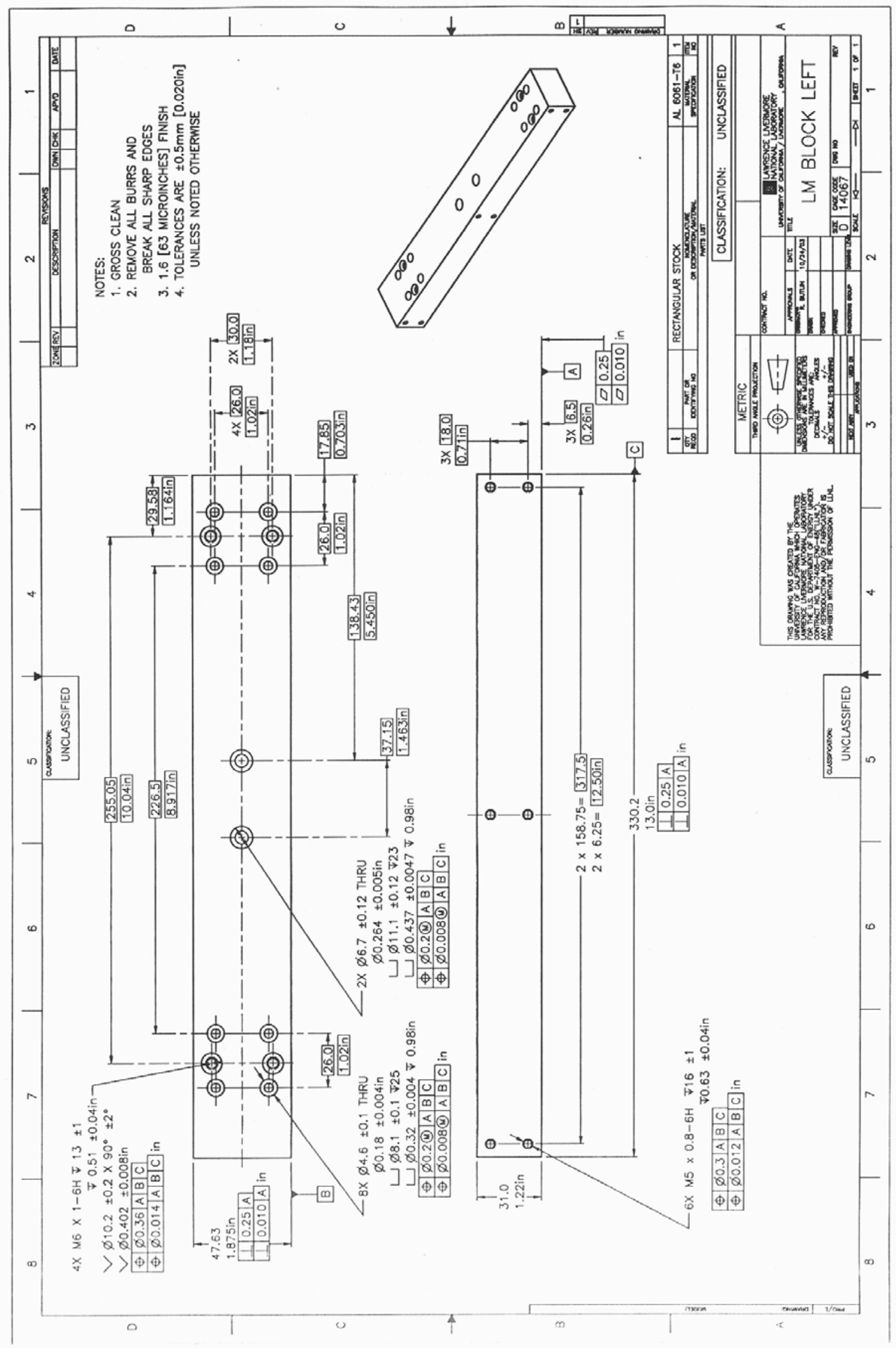




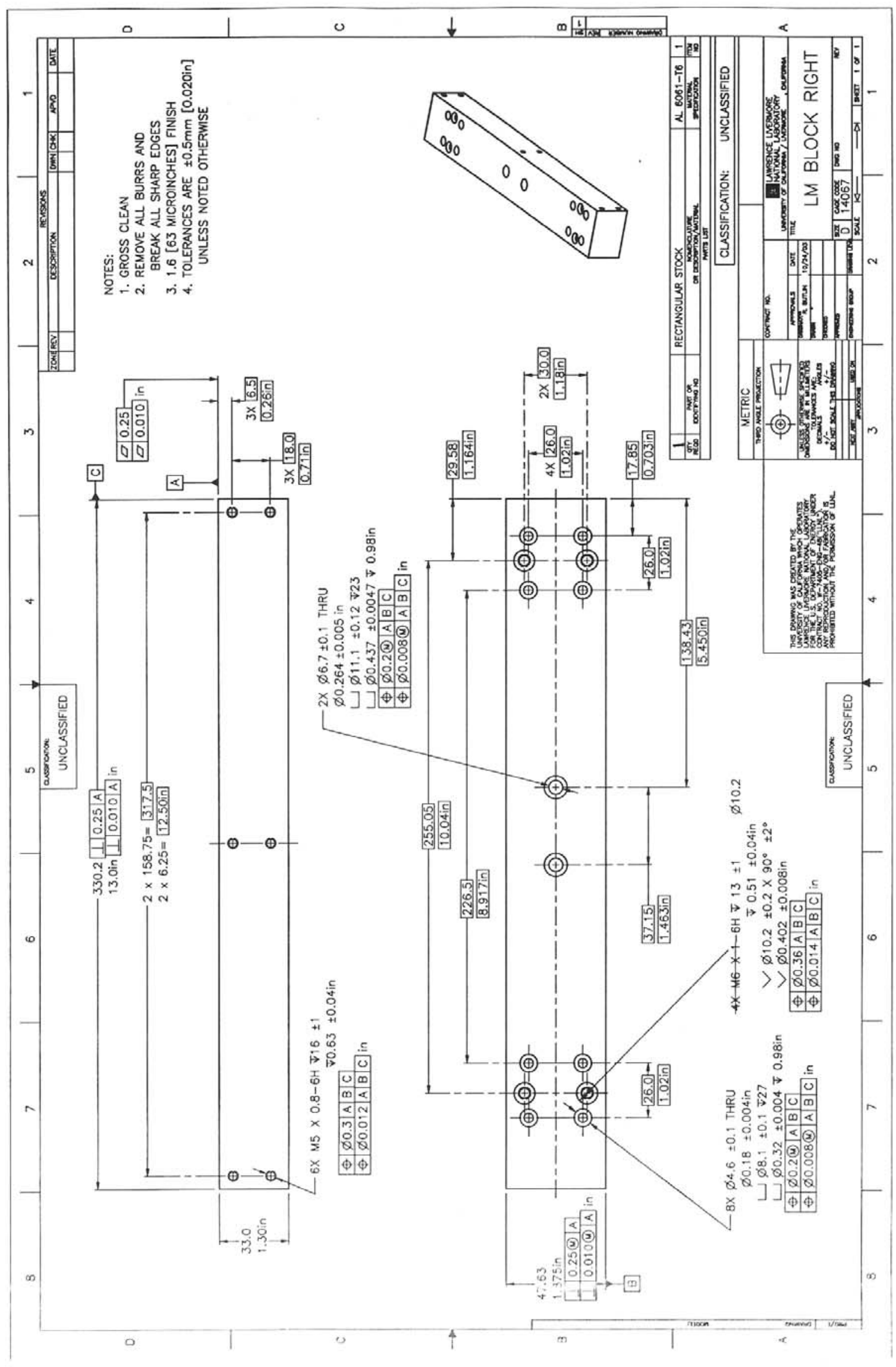




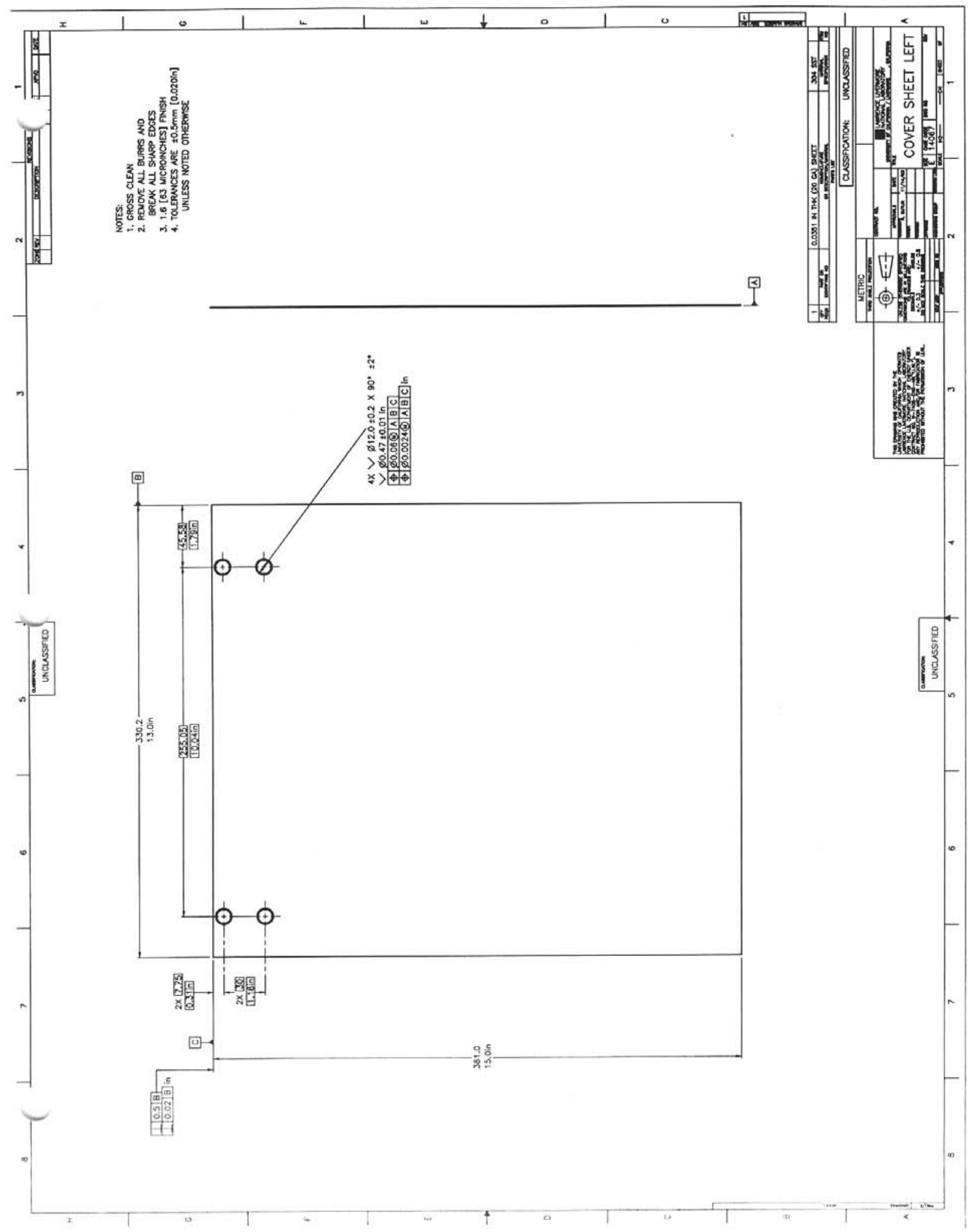




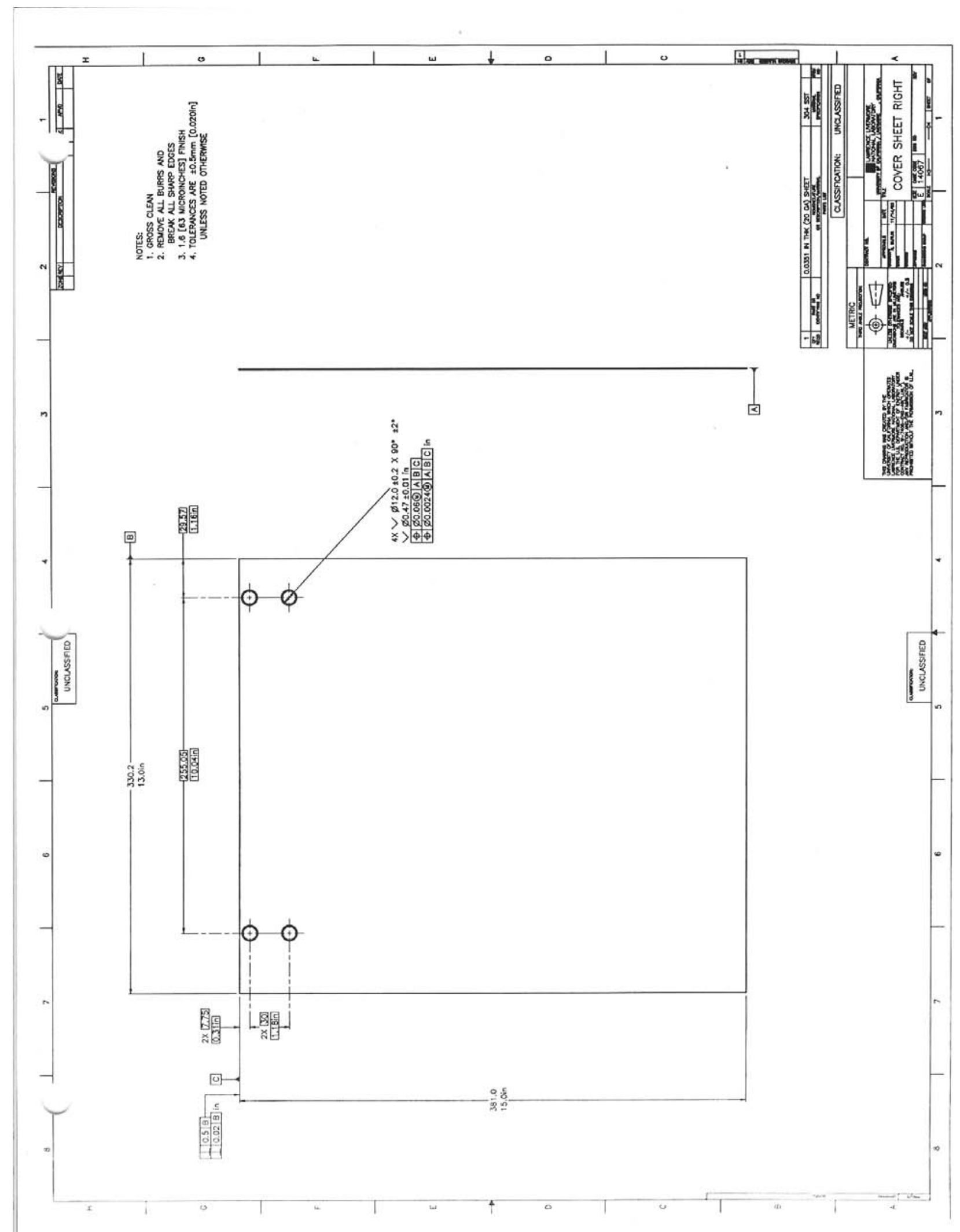




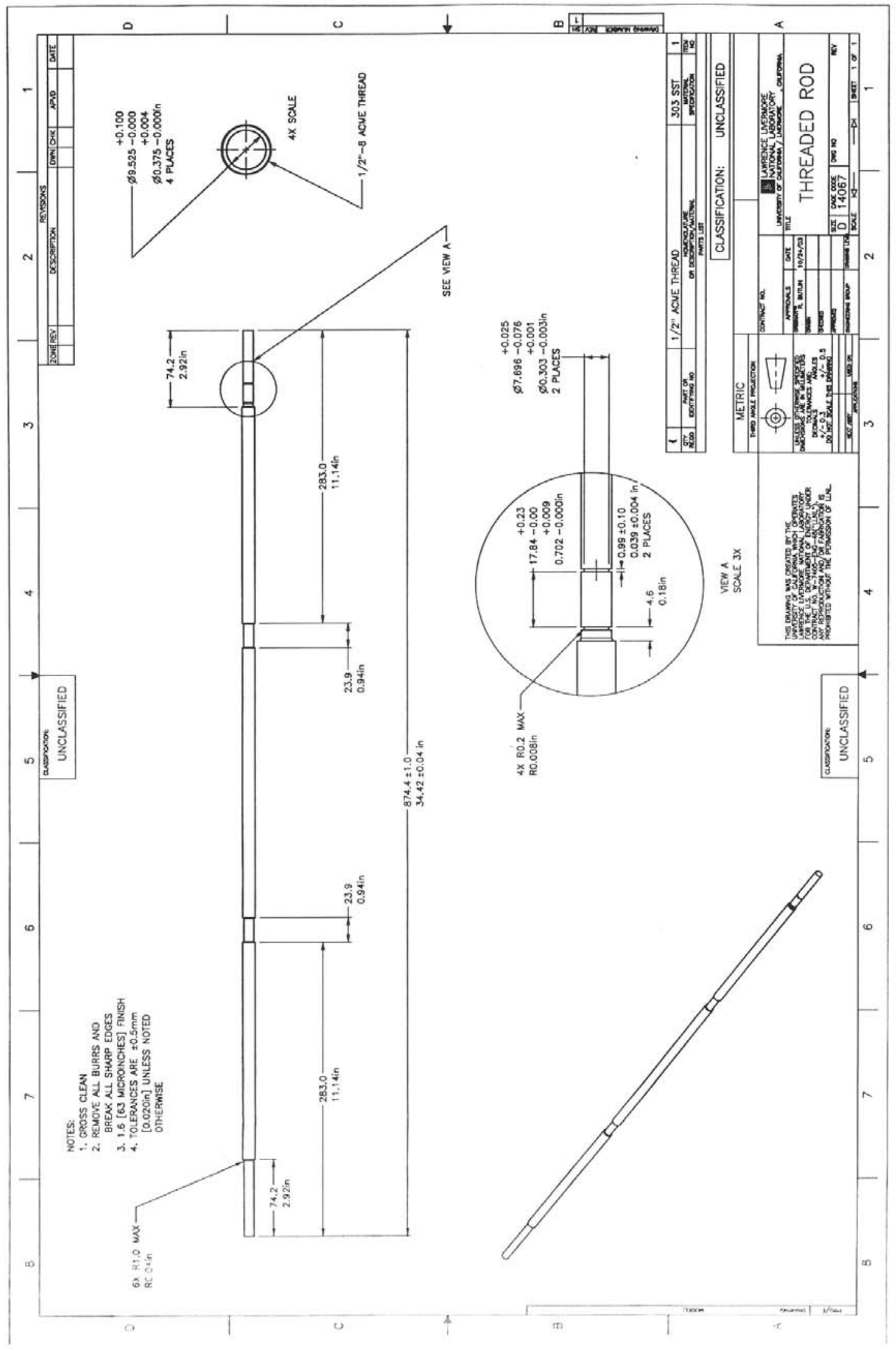




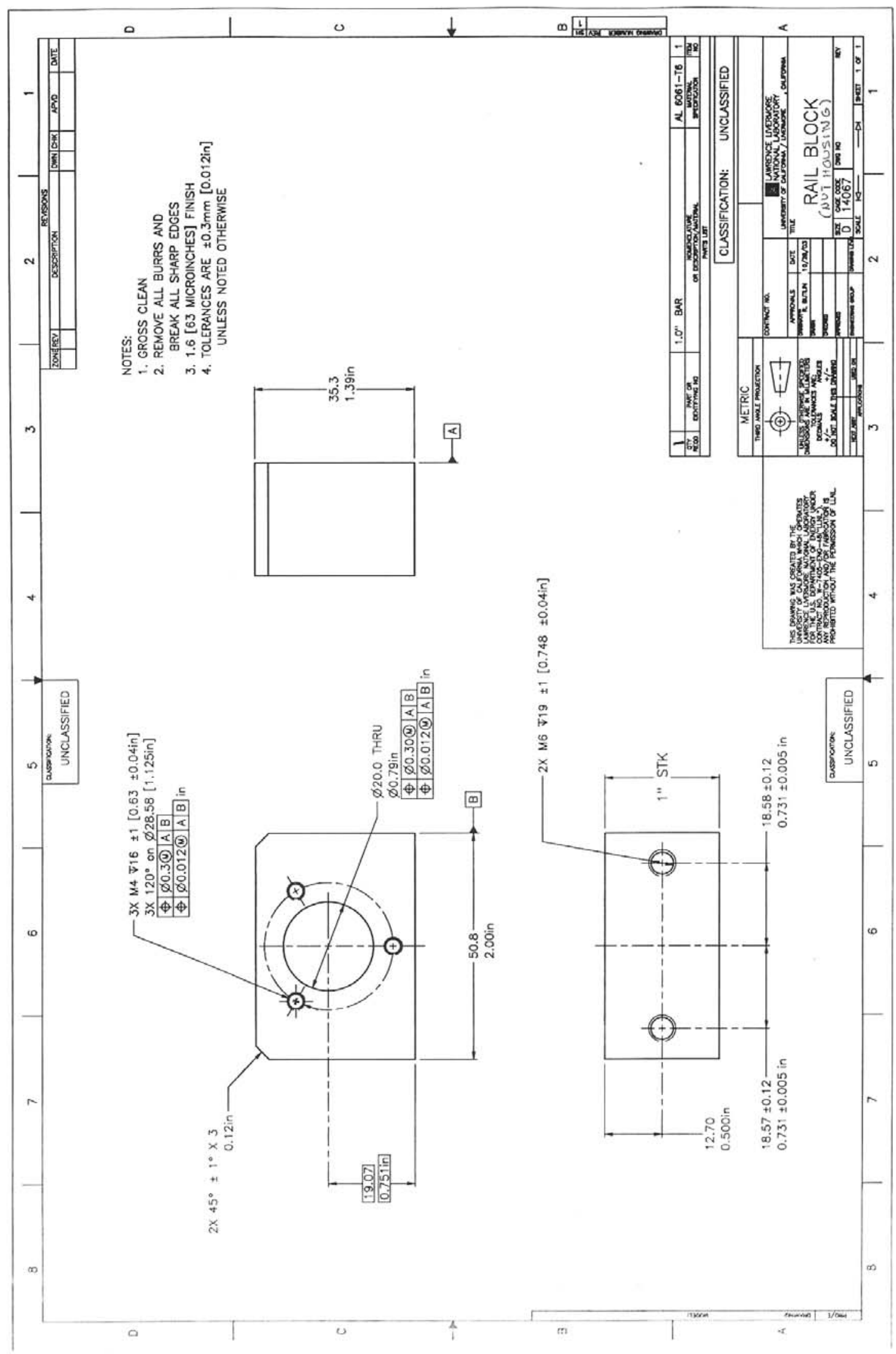




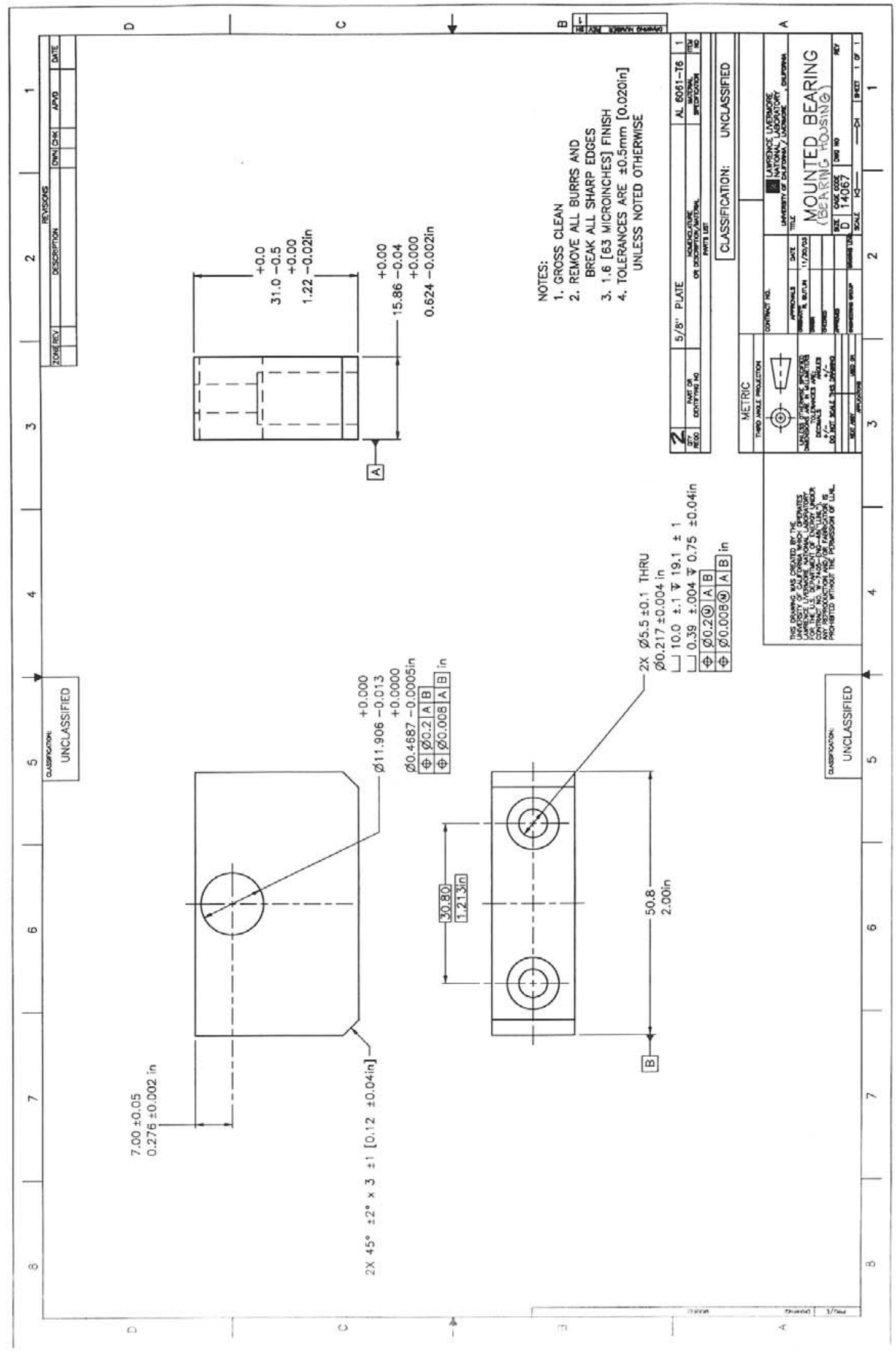




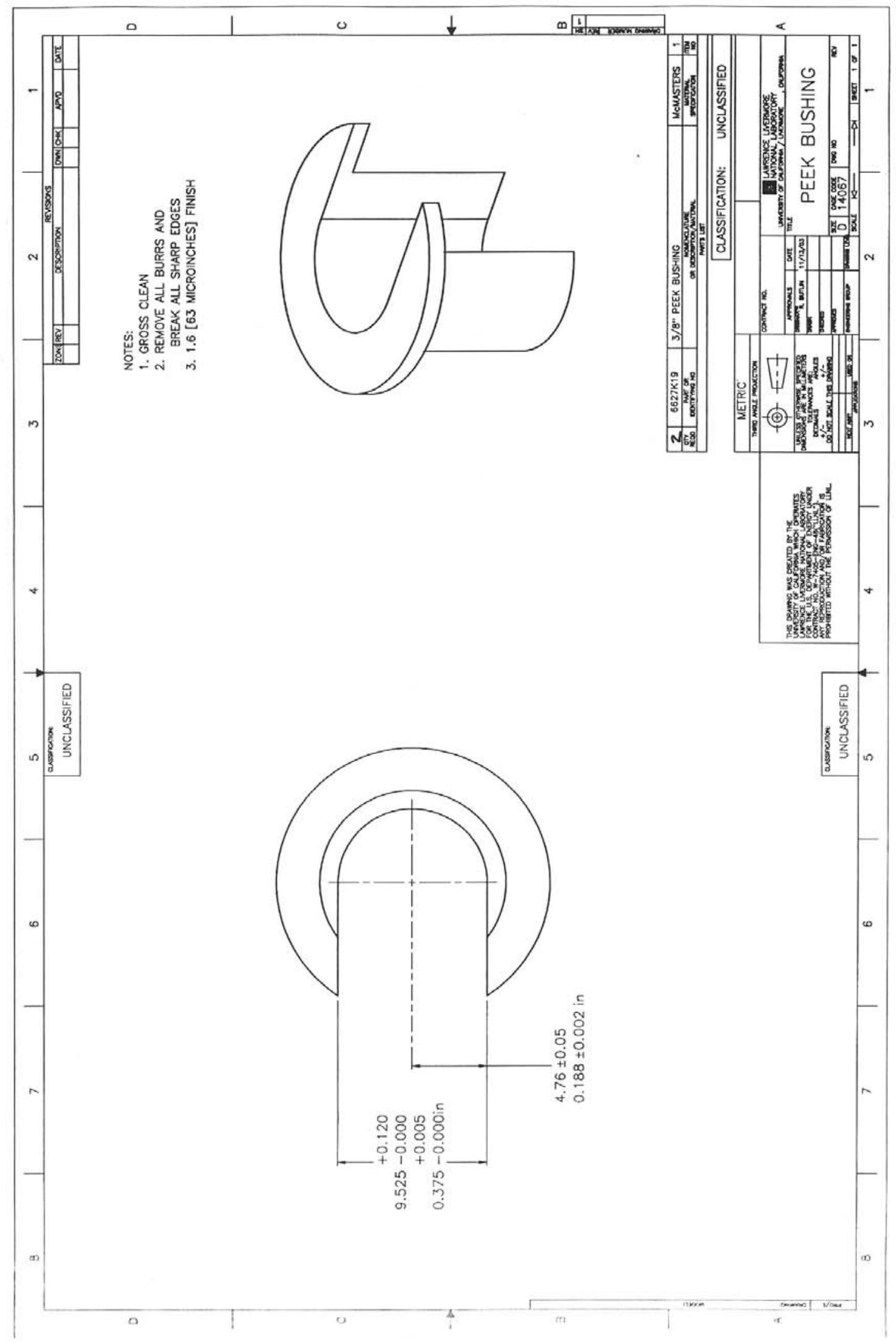




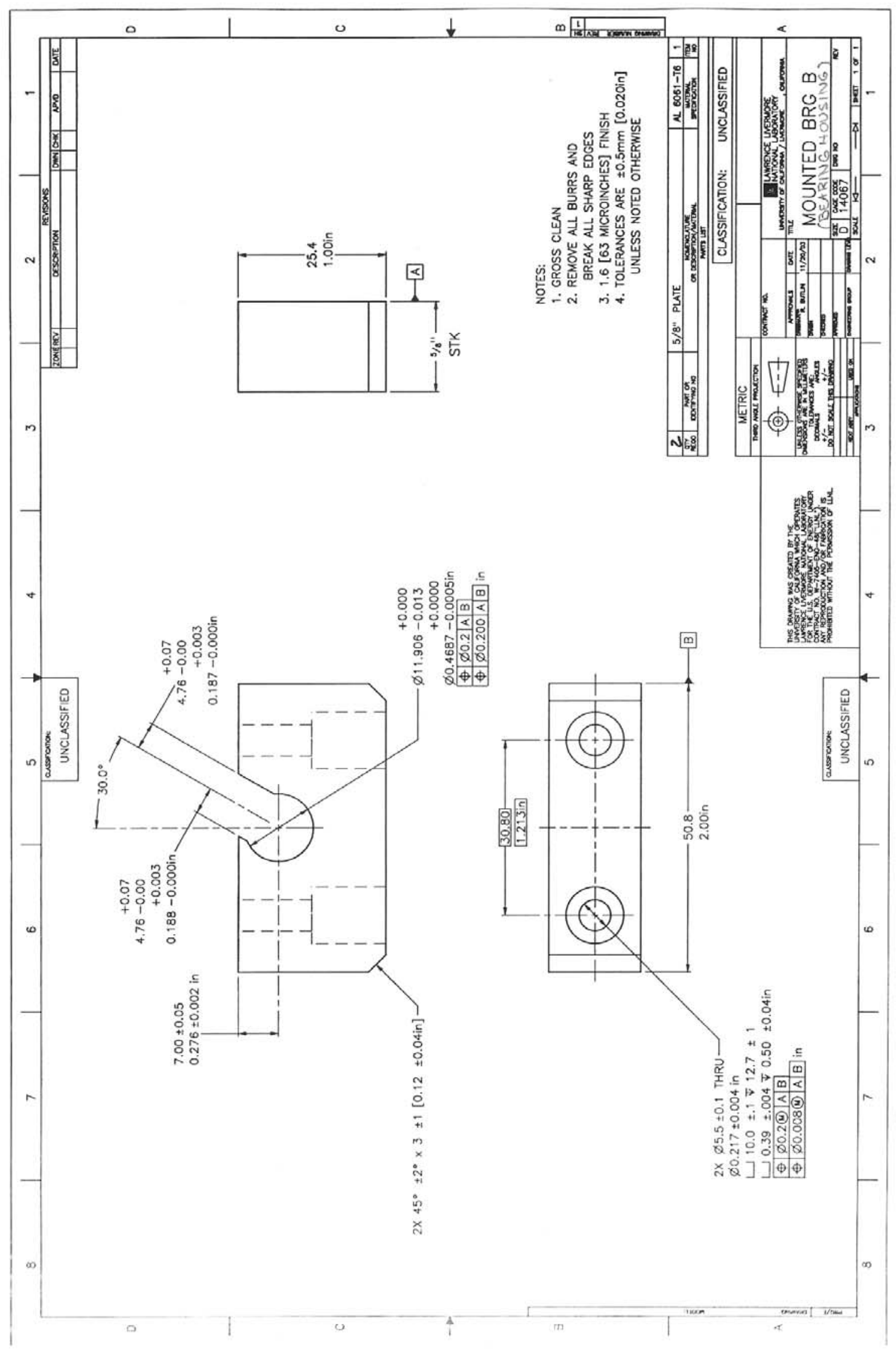




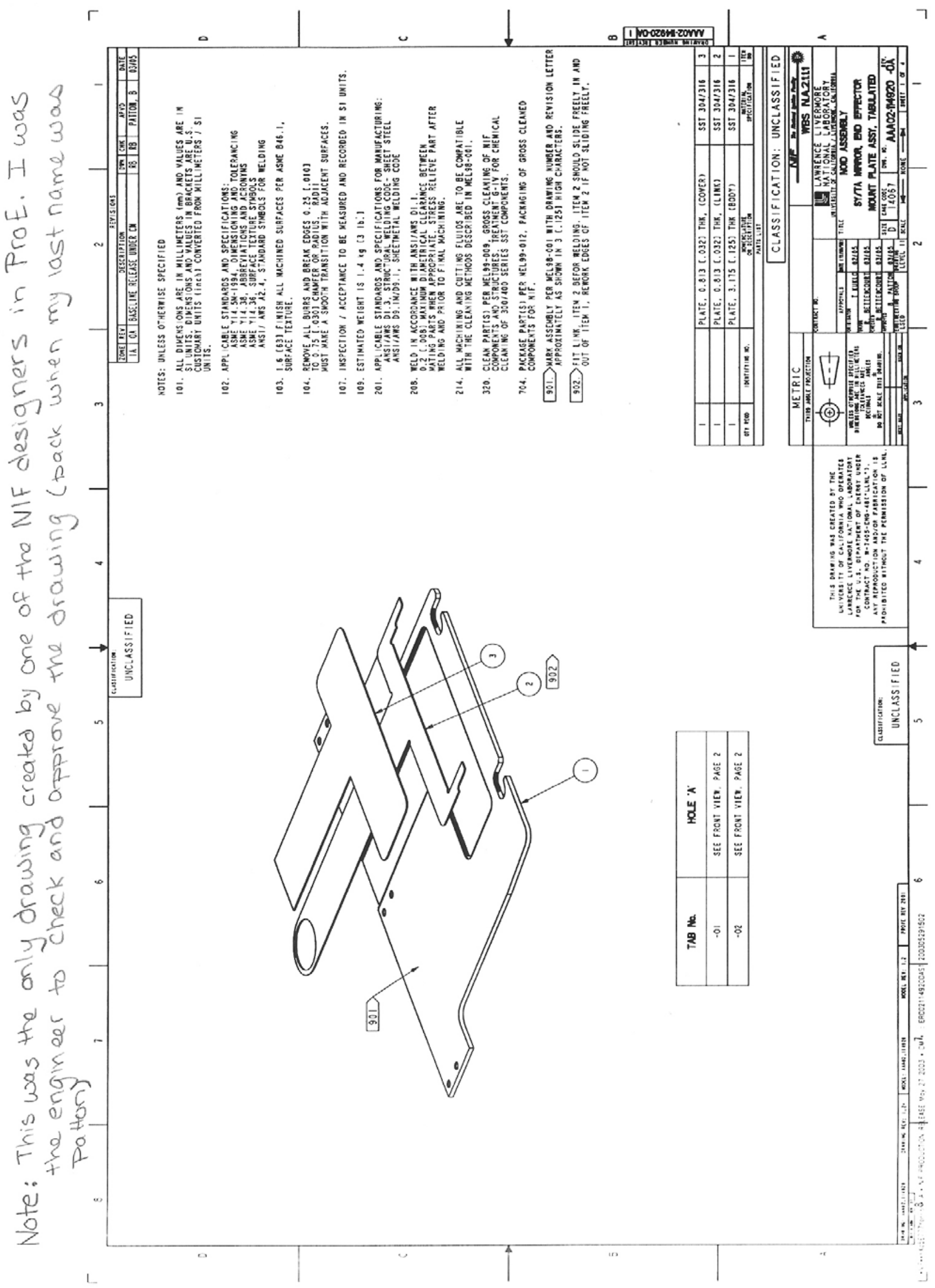




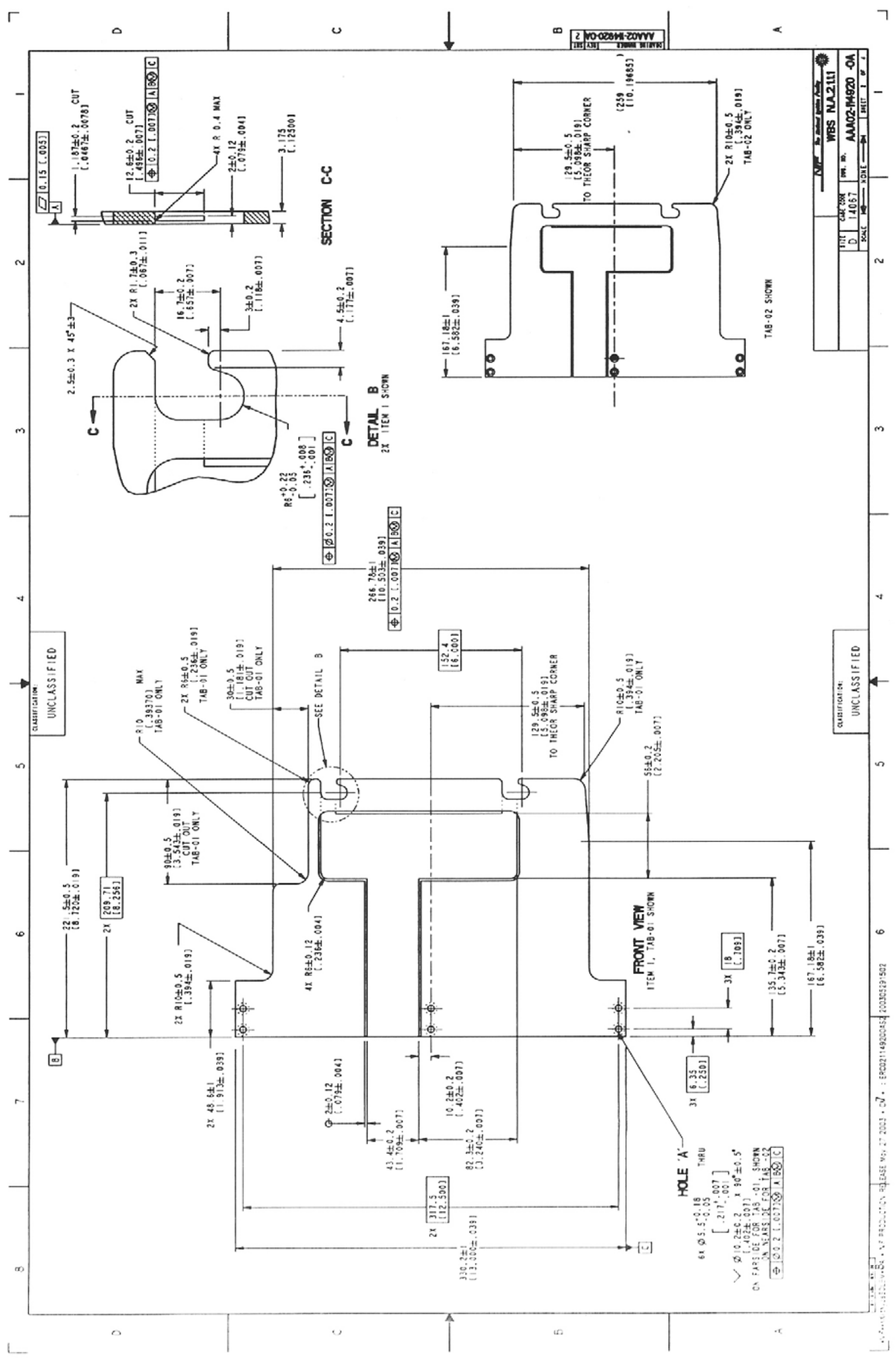




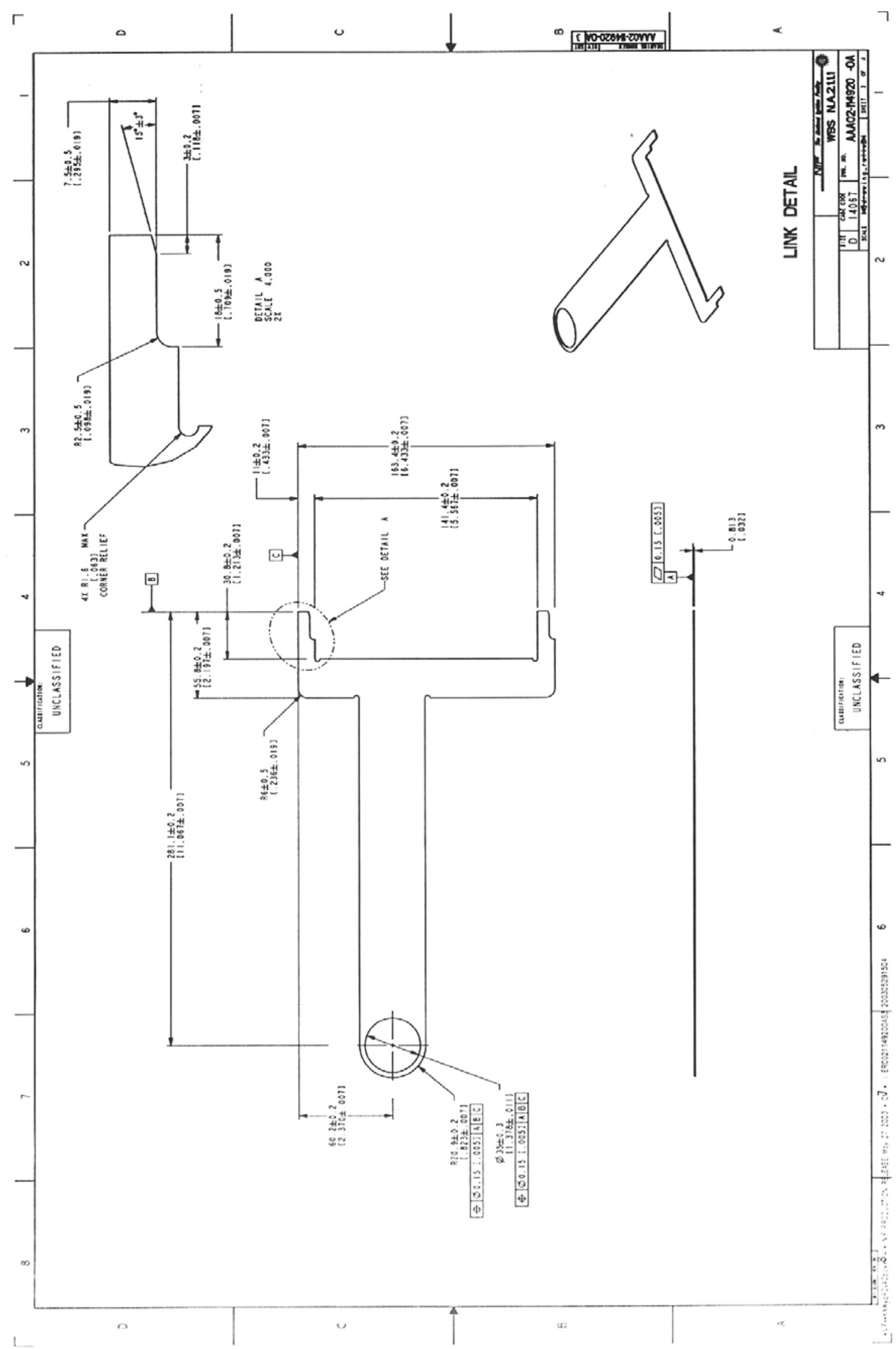




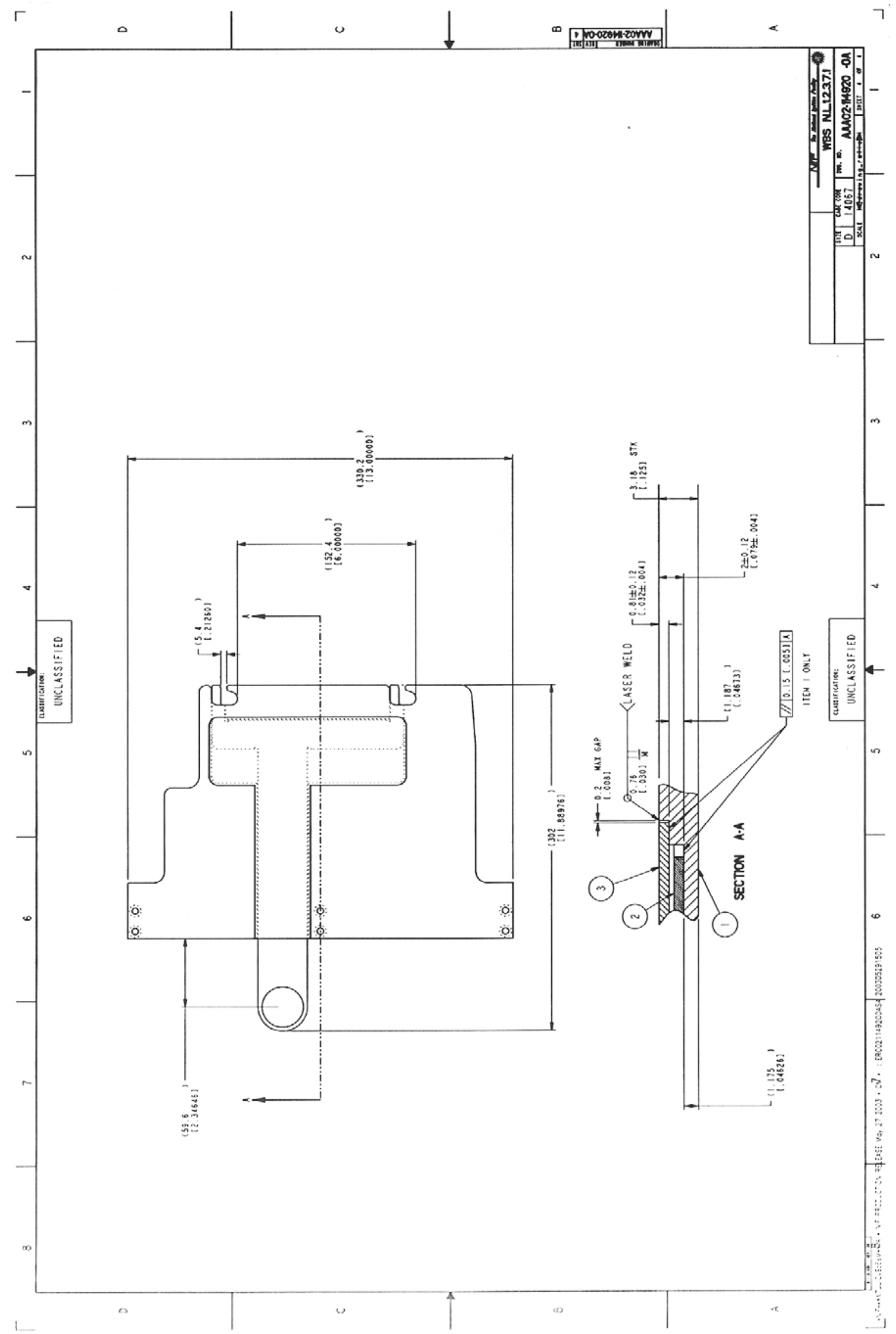




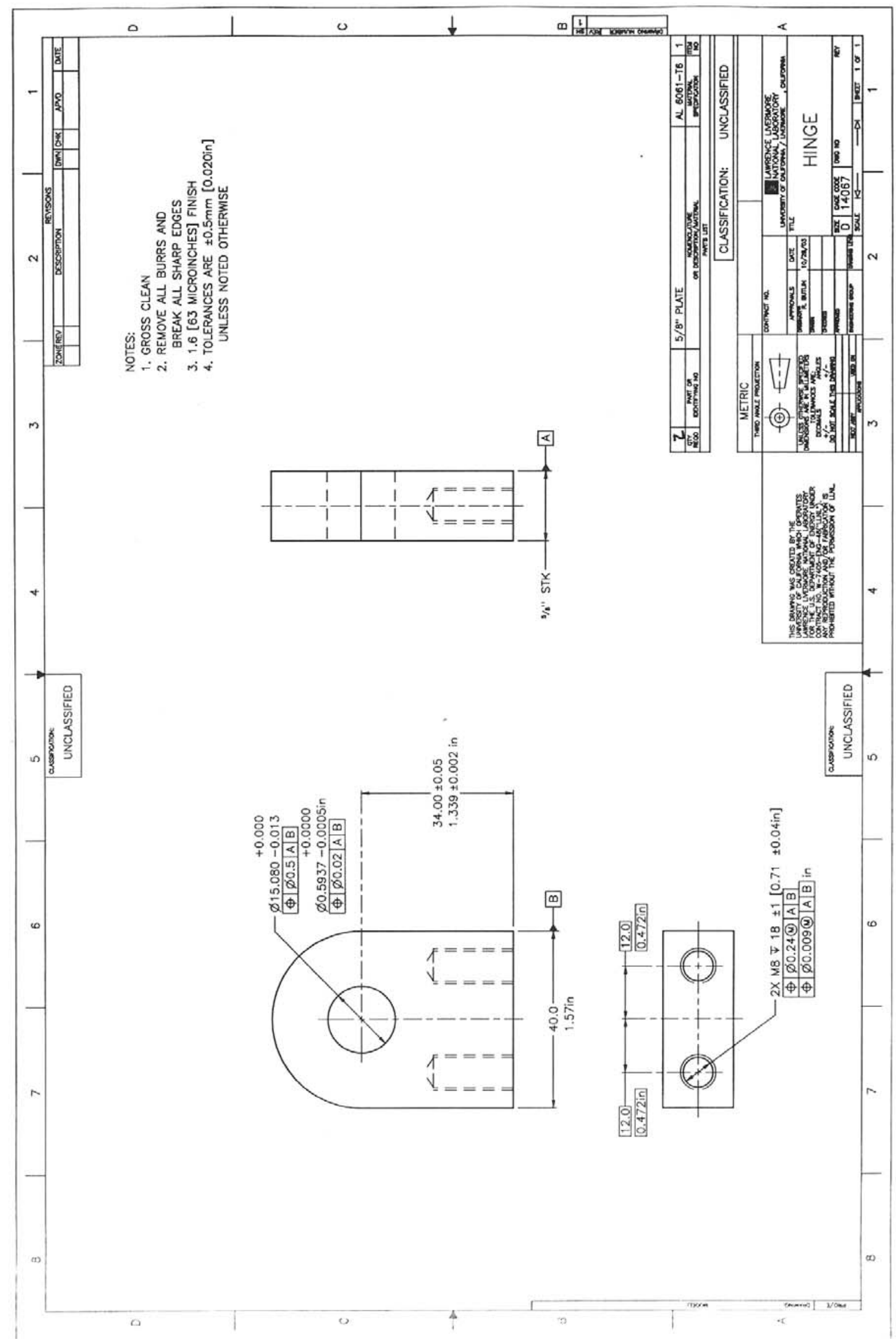




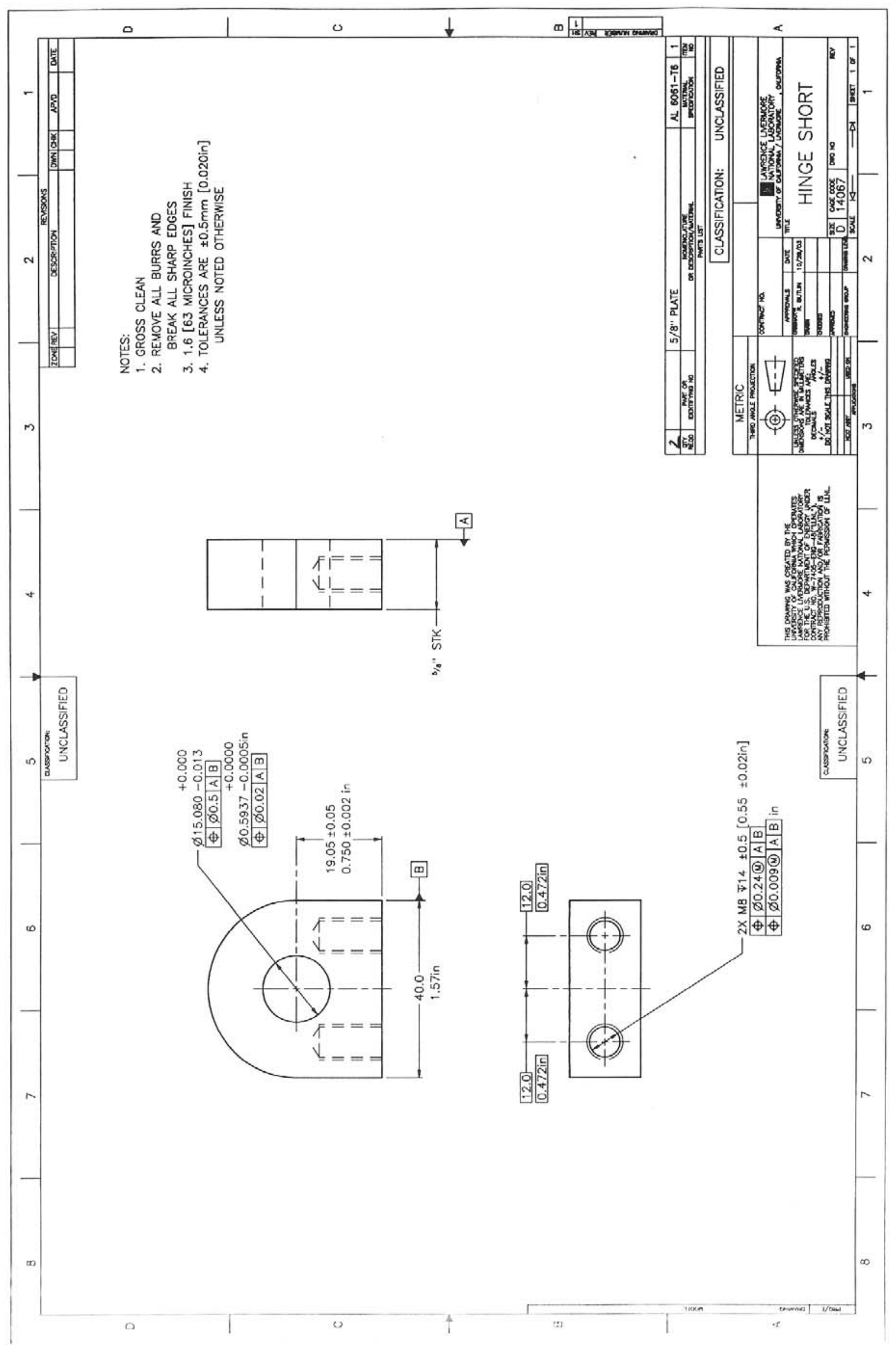




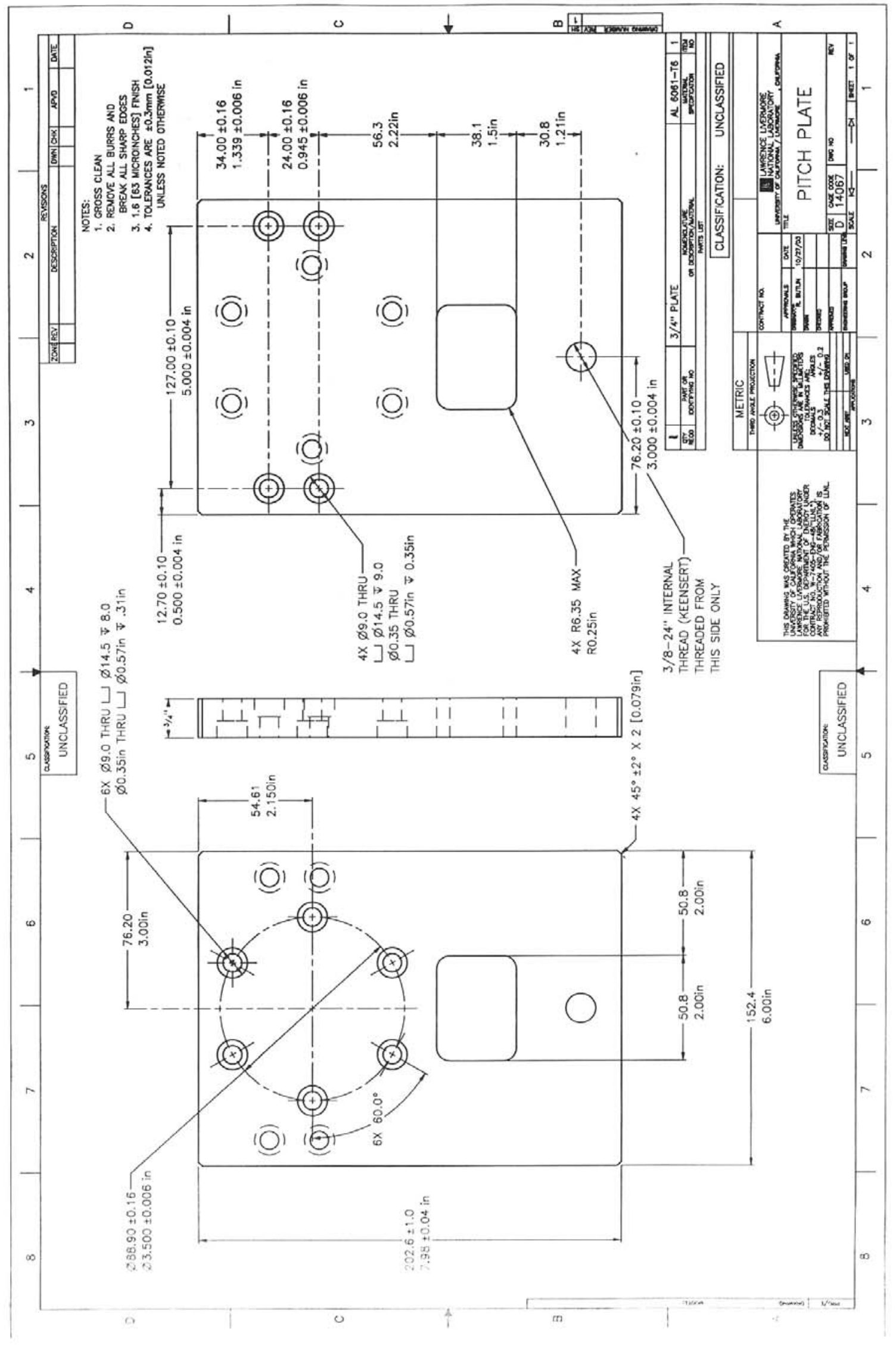




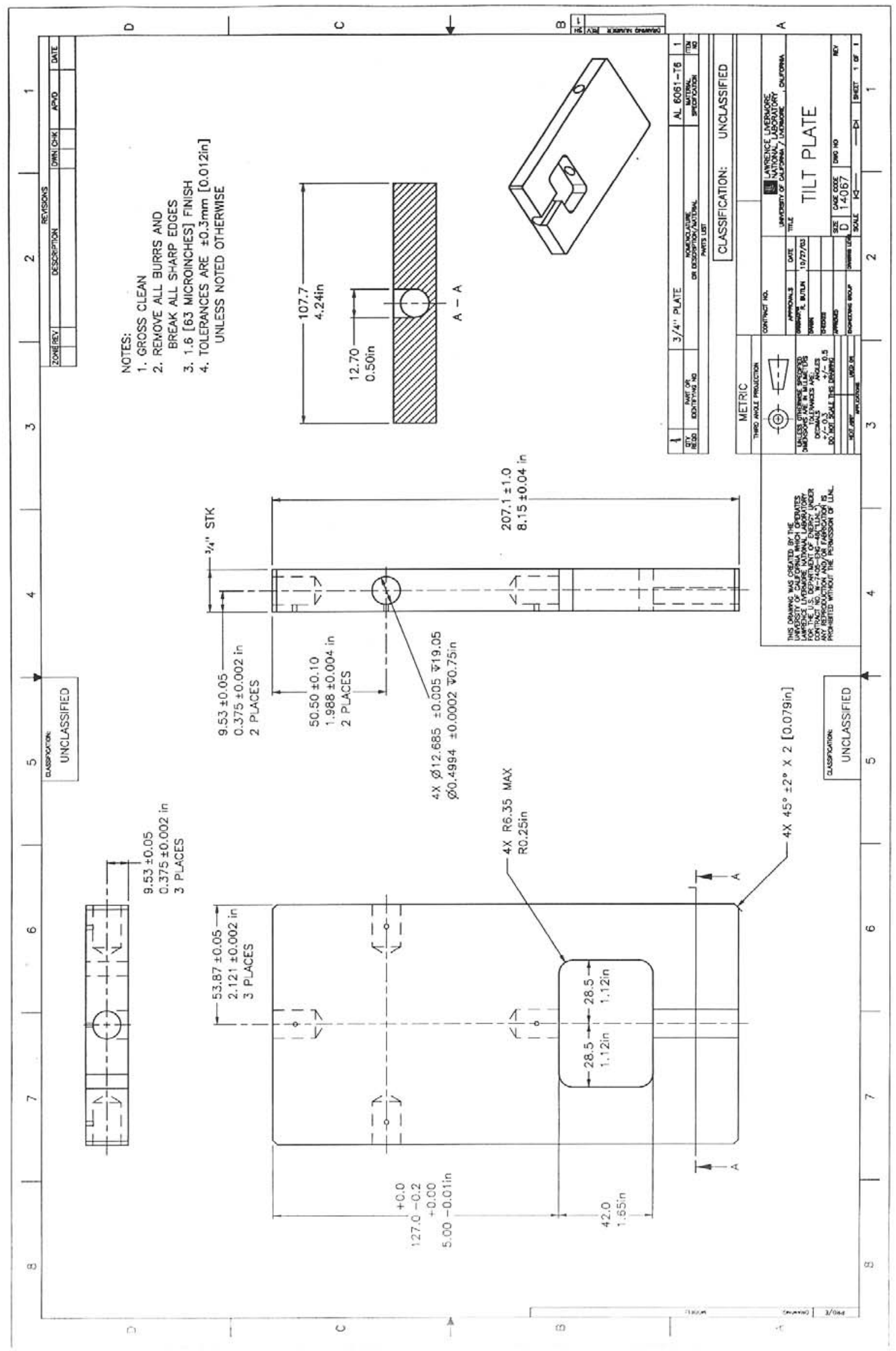




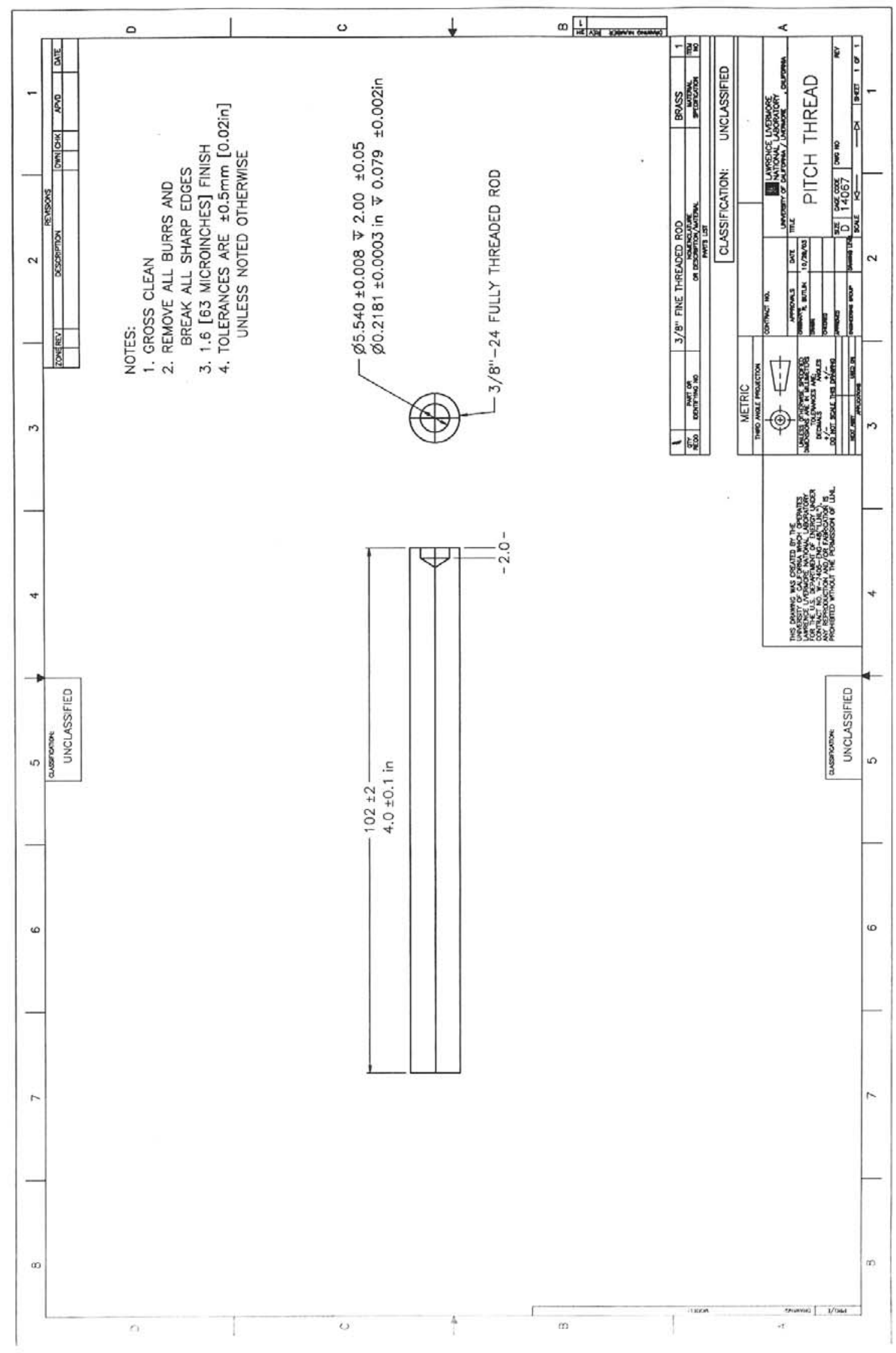




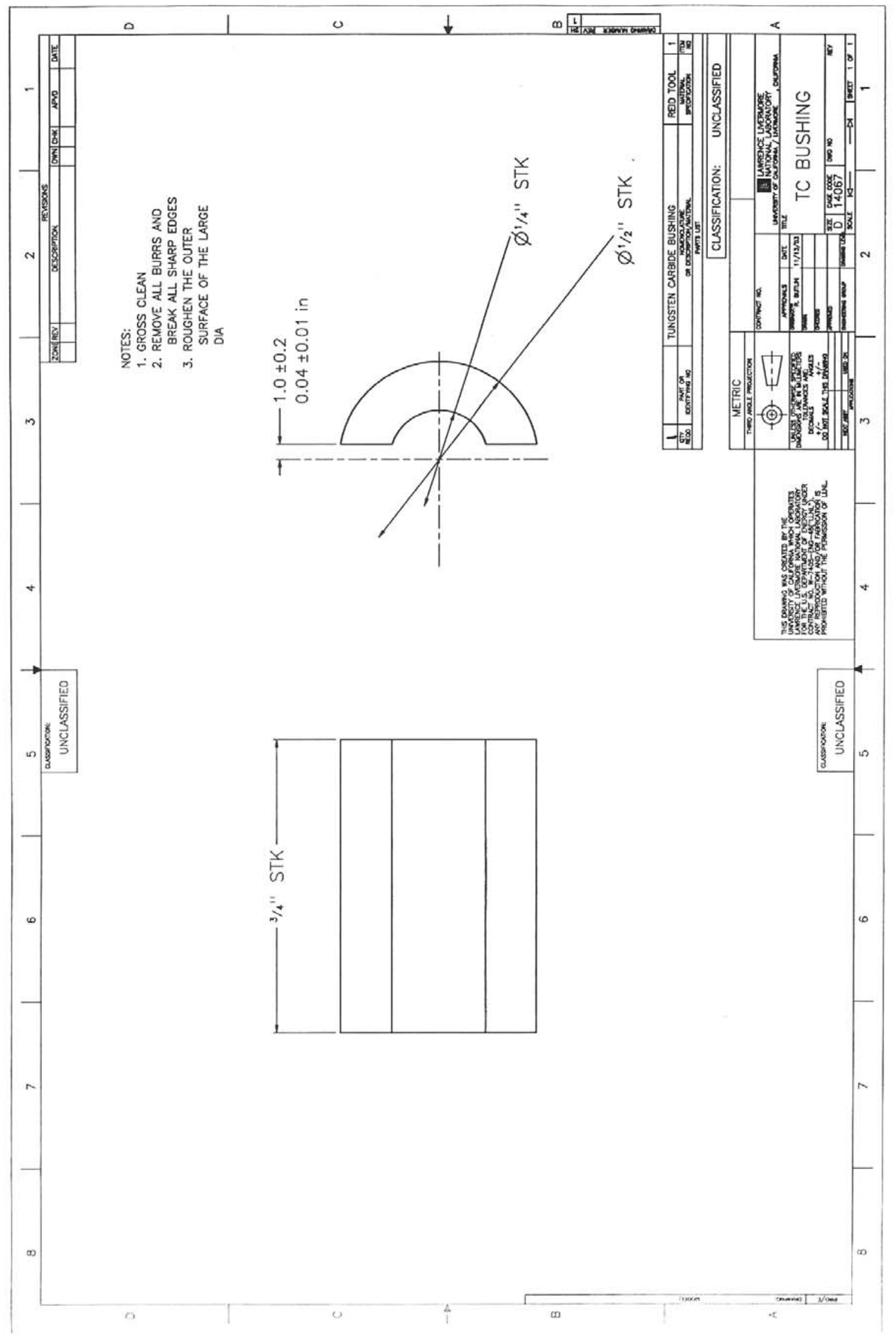




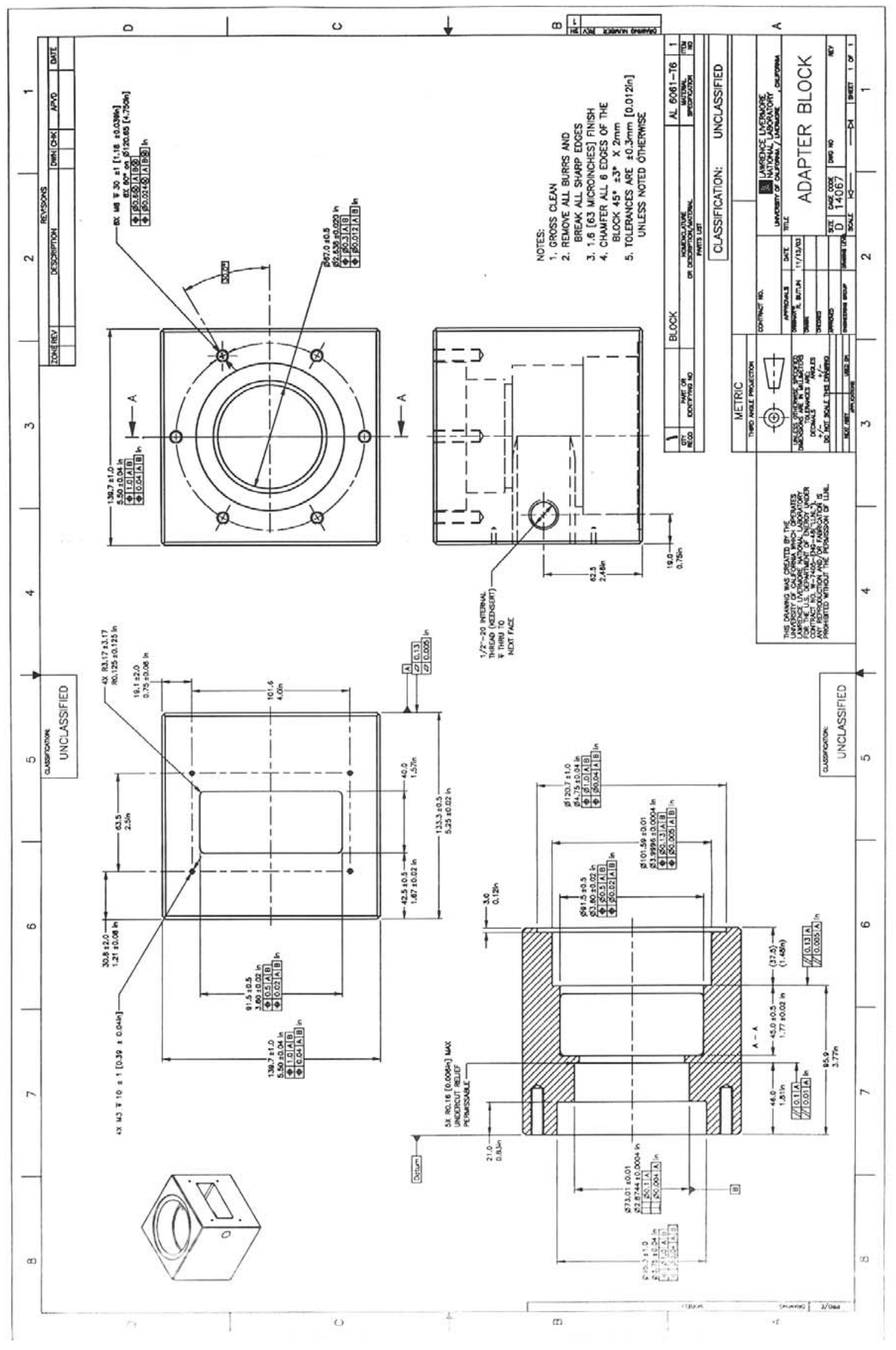




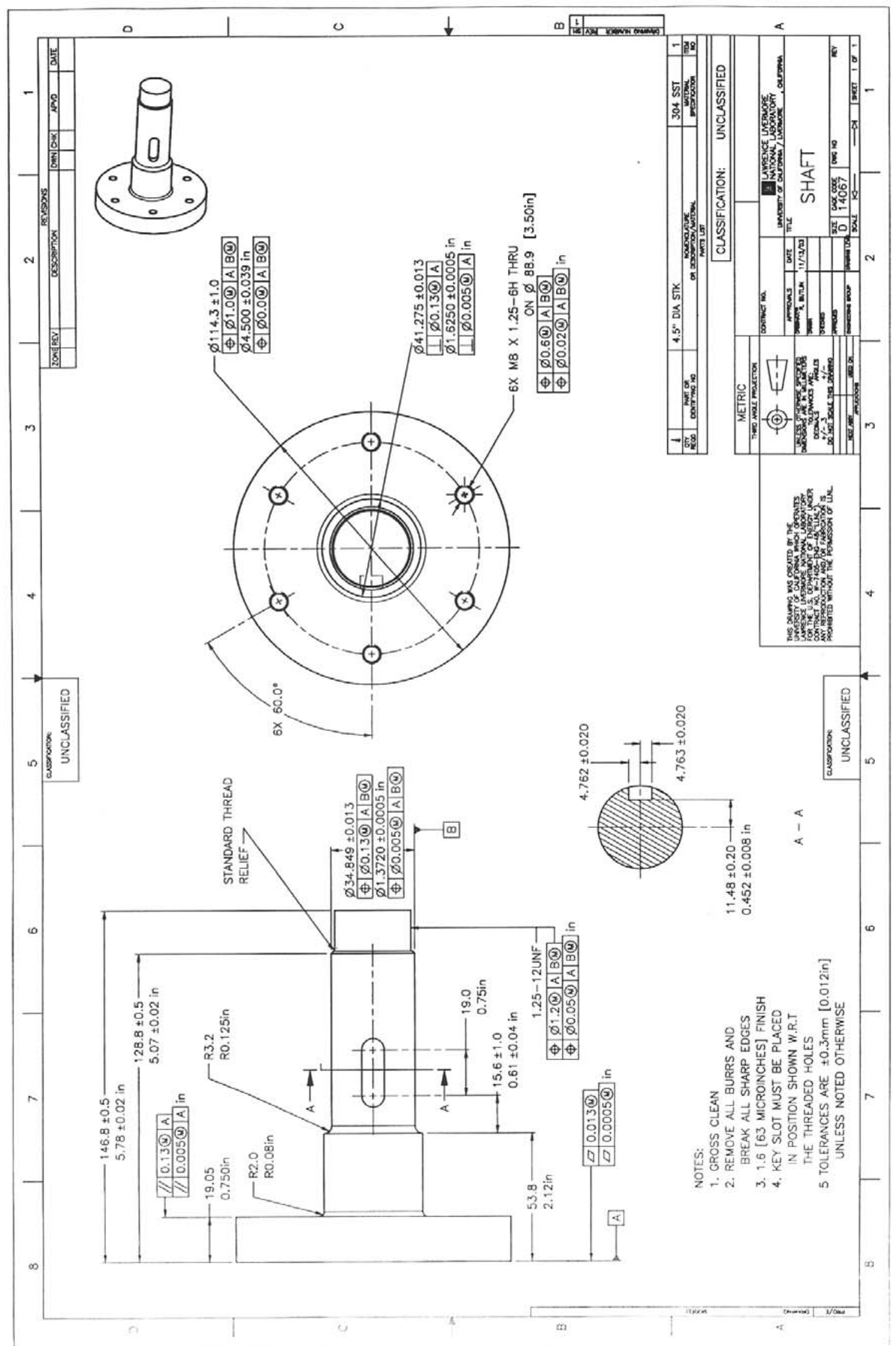




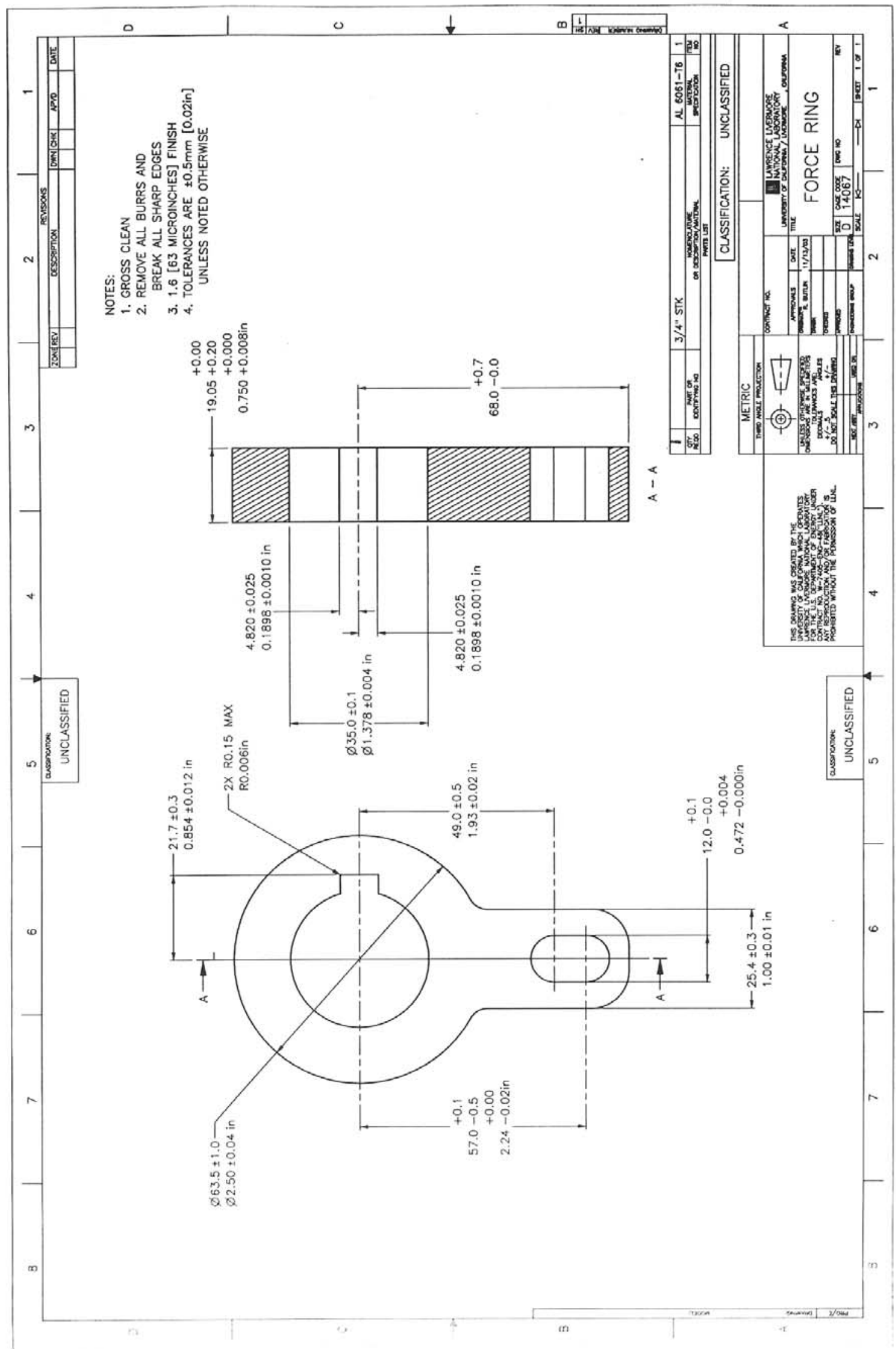




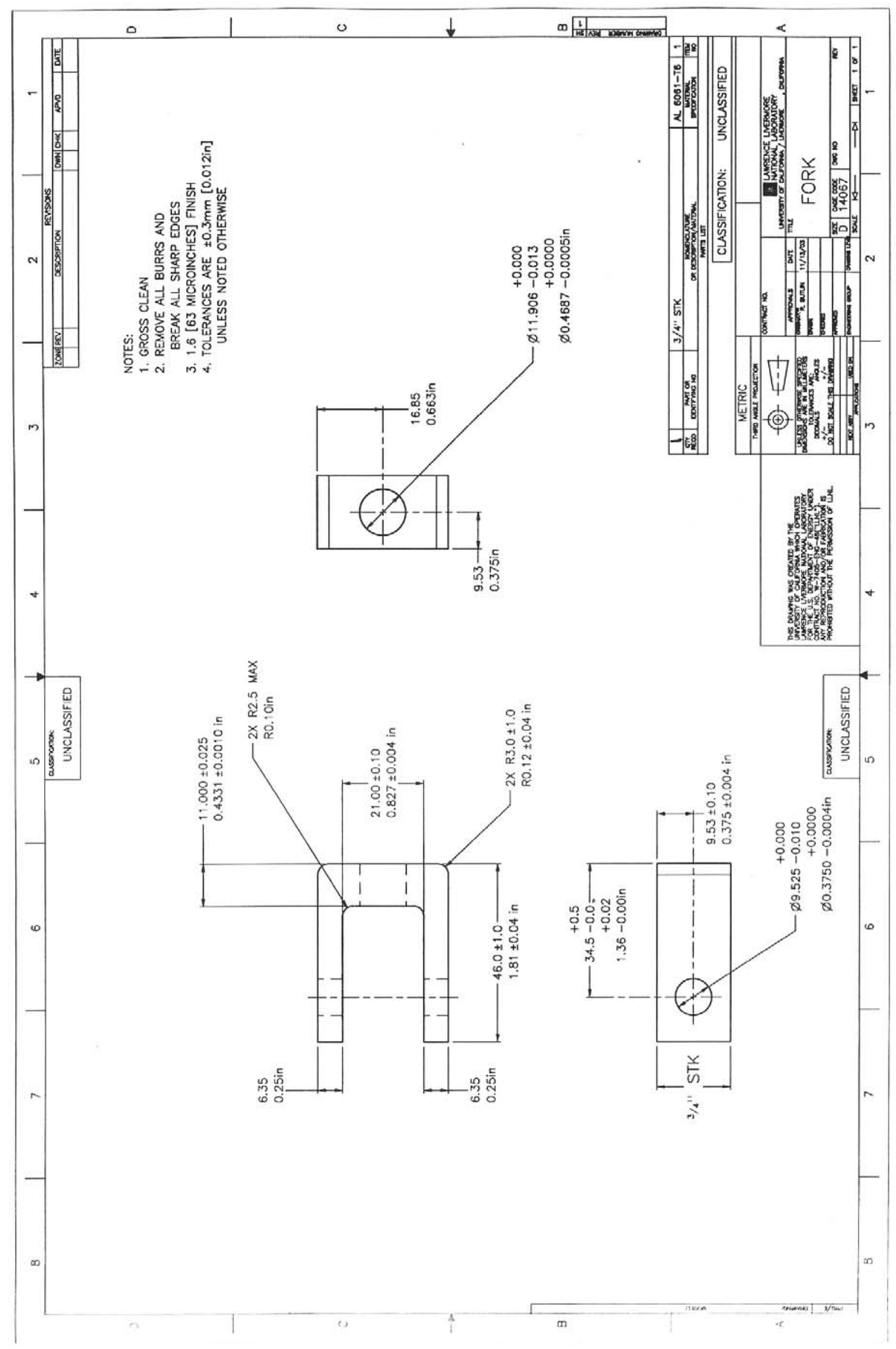




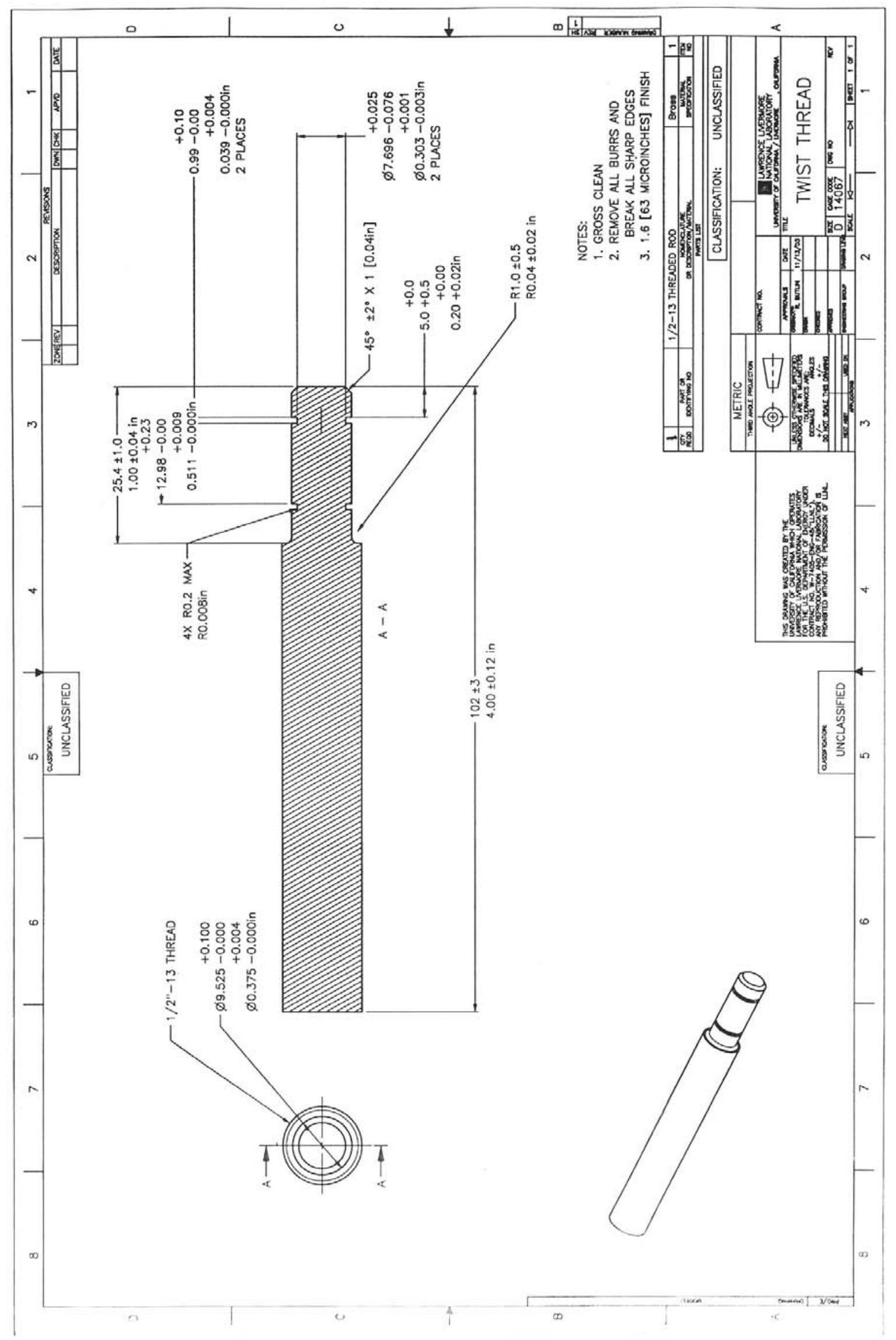




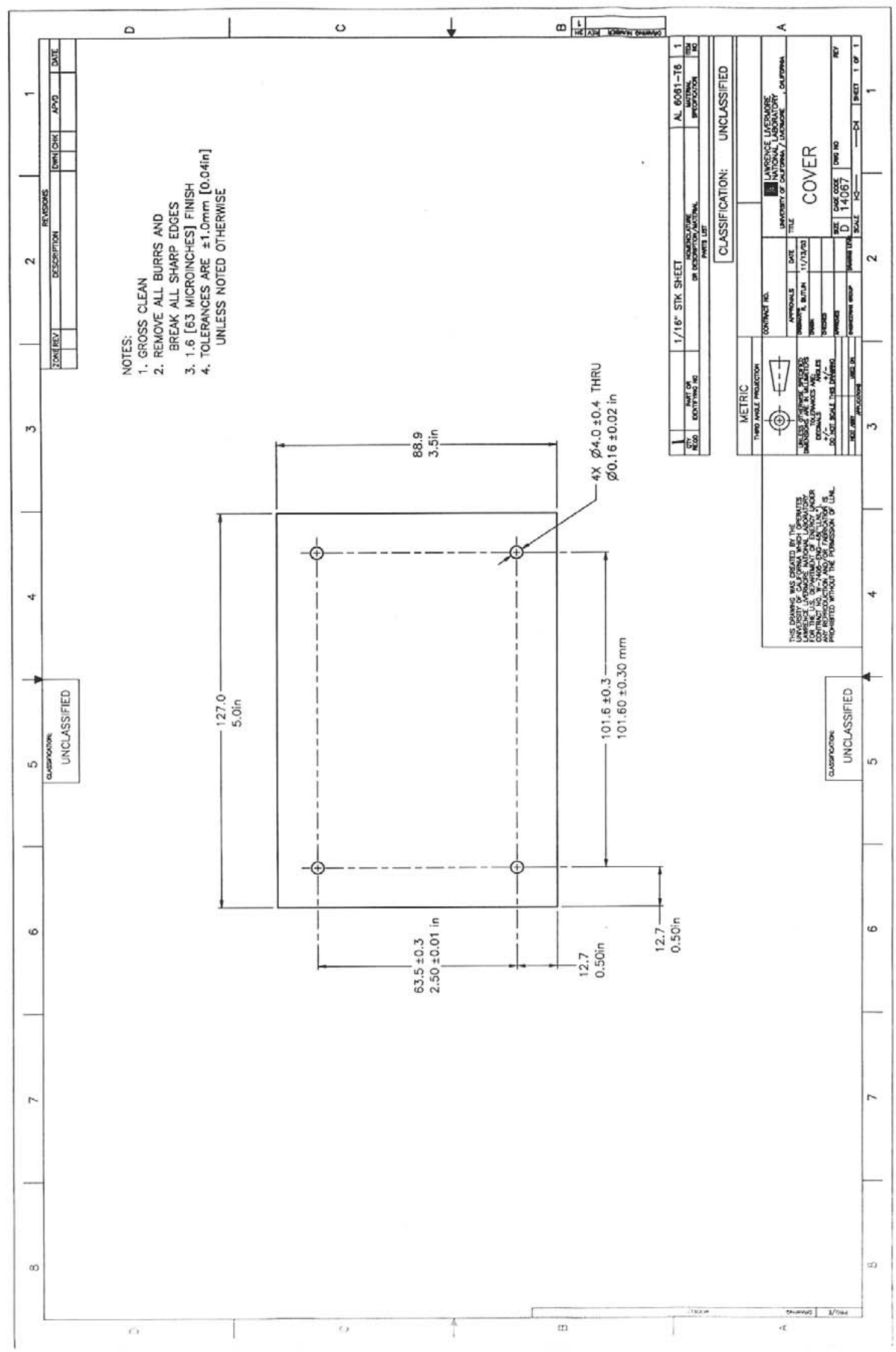




\title{
Appendix B-Supporting Calculations
}

\author{
55 attached pages
}

\section{Weight Definitions:}

$\mathrm{W}_{1}=276 \mathrm{lb}$ (Weight of largest MSA + Side Mounting Plates)

$\mathrm{W}_{2}=6 \mathrm{lb}$ (Weight of $2 \mathrm{LM}$ Mounts)

$\mathrm{W}_{3}=26.5 \mathrm{lb}\left(\mathrm{W}_{2}+\right.$ Weight of THK Rails, LM Blocks, Threaded Rod, and Rail Plate $)$

$\mathrm{W}_{4}=3 \mathrm{lb}$ (Weight of Tilt Plate and Hinges)

$\mathrm{W}_{5}=6.7 \mathrm{lb}\left(\mathrm{W}_{4}+\right.$ Weight of Pitch Plate and Pitch Crank $)$

$\mathrm{W}_{6}=17.9 \mathrm{lb}$ (Weight of Shaft + Adapter Block) 
Table B1 Safety Factors calculated for the MSA NOID End-Effector

\begin{tabular}{|c|c|c|c|}
\hline Component Description & Failure Mode & $\begin{array}{l}\text { S.F. } \\
\text { Static }\end{array}$ & $\begin{array}{c}\text { S.F. } \\
\text { Dynamic }\end{array}$ \\
\hline \multicolumn{4}{|l|}{ Rail Sub-Assembly } \\
\hline \multirow{2}{*}{ Side Mounting Plates } & Bending stress & 133.3 & 48.1 \\
\hline & Von Mises Stress in the tangs & N/A & 1.6 \\
\hline $\begin{array}{l}\text { Screws securing Side Mounting Plates to } \\
\text { the LM Mounts (M5) }\end{array}$ & Von Mises Bolt Stress & $8.3^{1}$ & $2.9^{1}$ \\
\hline $\begin{array}{l}\text { Screws securing the LM Blocks to the LM } \\
\text { Mounts (M4) }\end{array}$ & Von Mises Bolt Stress & $7.9^{1}$ & $3.1^{1}$ \\
\hline THK Rails & Manufacturer's rated load & 16.7 & N/A \\
\hline \multirow{2}{*}{$\begin{array}{l}\text { Screws securing the THK Rails to the Back } \\
\text { Plate (M4) }\end{array}$} & Von Mises Bolt Stress & $7.3^{1}$ & $2.8^{1}$ \\
\hline & Al thread stripping & $18.4^{1}$ & N/A \\
\hline \multirow{2}{*}{$\begin{array}{l}\text { Screws securing the Hinges to the Back } \\
\text { Plate (M8) }\end{array}$} & Von Mises Bolt Stress & $5.8^{1}$ & $2.1^{1}$ \\
\hline & Al thread stripping & $27.7^{1}$ & $10.0^{1}$ \\
\hline \multicolumn{4}{|l|}{ Tilt Sub-Assembly } \\
\hline Tilt Plate Pins & Von Mises Stress & $4.0^{1}$ & $1.6^{1}$ \\
\hline $\begin{array}{l}\text { Screws securing the Hinges to the Pitch } \\
\text { Plate (M8) }\end{array}$ & Von Mises Bolt Stress & $4.2^{1}$ & $1.6^{1}$ \\
\hline \multirow{2}{*}{ Threaded Rod through the Pitch Plate } & Brass thread stripping & $13.5^{1}$ & $5.0^{1}$ \\
\hline & Max force to turn handle & $13.1 \mathrm{lbf}$ & N/A \\
\hline Tungsten Carbide ball & Contact stress & $1.1^{2}$ & N/A \\
\hline \multicolumn{4}{|l|}{ Twist Sub-Assembly } \\
\hline \multirow{2}{*}{$\begin{array}{l}\text { Screws securing the Pitch Plate to the Shaft } \\
\text { (M8) }\end{array}$} & Von Mises Bolt Stress & $4.4^{1}$ & $1.6^{1}$ \\
\hline & SST thread stripping & 5.4 & 3.3 \\
\hline Timken Bearing \#526/522 & Manufacturer's rated load & 6.5 & N/A \\
\hline Timken Bearing \#23620/23690 & Manufacturer's rated load & 4.5 & N/A \\
\hline \multirow{3}{*}{ Shaft } & Von Mises Stress (pt A) & 3.7 & 1.6 \\
\hline & Von Mises Stress (pt B) & 4.4 & $\mathrm{~N} / \mathrm{A}^{3}$ \\
\hline & Von Mises Stress (pt C) & $4.3^{1}$ & 1.1 \\
\hline Shaft Key & Shear & $4.8^{1}$ & $1.9^{1}$ \\
\hline Force Ring Pin & Shear & $4.6^{1}$ & $1.8^{1}$ \\
\hline \multirow{2}{*}{ Force Ring } & Shear at the slot & $2.9^{4}$ & 1.1 \\
\hline & Von Mises at the base & 4.4 & 1.7 \\
\hline Fork & Axial Pull Stress & 7.2 & 2.8 \\
\hline \multirow{3}{*}{ Threaded Rod through the Adapter Block } & Axial Pull Stress & $3.8^{1,4}$ & $1.5^{1}$ \\
\hline & Brass thread stripping & $12.4^{1}$ & $4.8^{1}$ \\
\hline & Max force to turn handle & $7.6 \mathrm{lbf}$ & N/A \\
\hline E-Clip & Shear & $3.4^{1,4}$ & $1.3^{1}$ \\
\hline \multirow{2}{*}{$\begin{array}{l}\text { Screws securing the Adapter Block to the } \\
\text { Robohand (M8) }\end{array}$} & Von Mises Bolt Stress & $4.5^{1}$ & $2^{1}$ \\
\hline & Al thread stripping & 9.4 & 3.6 \\
\hline
\end{tabular}

1. Ultimate Strength used, in most cases the Ultimate Strength is all the manufacturer provided

2. Not a critical part and yielding would be acceptable

3. Calculation was not needed, see notes within the calculations

4. Values are slightly lower than the Safety Factors recommended in the MEDSS, but the stress on these components are primarily a result of a twist moment caused by the unlikely event of the MSA being 3" off center on the rails 
Table B2 MSA NOID End-Effector purchased items

\begin{tabular}{|c|c|c|c|c|}
\hline Part & $\begin{array}{l}\text { Sub- } \\
\text { Assembly }\end{array}$ & Quantity & Manufacturer & Description \\
\hline Twist Thread & Twist & 1 & McMasters & Brass, 1/2-20 Thread \\
\hline Keensert & Twist & 1 & LLNL Shop & SST, 1/2-20 Inner Thread \\
\hline Delrin Washer & Twist/Rail & 4 & McMasters & 3/8" ID, 0.625 OD, 0.031" THK \\
\hline E-Clips & Twist/Rail & 4 & McMasters & 3/8" Stainless Steel \\
\hline Peek Flanged Bearing & Twist & 1 & McMasters & 3/8" ID, 15/32 OD, 1/2" Lg \\
\hline Peek Flanged Bearing & Rail & 4 & McMasters & 3/8" ID, 15/32 OD, 3/4" Lg \\
\hline Pin & Twist & 1 & Fabroy & $\begin{array}{l}\text { 3/8" DIA Oversized, 1.25" Lg, A2 or A4 } \\
\text { equivalent }\end{array}$ \\
\hline Peek Sleeve Bearing & Twist & 1 & McMasters & 3/8" ID, 15/32 OD, 3/4" Lg \\
\hline $\begin{array}{l}\text { Open Cage Roller } \\
\text { Bearing }\end{array}$ & Twist & 1 & Timken & 4" OD \\
\hline $\begin{array}{l}\text { Open Cage Roller } \\
\text { Bearing }\end{array}$ & Twist & 1 & Timken & $2.875^{\prime \prime}$ OD \\
\hline Clamp Collar & Twist & 1 & King Bearing & $11 / 4-12$ SST \\
\hline Key stock & Twist & 1 & McMasters & 3/8"x3/8" 303 (8-18) oversized \\
\hline Pitch Thread & Tilt & 1 & McMasters & Brass, 3/8" -24 \\
\hline Keensert & Tilt & 1 & LLNL Shop & SST, 3/8" -24 \\
\hline Tungsten Carbide Ball & Tilt & 1 & McMasters & 7/32" DIA Ball \\
\hline $\begin{array}{l}\text { Tungsten Carbide } \\
\text { Bushing }\end{array}$ & Tilt & 1 & Reid Tool & 1/4" ID, 1/2" OD, 3/4" Lg \\
\hline Pins & Tilt & 4 & Fabroy & $\begin{array}{l}\text { 1/2" DIA Oversived, 1.5" Lg, A2 or A4 } \\
\text { equivalent }\end{array}$ \\
\hline Peek Flanged Bearing & Tilt/Rail & 4 & McMasters & 1/2" ID, 19/32" OD, 3/4" Lg \\
\hline Rail Thread & Rail & 1 & McMasters & $\begin{array}{l}\text { 1/2" Precision Modified-ACME Lead Screw, } \\
\text { SST }\end{array}$ \\
\hline Flanged Nut & Rail & 1 & McMasters & $\begin{array}{l}\text { 1/2" ACME Nut, wear compensating, } \\
\text { Polyacetal }\end{array}$ \\
\hline Belville Washers & Rail & 8 & McMasters & 1/4" screw size, SST, Serrated \\
\hline Rail with two LM Blocks & Rail & 2 & THK & Rails and two LM Mounts, $760 \mathrm{~mm} \mathrm{Lg}$ \\
\hline Pin & Rail & 4 & McMasters & M2 DIA, 10mm 18-8 SST \\
\hline All Fasteners & All & 99 & Fabroy & All Fasteners \\
\hline Standard Dowel Pin & Tilt & 1 & McMasters & 3/16 DIA, 3/4" Type 416 SST \\
\hline Set Screws & Twist & 8 & Danforth & $\begin{array}{l}10-32 \times 3 / 16 ", 1 / 2 \text { dogend, Heat-treated alloy } \\
\text { steel }\end{array}$ \\
\hline
\end{tabular}




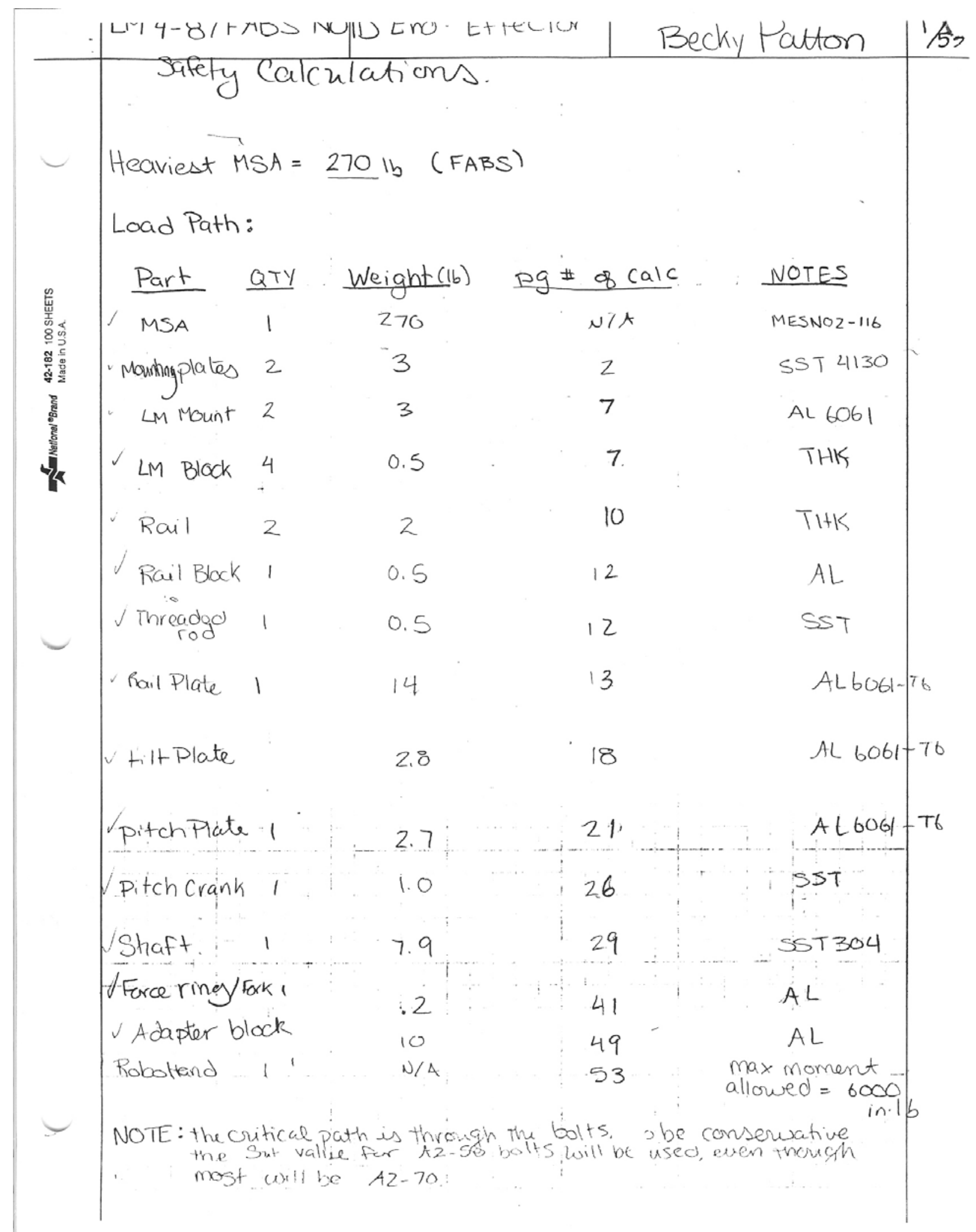




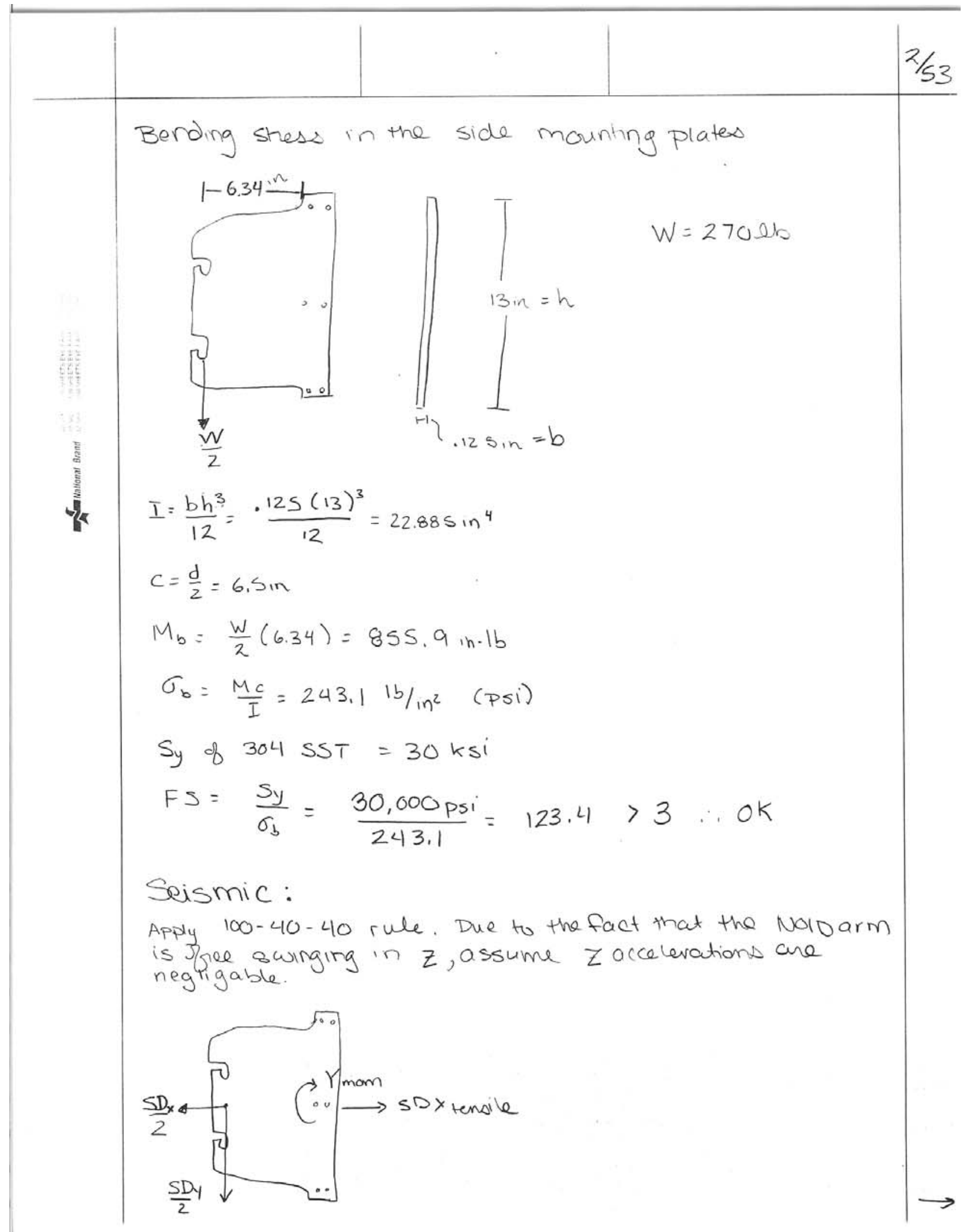




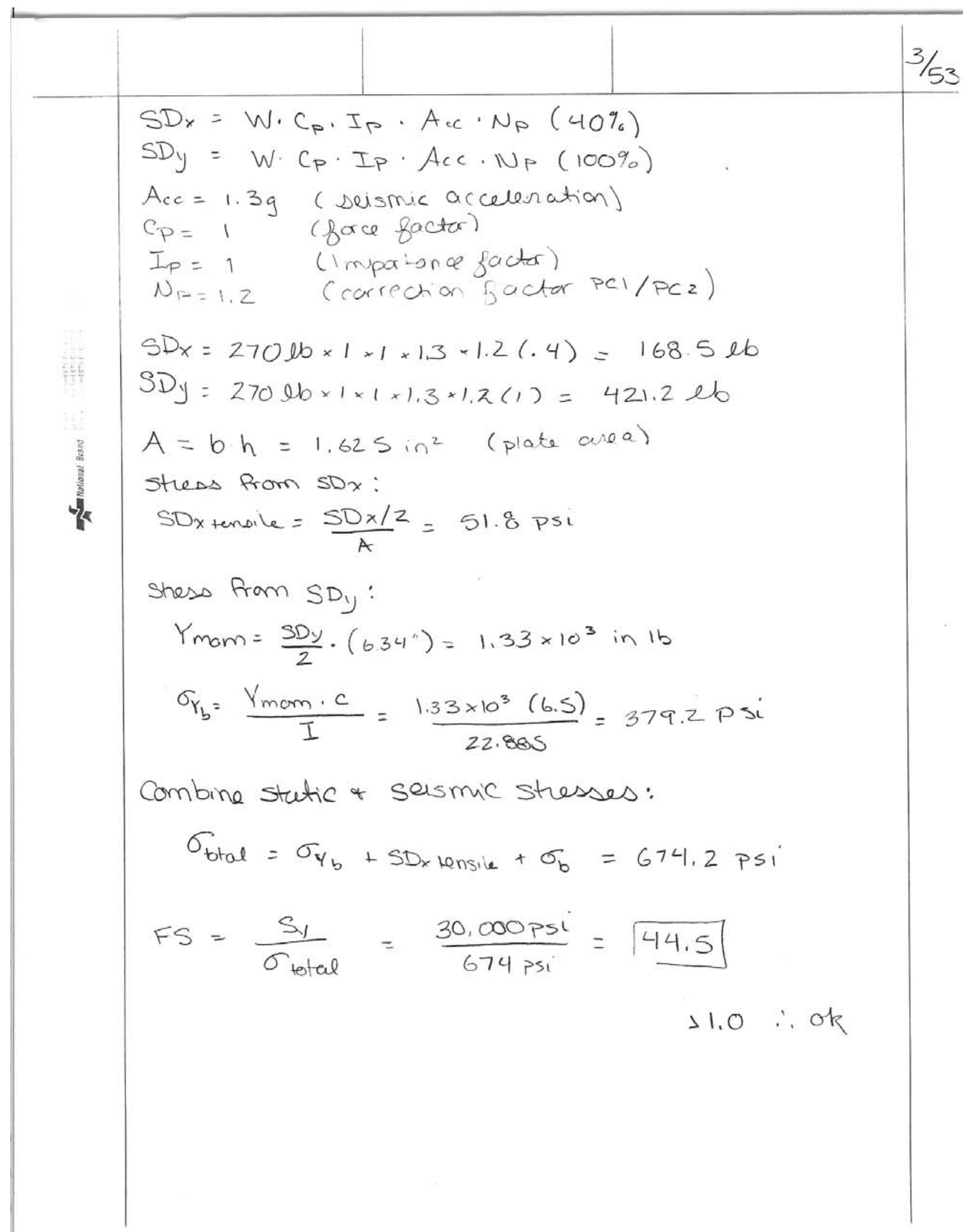




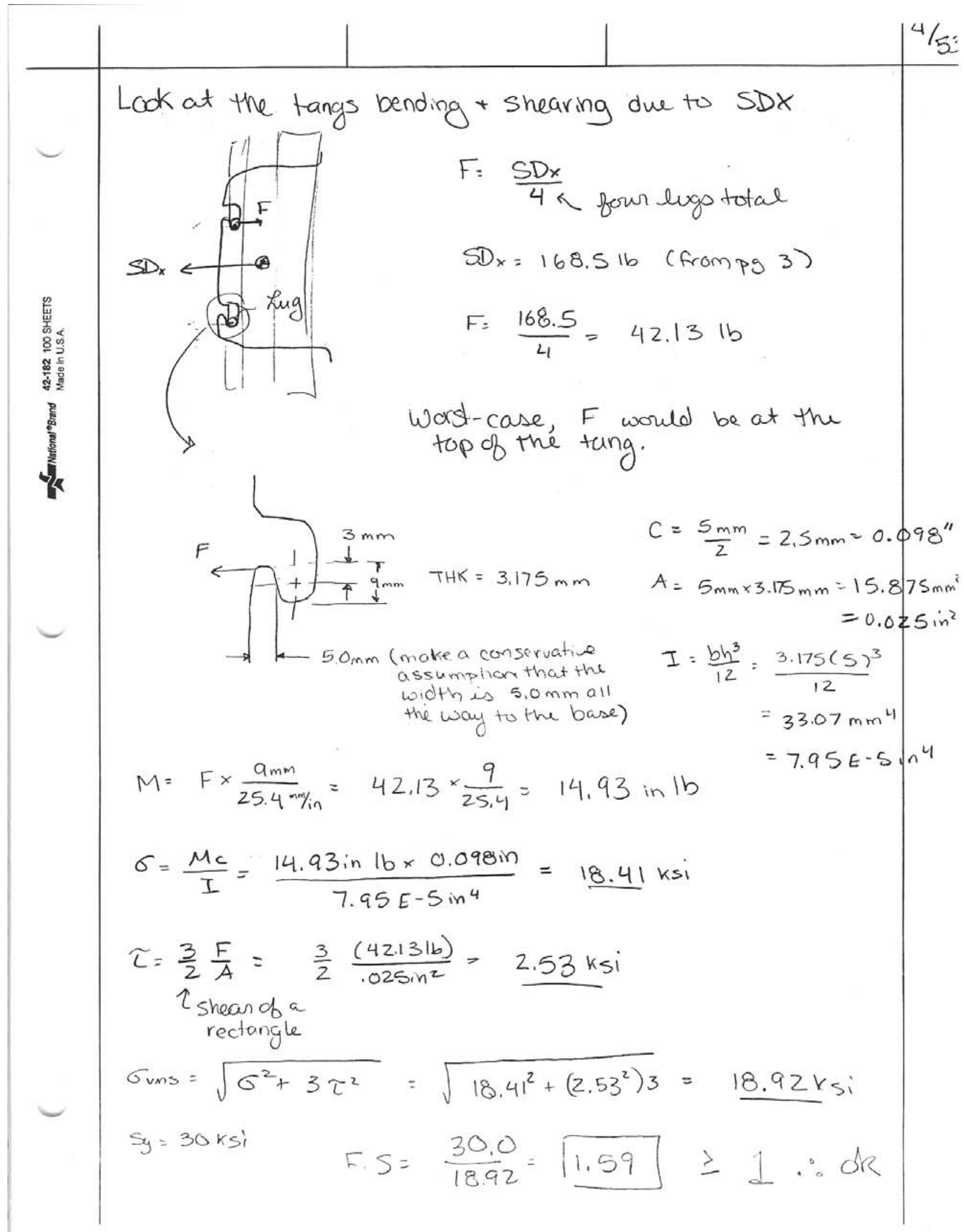




\section{Side Plates (Shear in screws)}

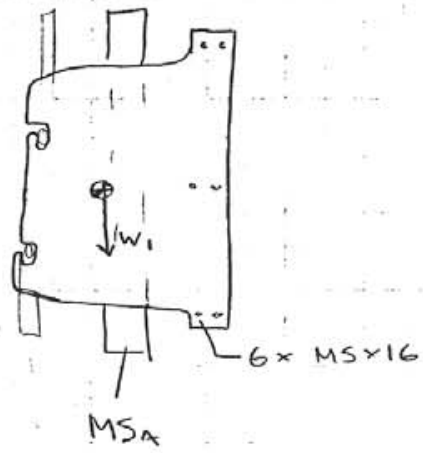

$W_{1}=$ MSA weight $+2 \times$ sideplate

$W_{1}=270+6=27616$

A moment is created which places a shear stress on the bolts.

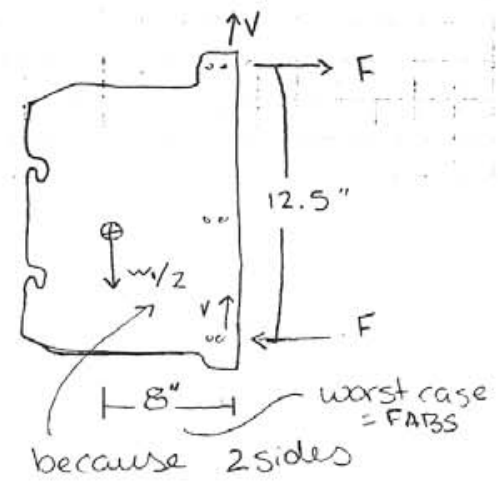

$F=\frac{\omega / 2 \times 8^{\prime \prime}}{12.5^{\prime \prime}}=88.3$

for both F+V

assume that only

two screus carry

the load due to misalignment

$V=\frac{W / 2}{2}=67.516$

Total force on screw $=\sqrt{883^{2}+67.5^{2}}=111.2 \mathrm{Bb}$

$$
A_{s}=14.2 \mathrm{~mm}^{2}=0.022 \mathrm{in}^{2} \quad \sigma=\frac{111.2}{.022}=\frac{5.05 \mathrm{ksi}}{}
$$

Decause the bolt es in shear $S_{4 t}=\frac{72.5 \mathrm{ksi}}{\sqrt{3}}=41.9 \mathrm{ksi}$

Note: $725 \mathrm{ksi}$, sut came from Fabroy catolog for A2-50 S5T bolts.

$F S=\frac{41.9 \mathrm{ksi}}{5.05 \mathrm{ksi}}=8.3$ on ultimate ok $\geq 4$

Bolt stress under seismic Load: 


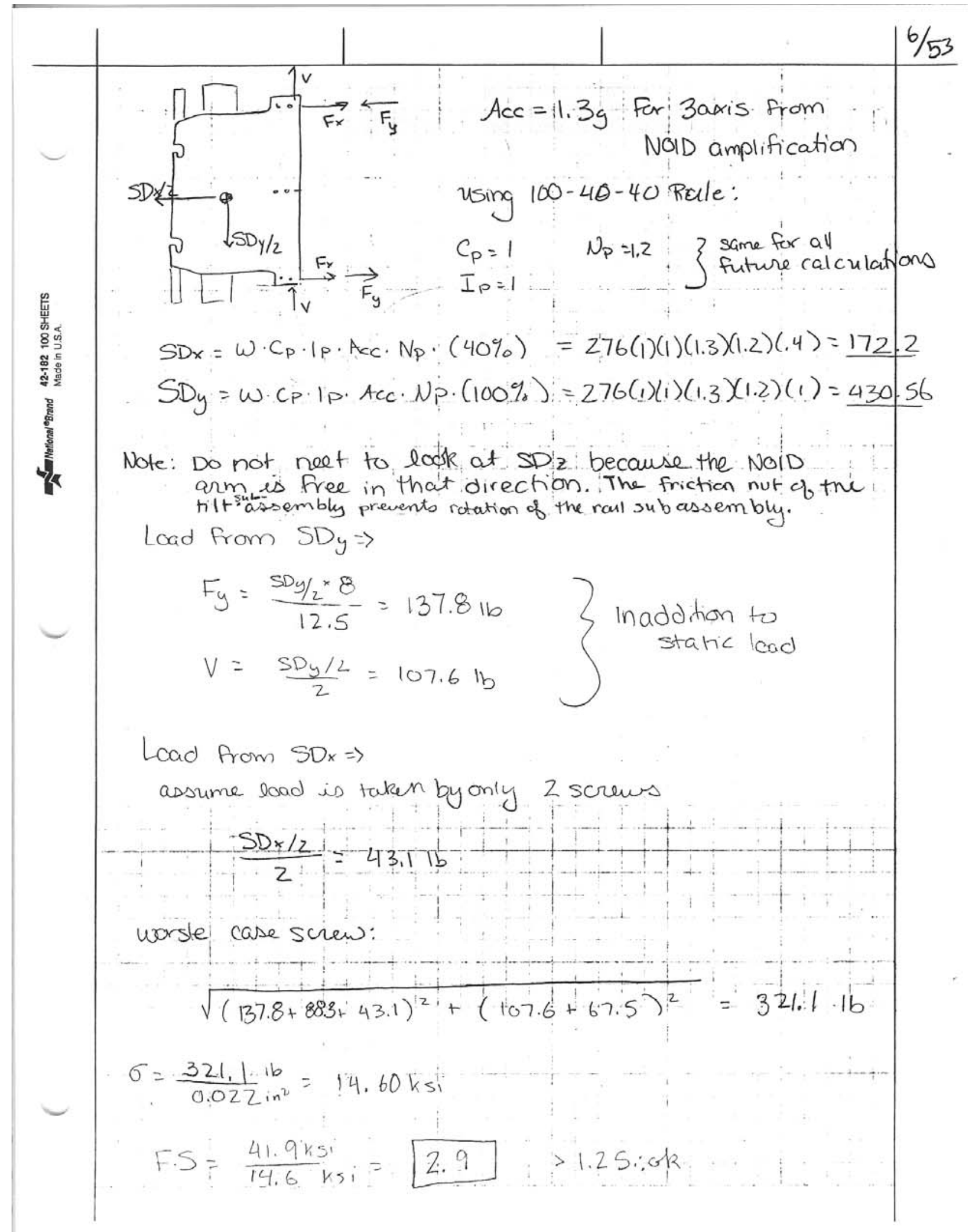




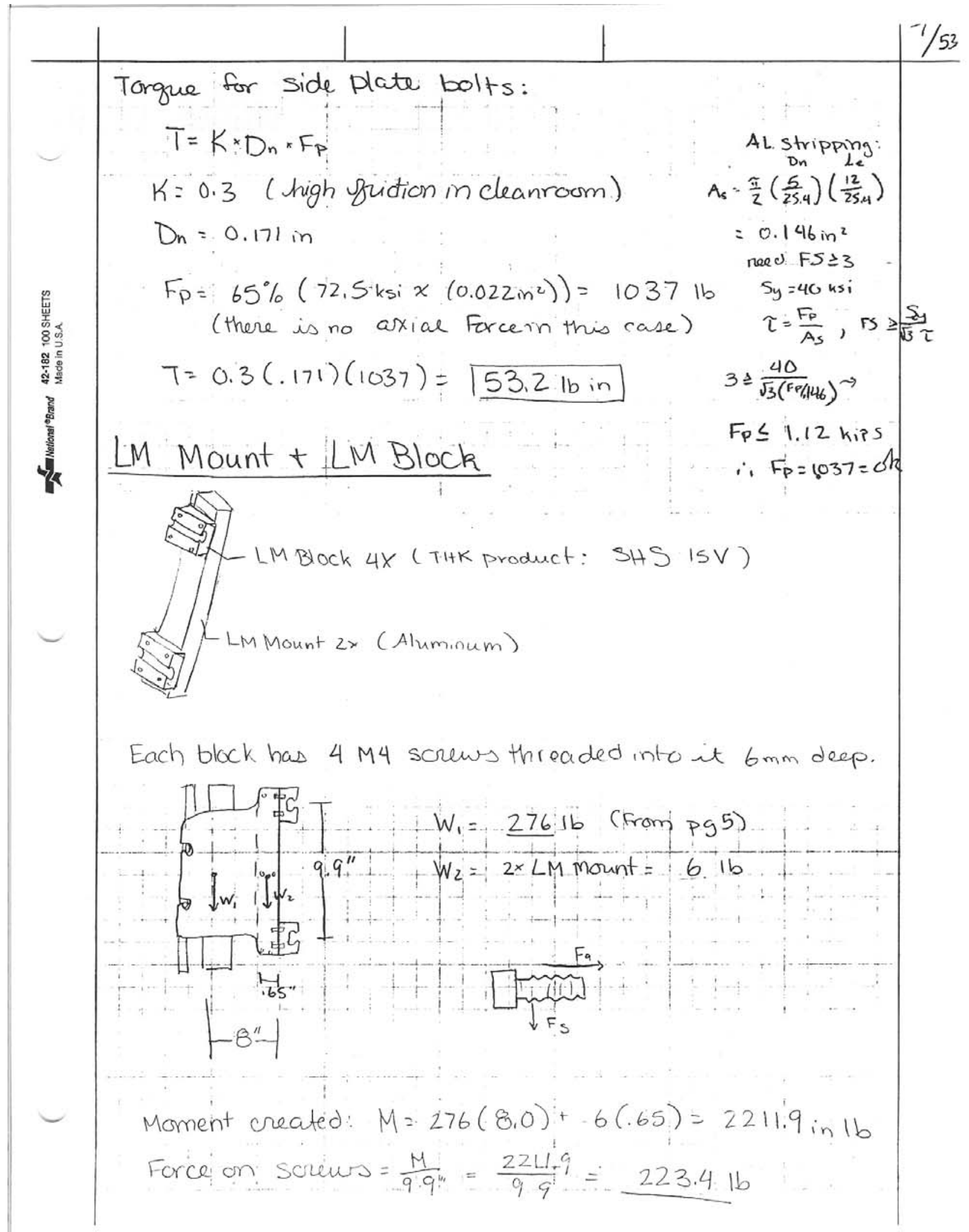




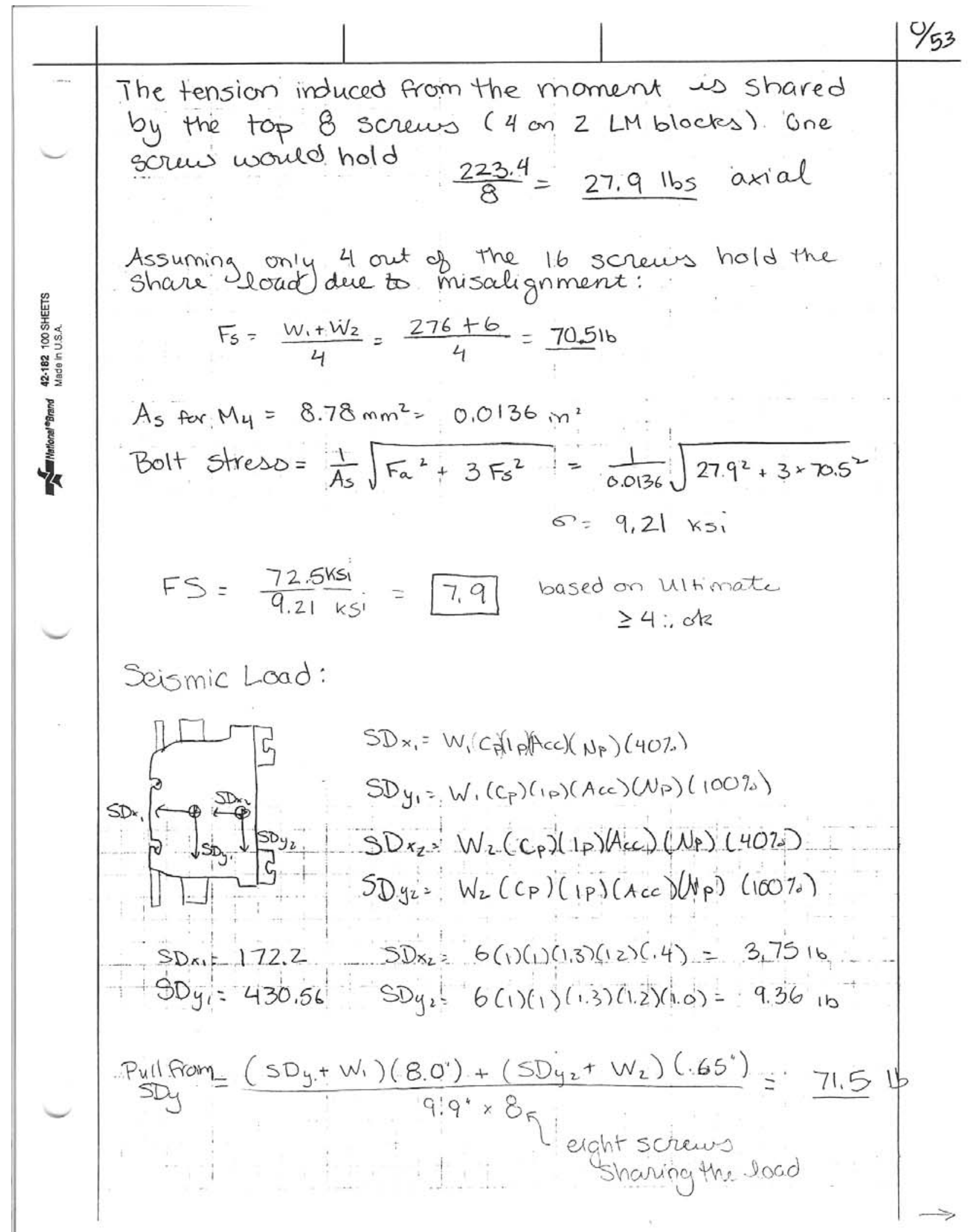




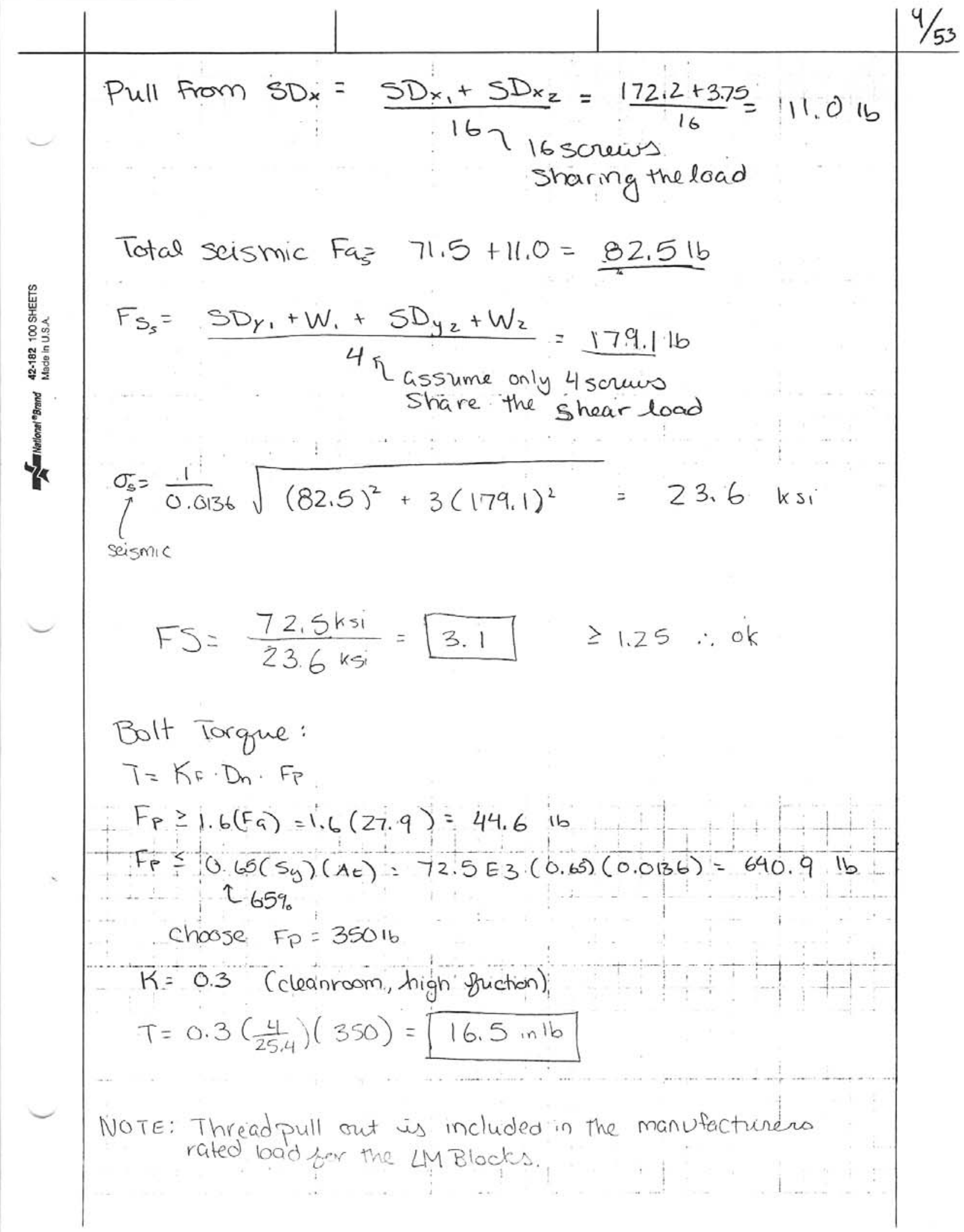




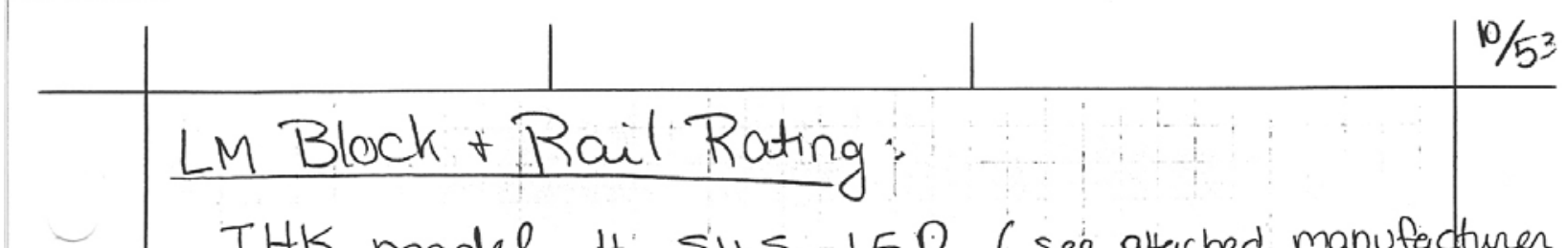
THK model \# SH S-15R. (see attached manufacture n

- This molded was selected because it is designed to have "4-way equal-load-rating"

Manufacturer Rating:

$$
\begin{aligned}
& \text { Static, } C_{0}=24.2 \mathrm{kN}=5,440 \mathrm{lb} \\
& \text { Dynamic, } C=9.8 \mathrm{kN}=2,200 \mathrm{lb}
\end{aligned}
$$

The 4 LM Blocks will resist the same moment + shear load that was used on the screws.

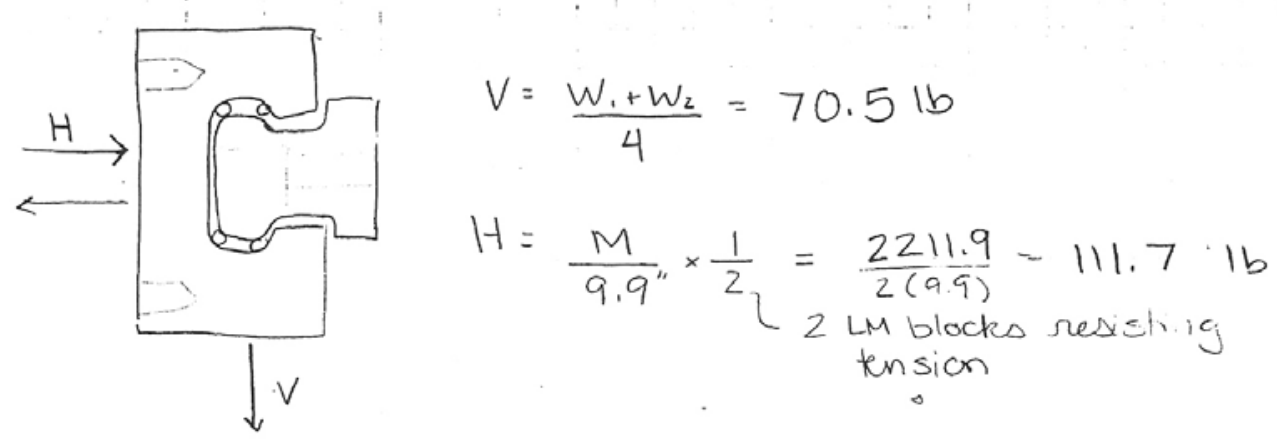

Total load per LM block $=\sqrt{70.5+111.7^{2}}=1321 \mathrm{~b}$

This is far from the $2,200 \mathrm{lb}$ Dynamic rated load

Rail Screws

Each of the two rails have a single row to s M4 screws placed 2.36" apart.

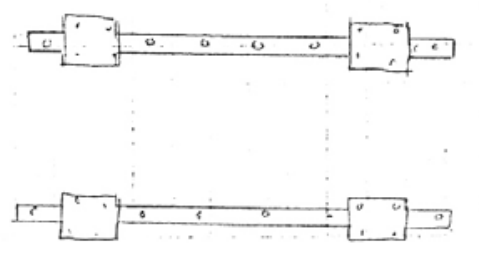

The same orient load applies.

(assumes the LM block's weight would contribute an insignificant amount te the moment at this part') 


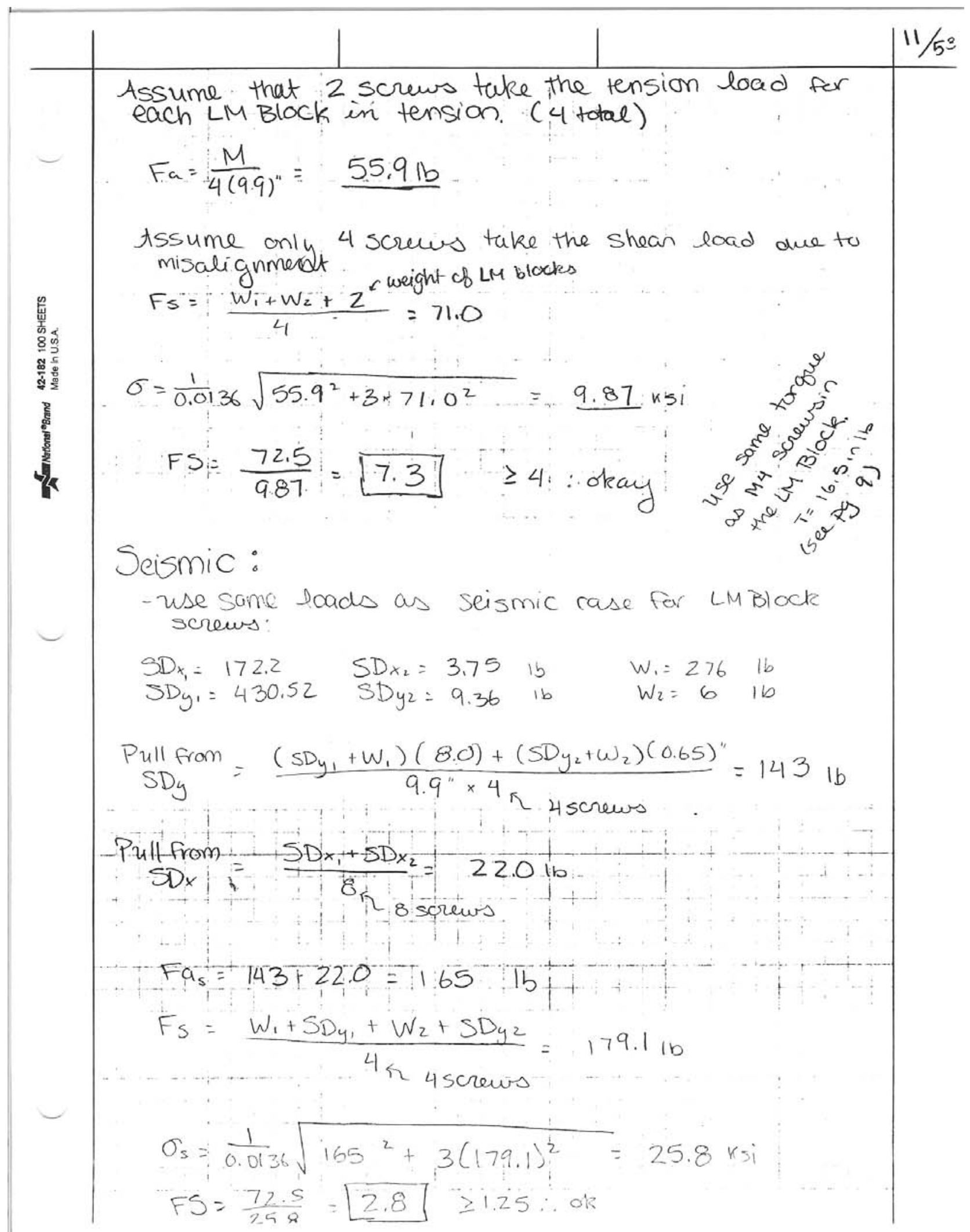




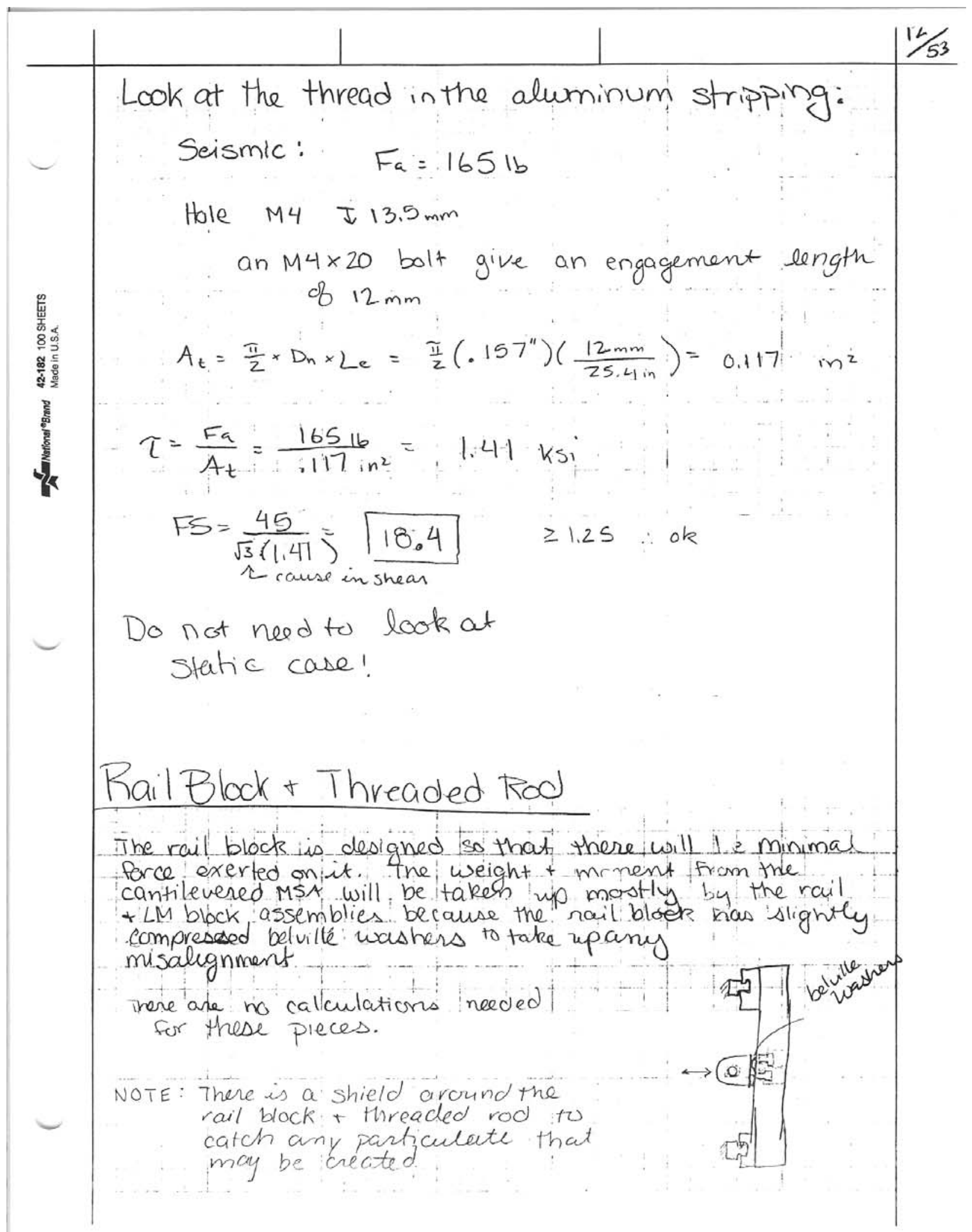




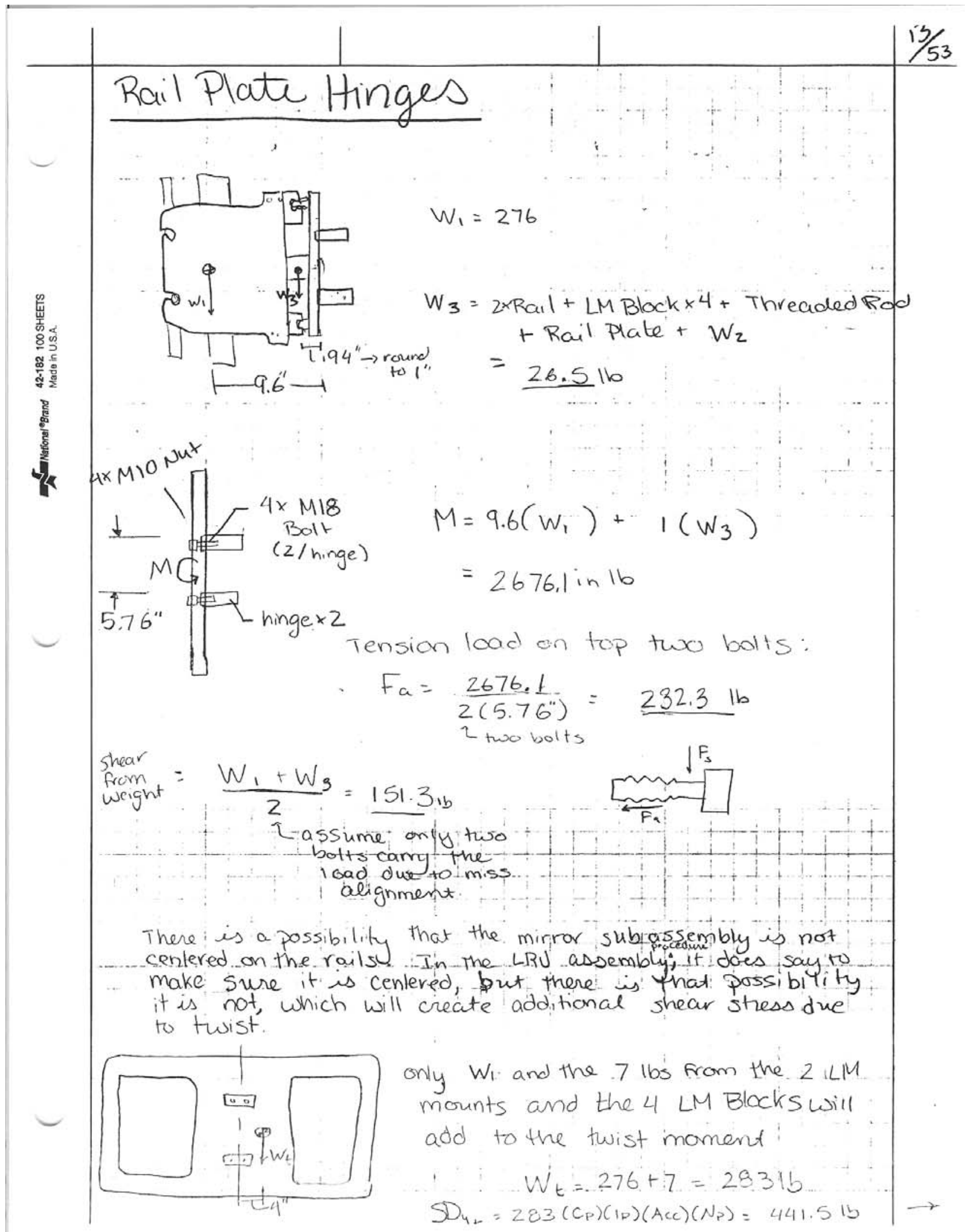




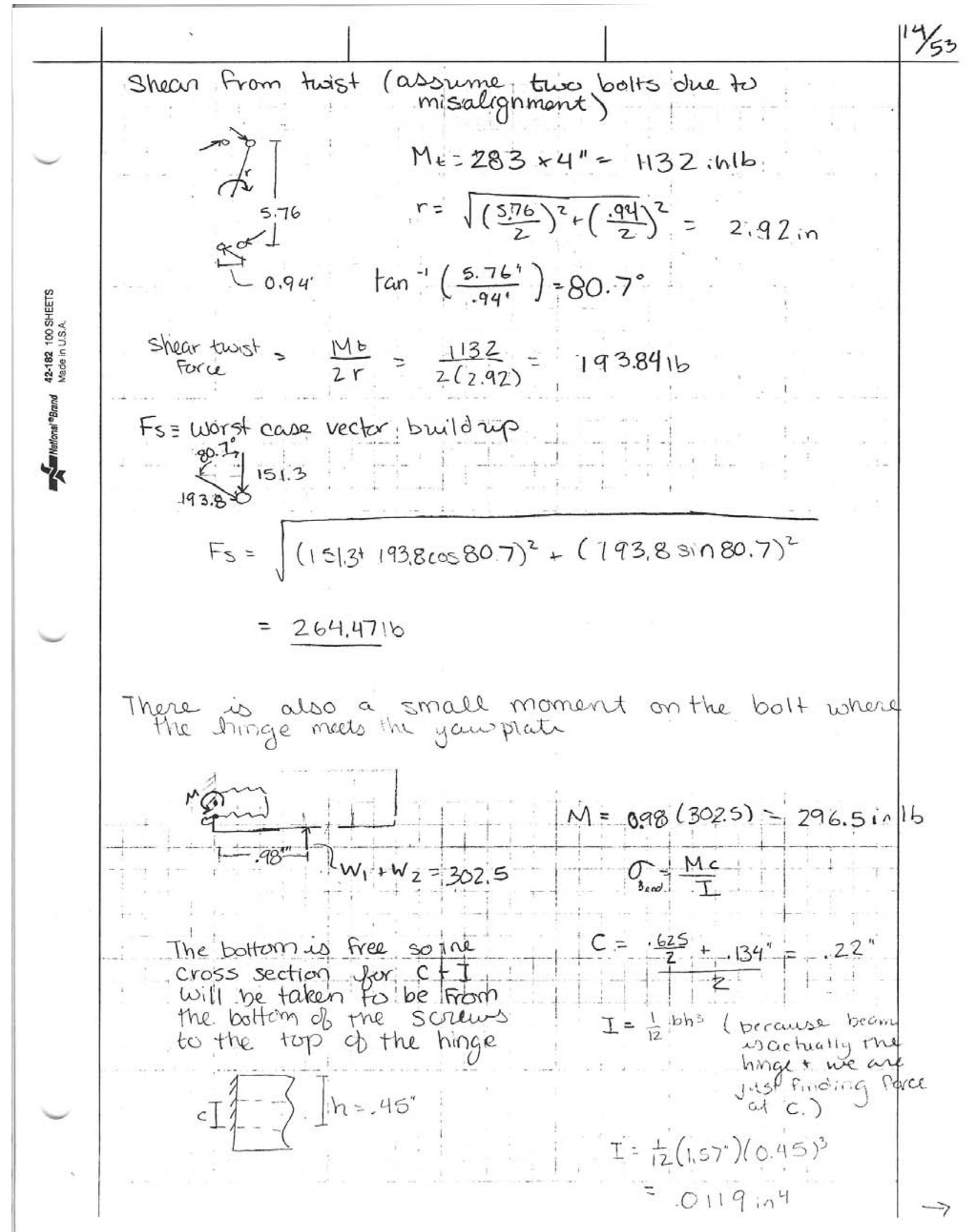




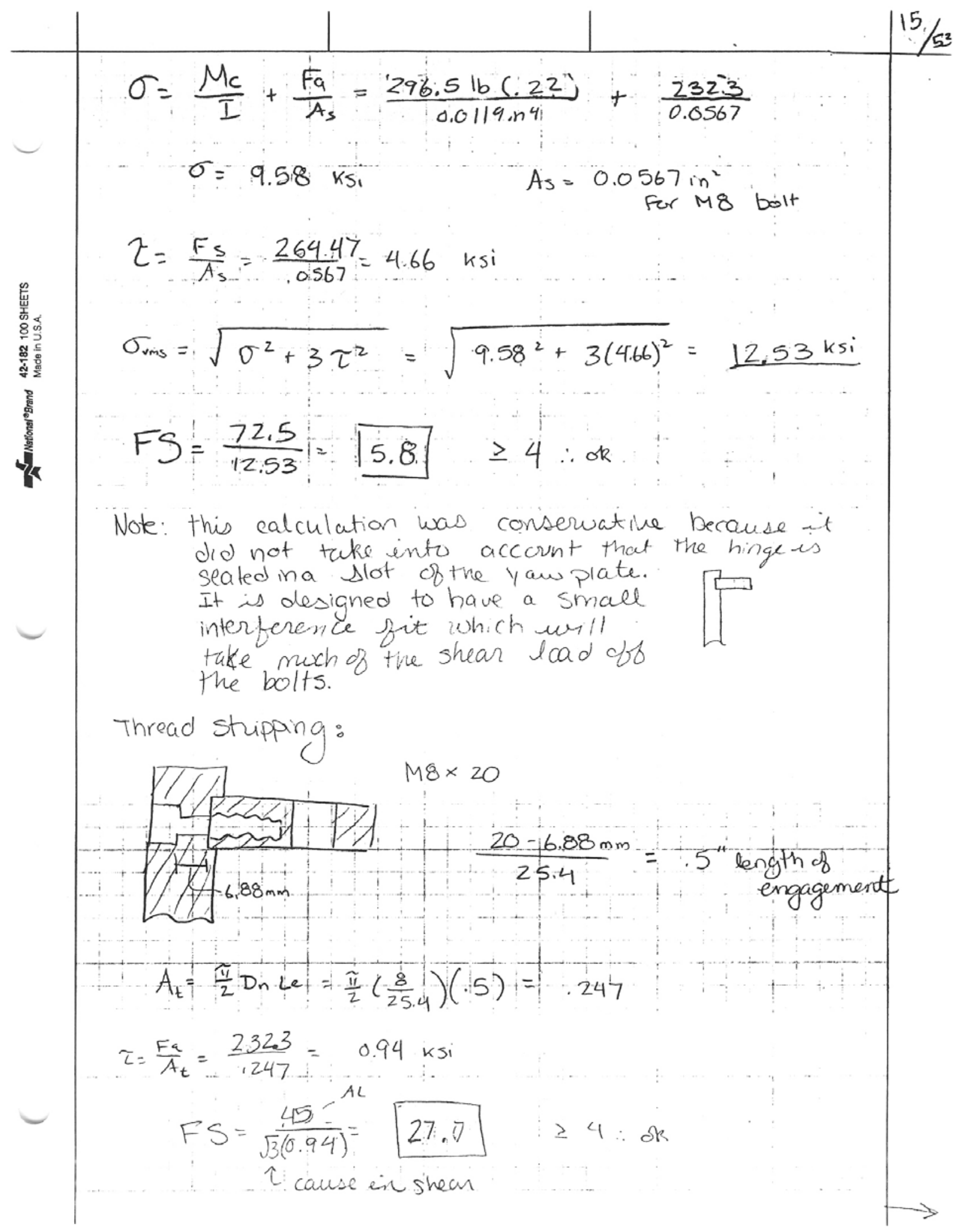




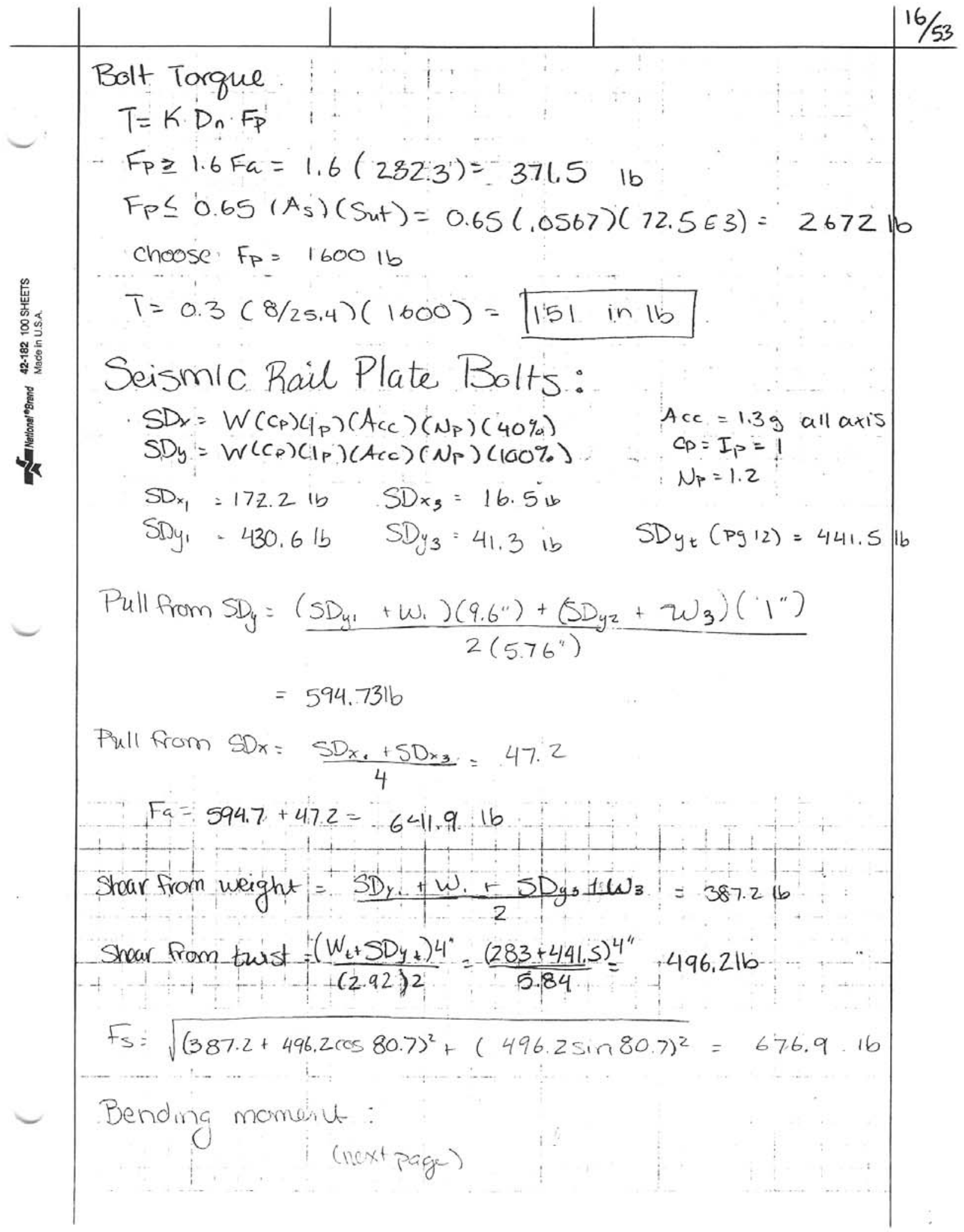




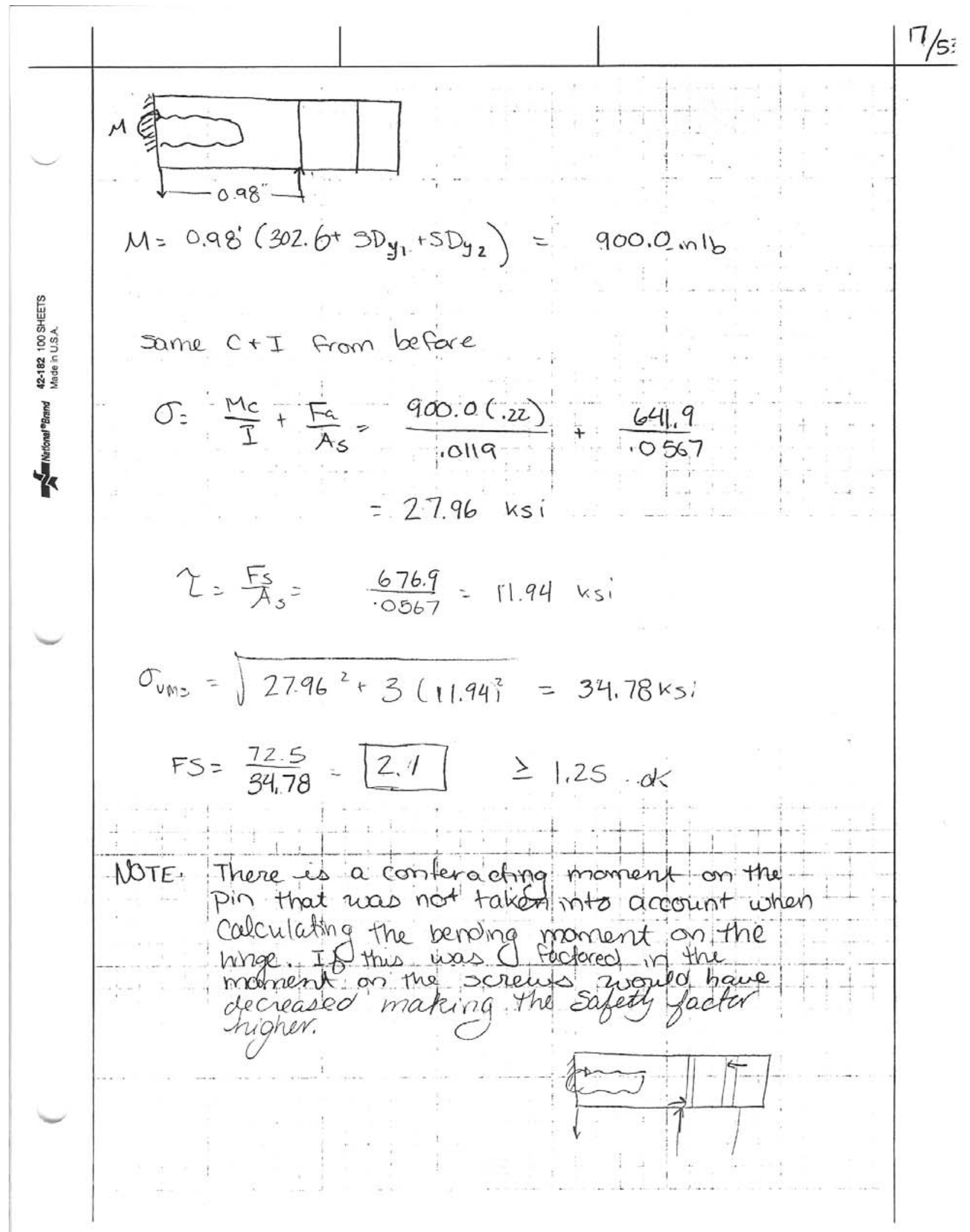




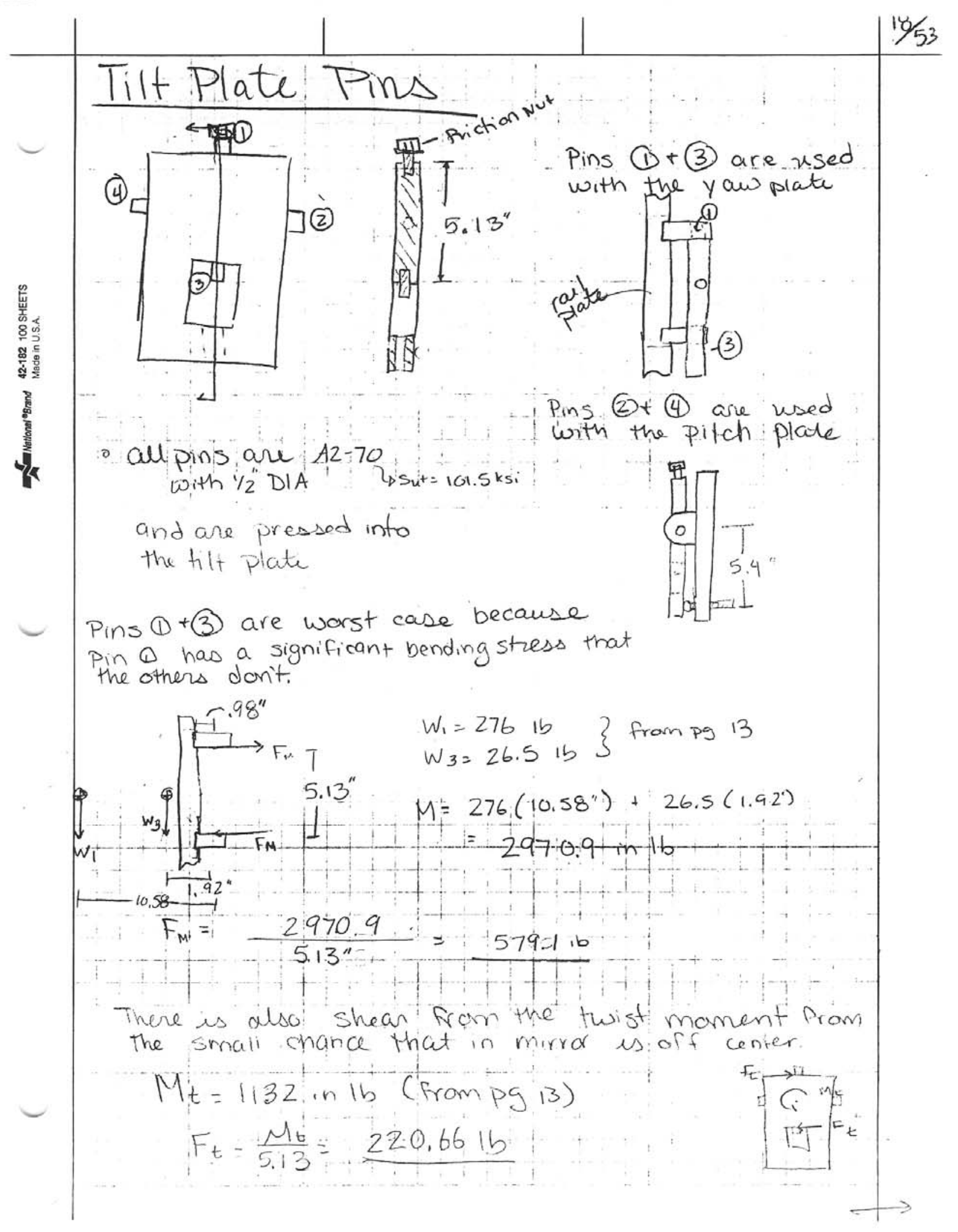




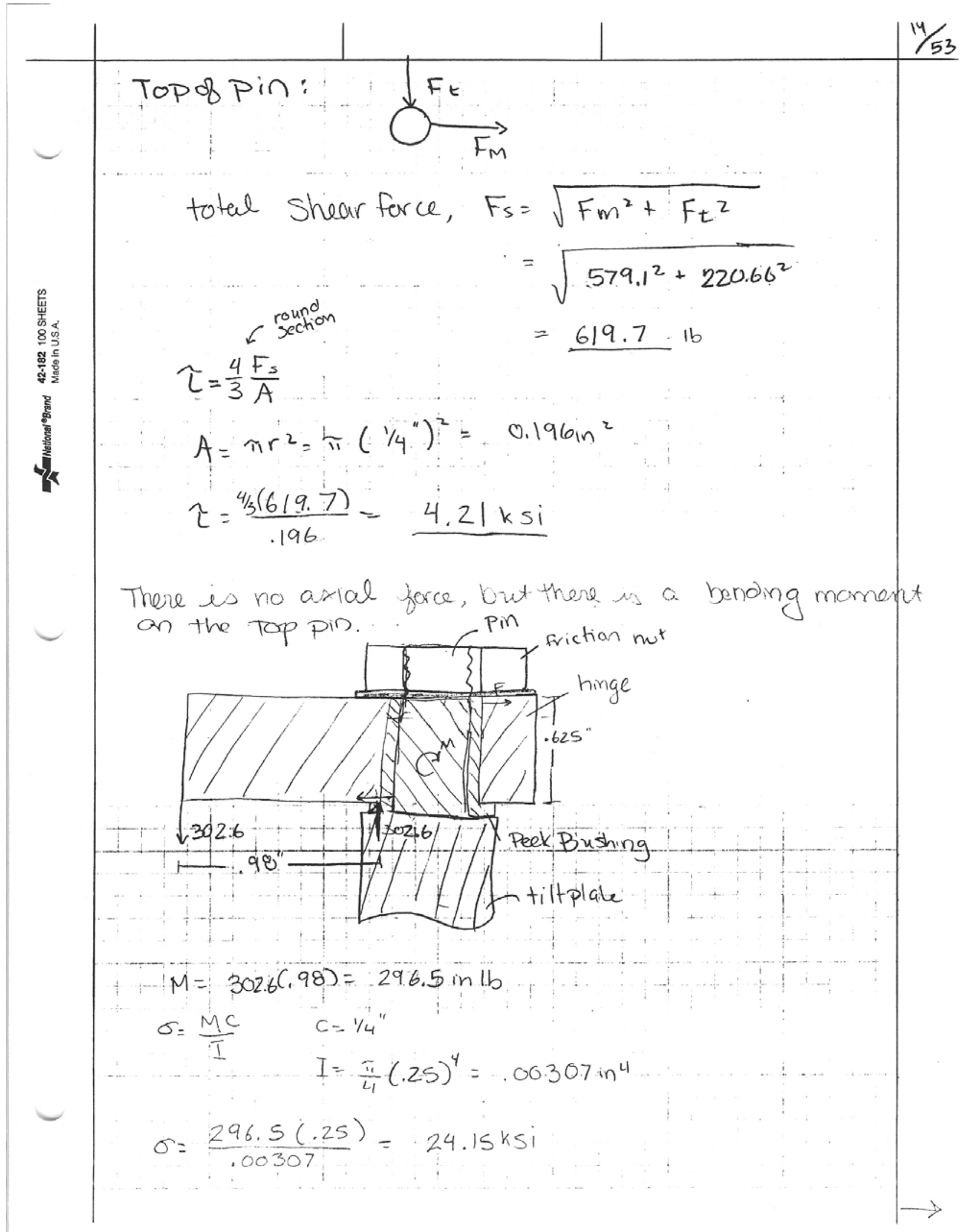




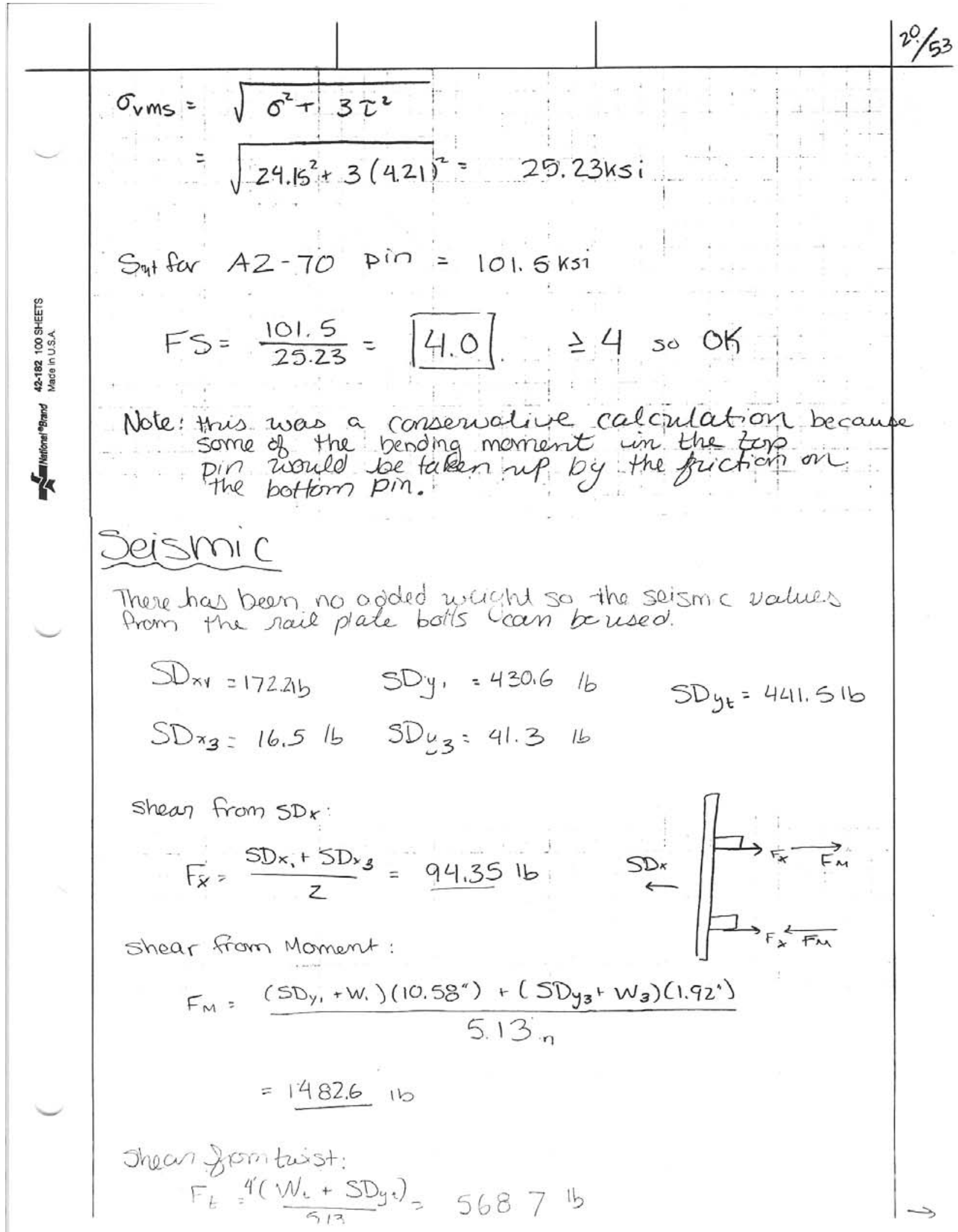




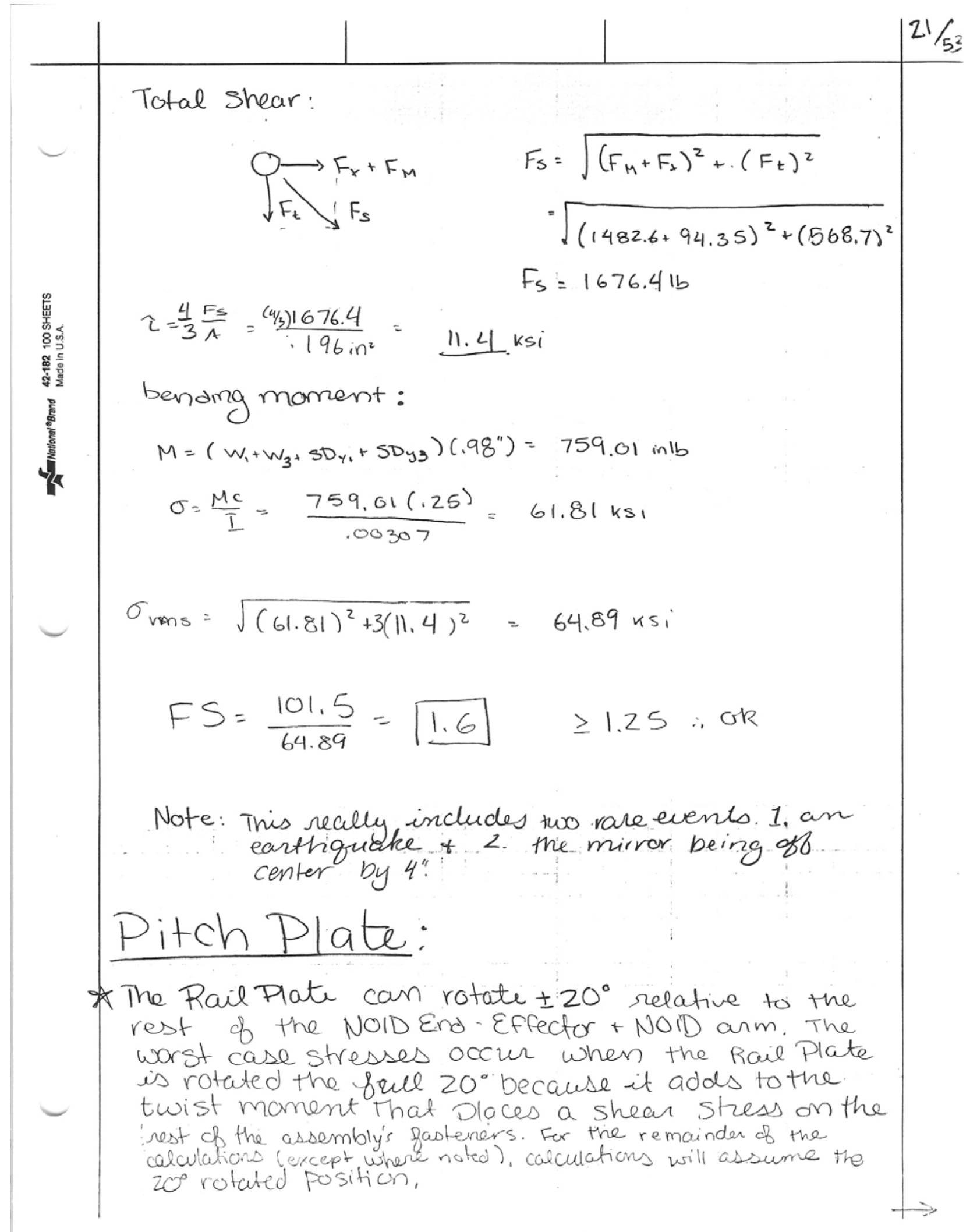




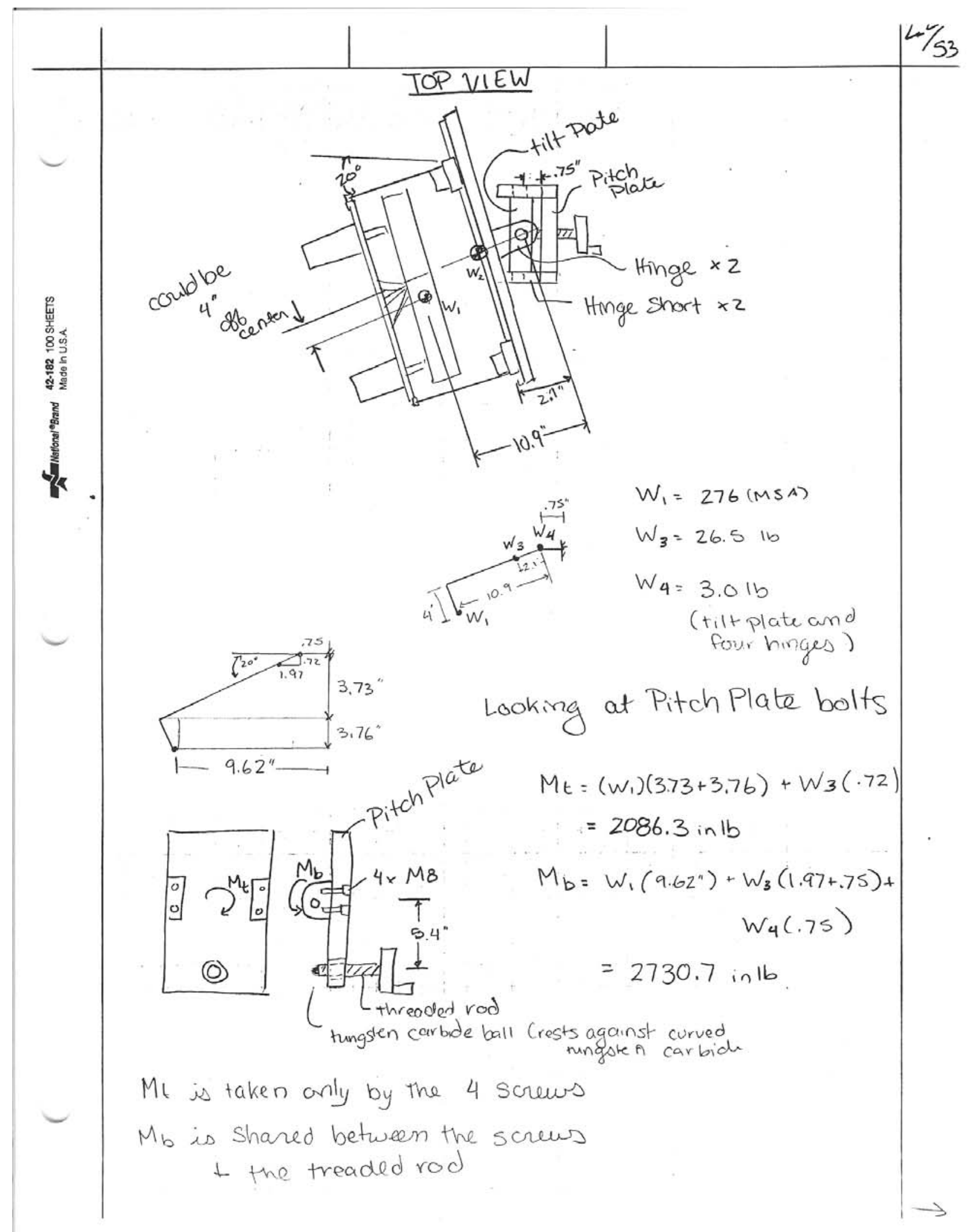




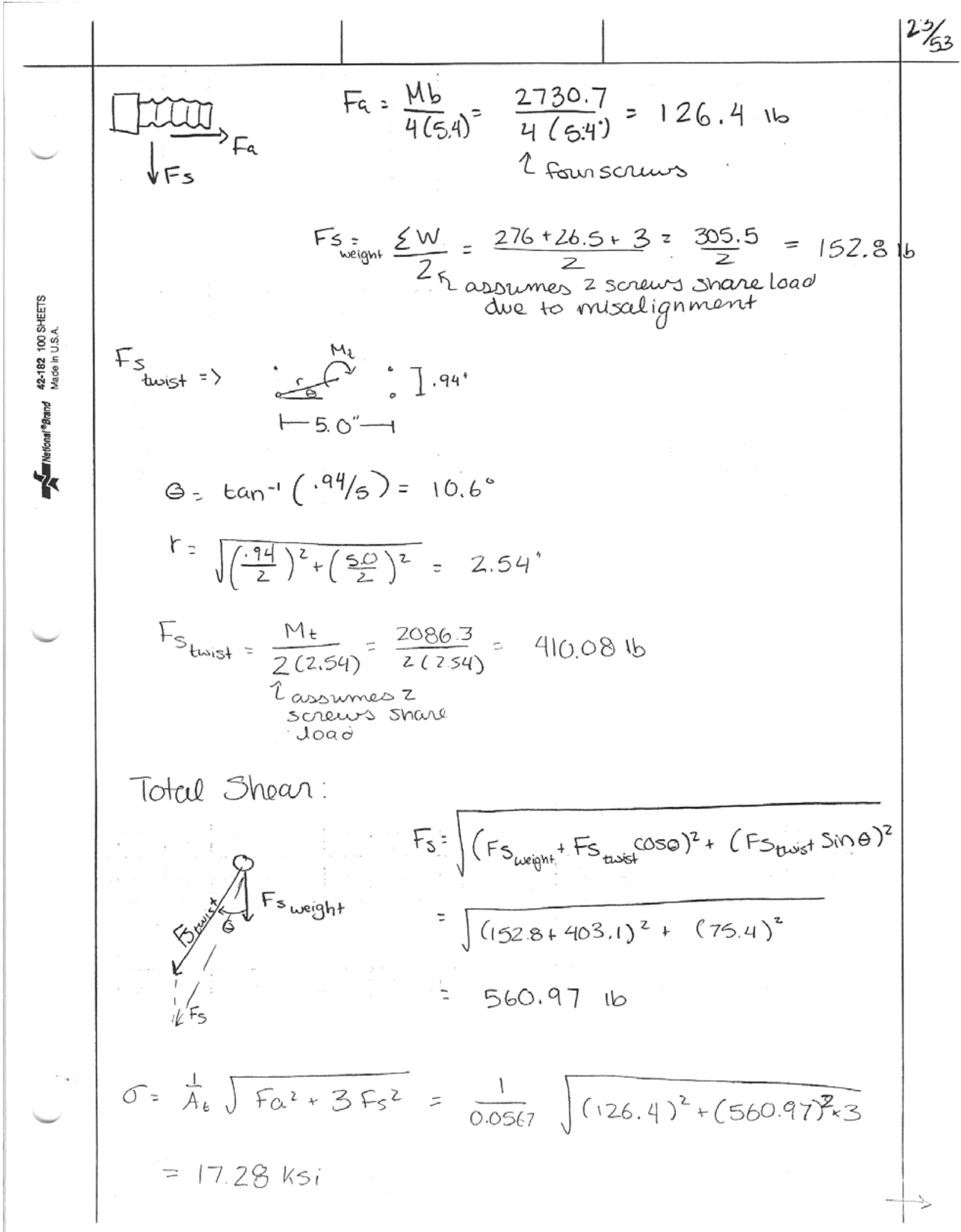




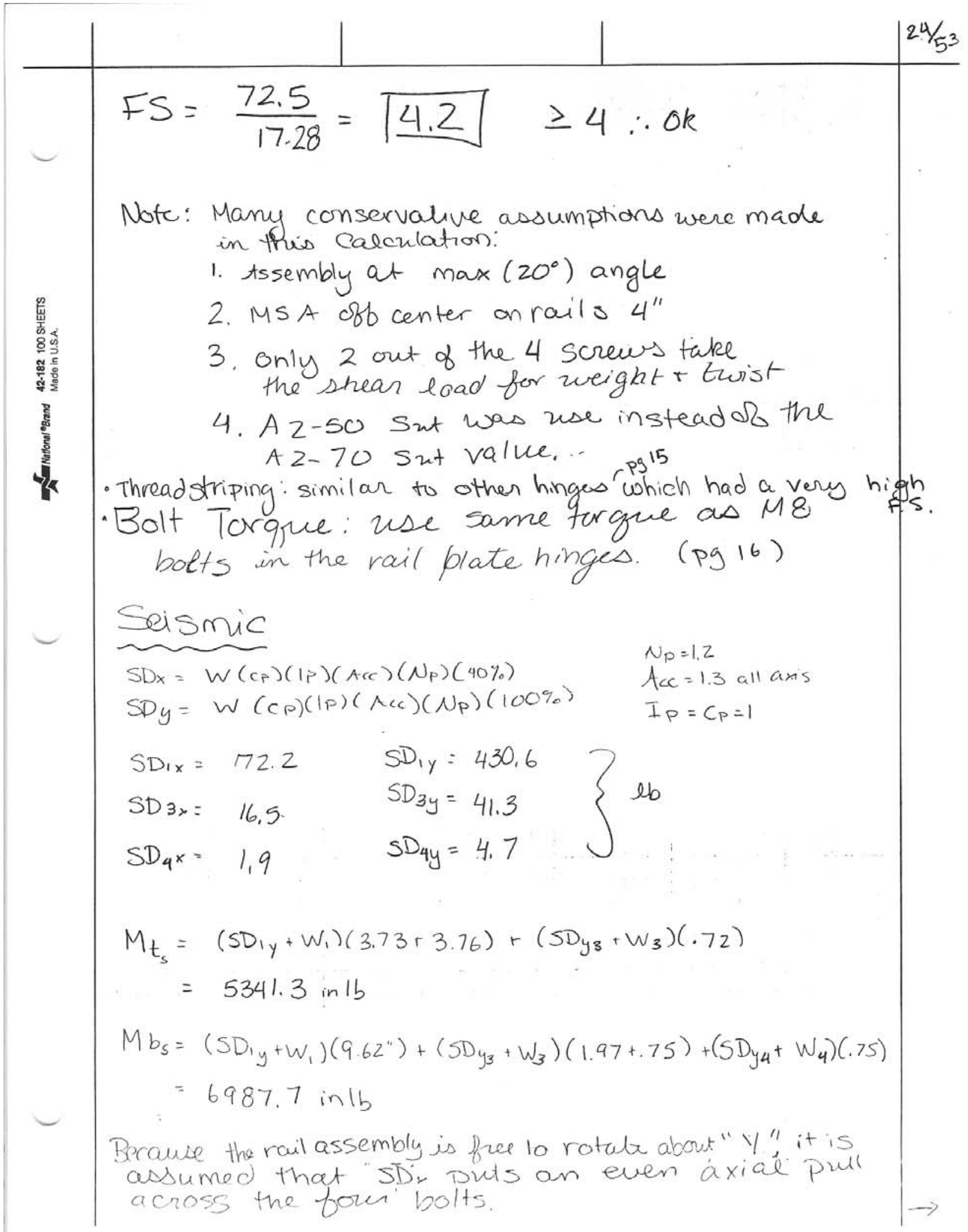




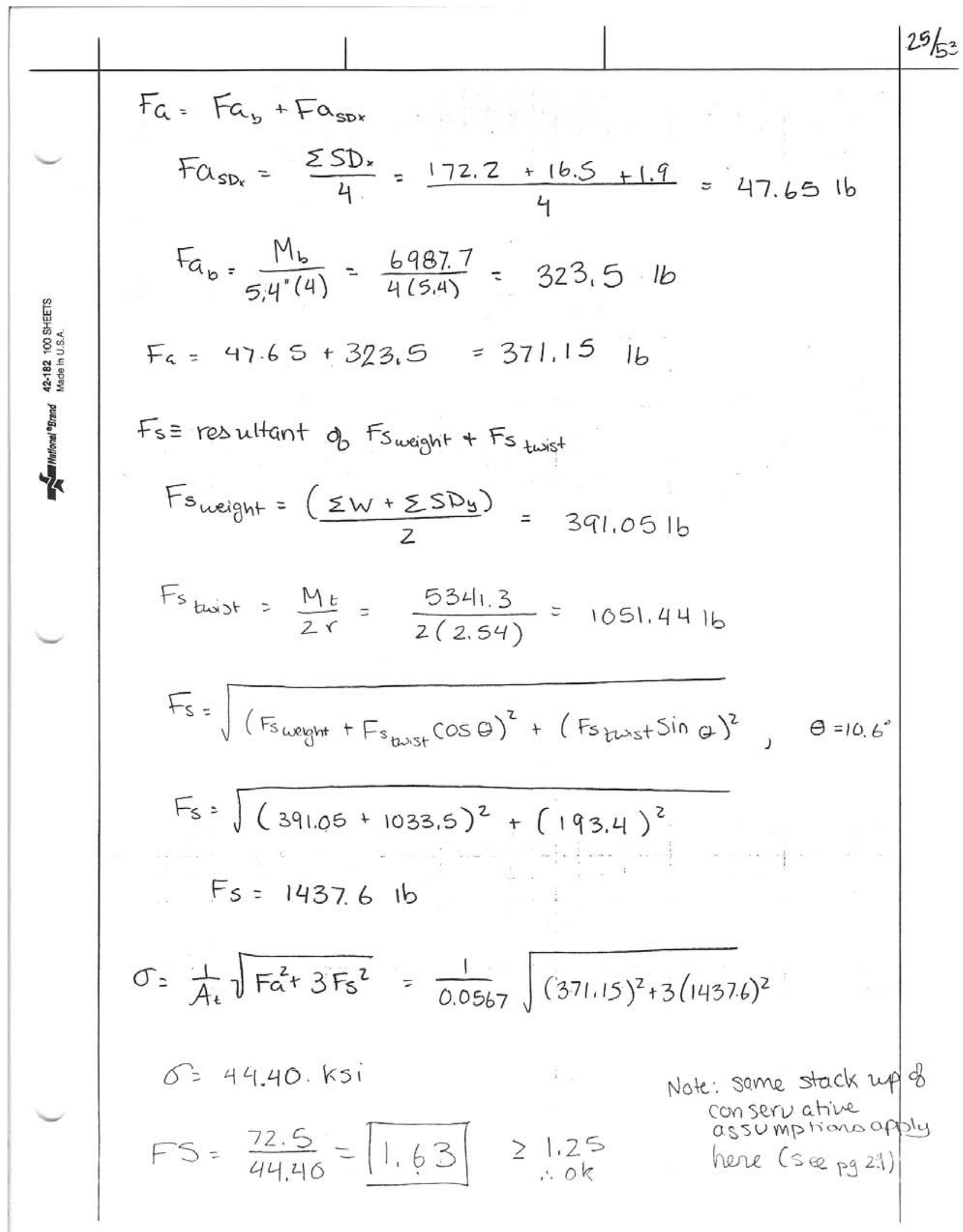




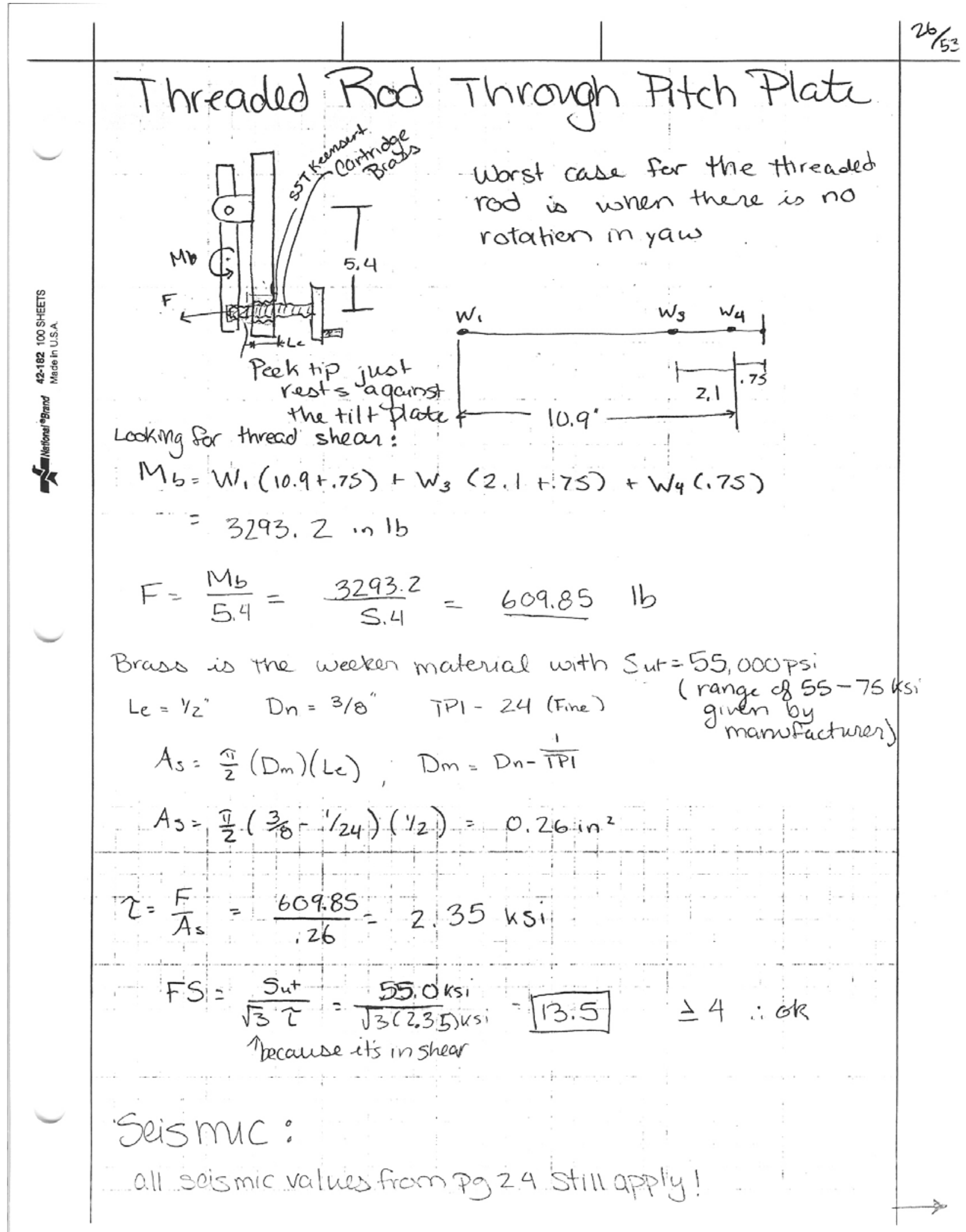




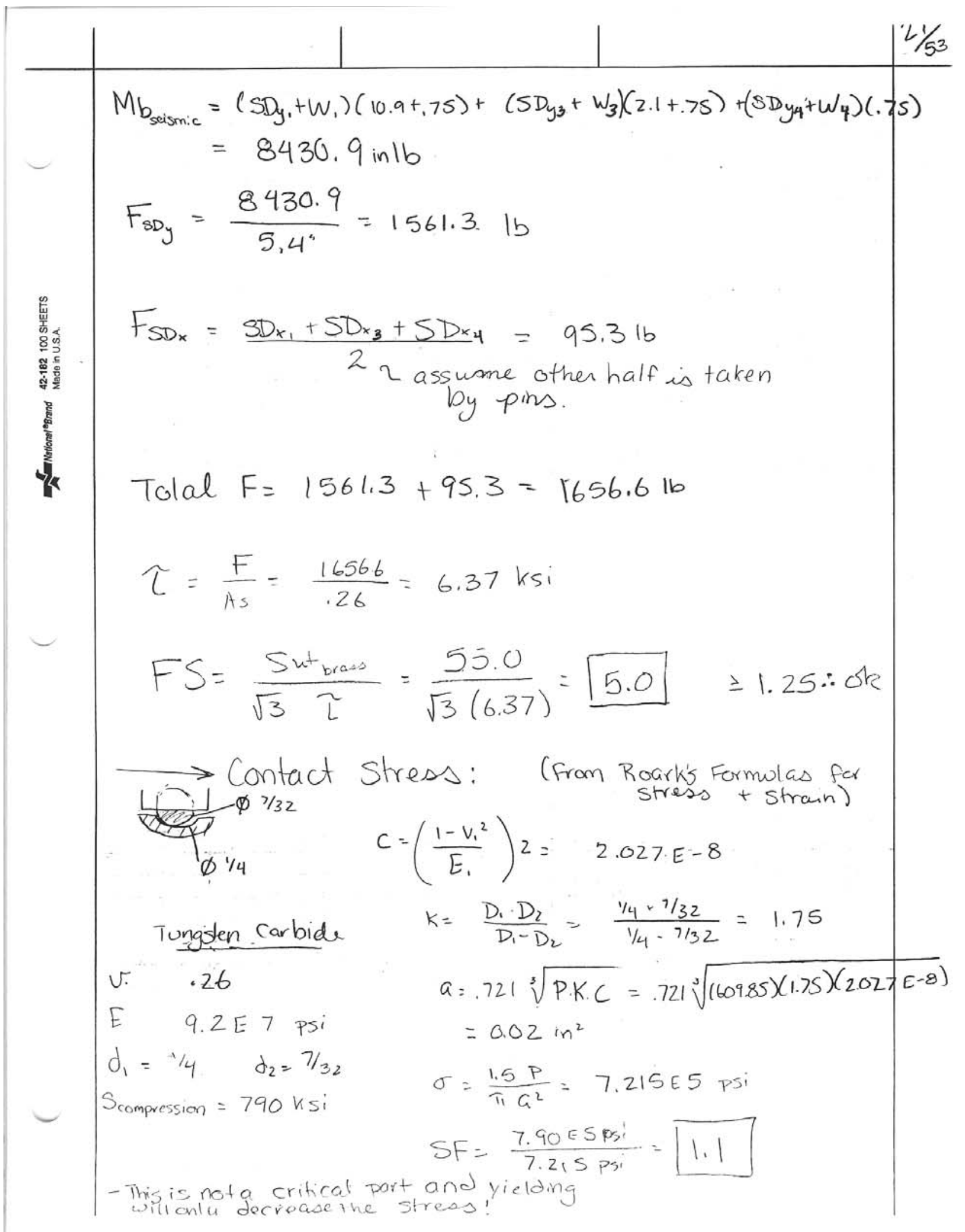




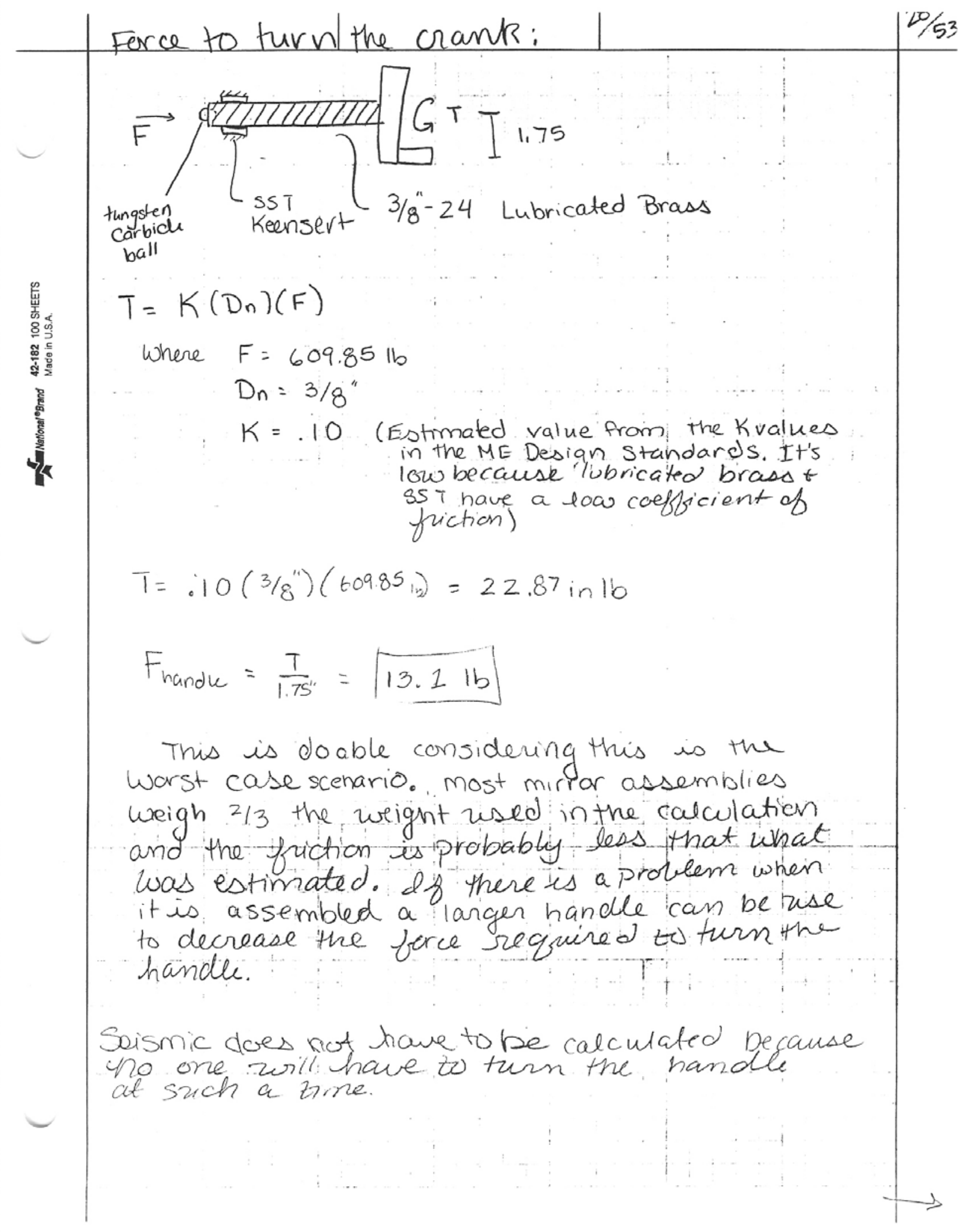




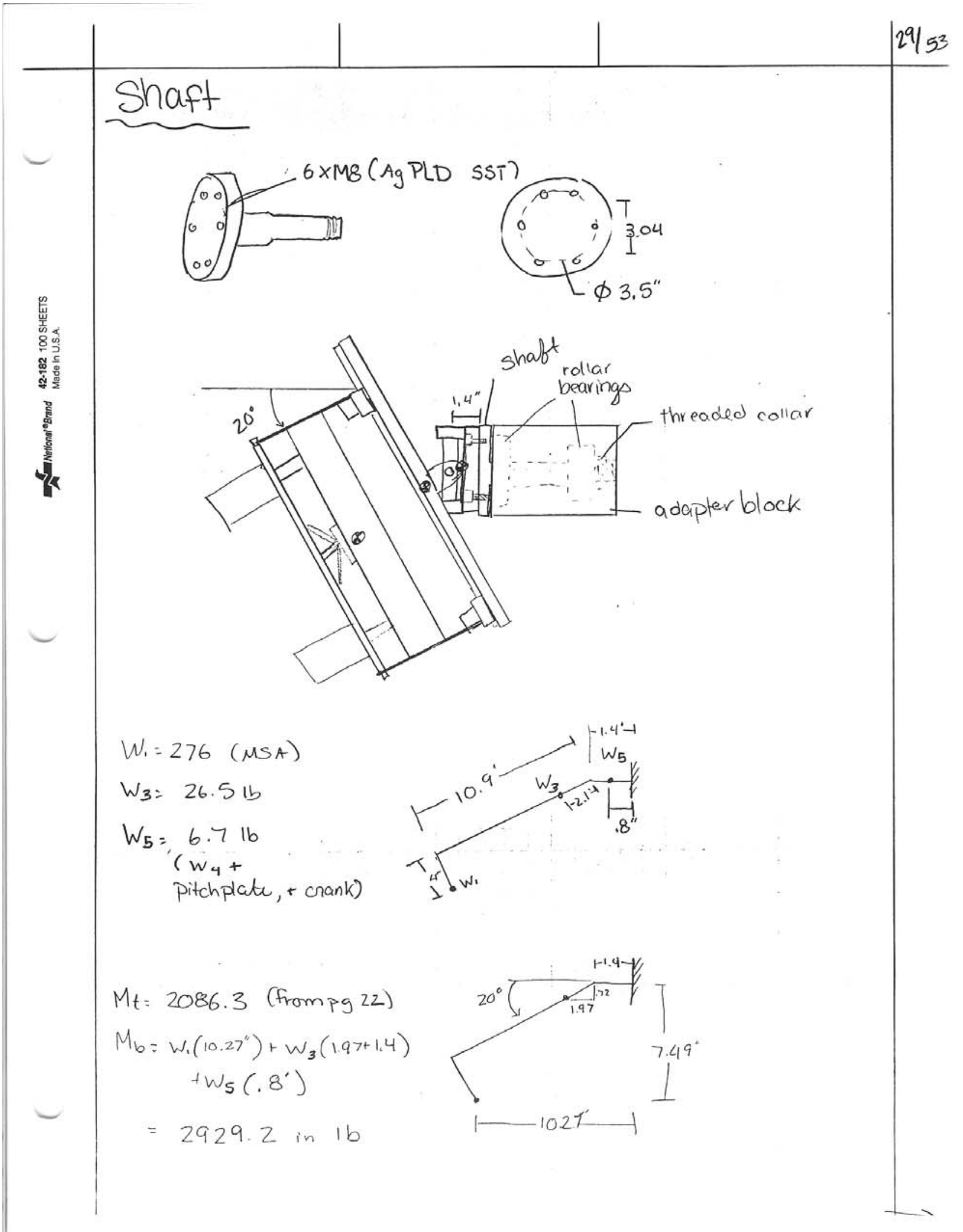




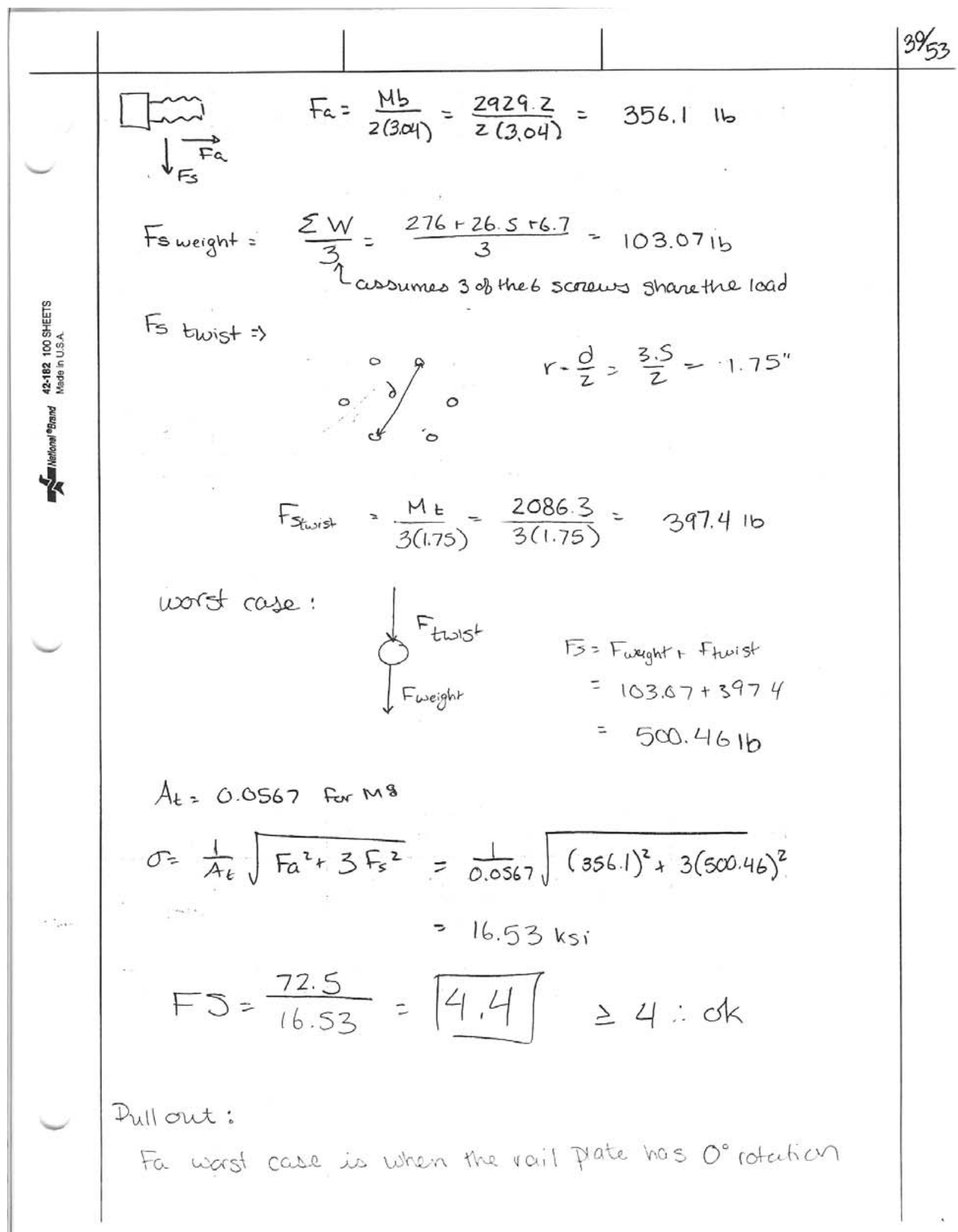




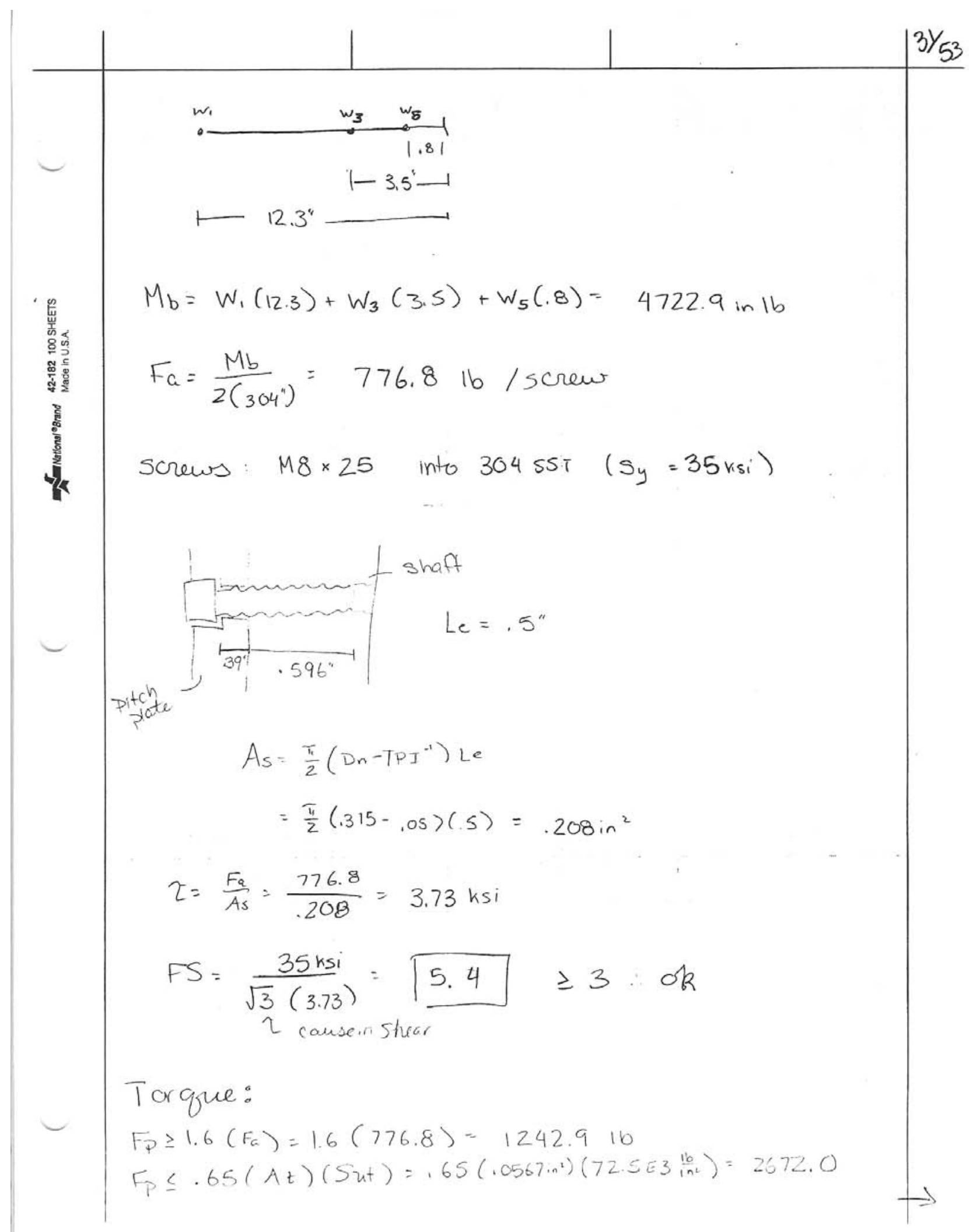




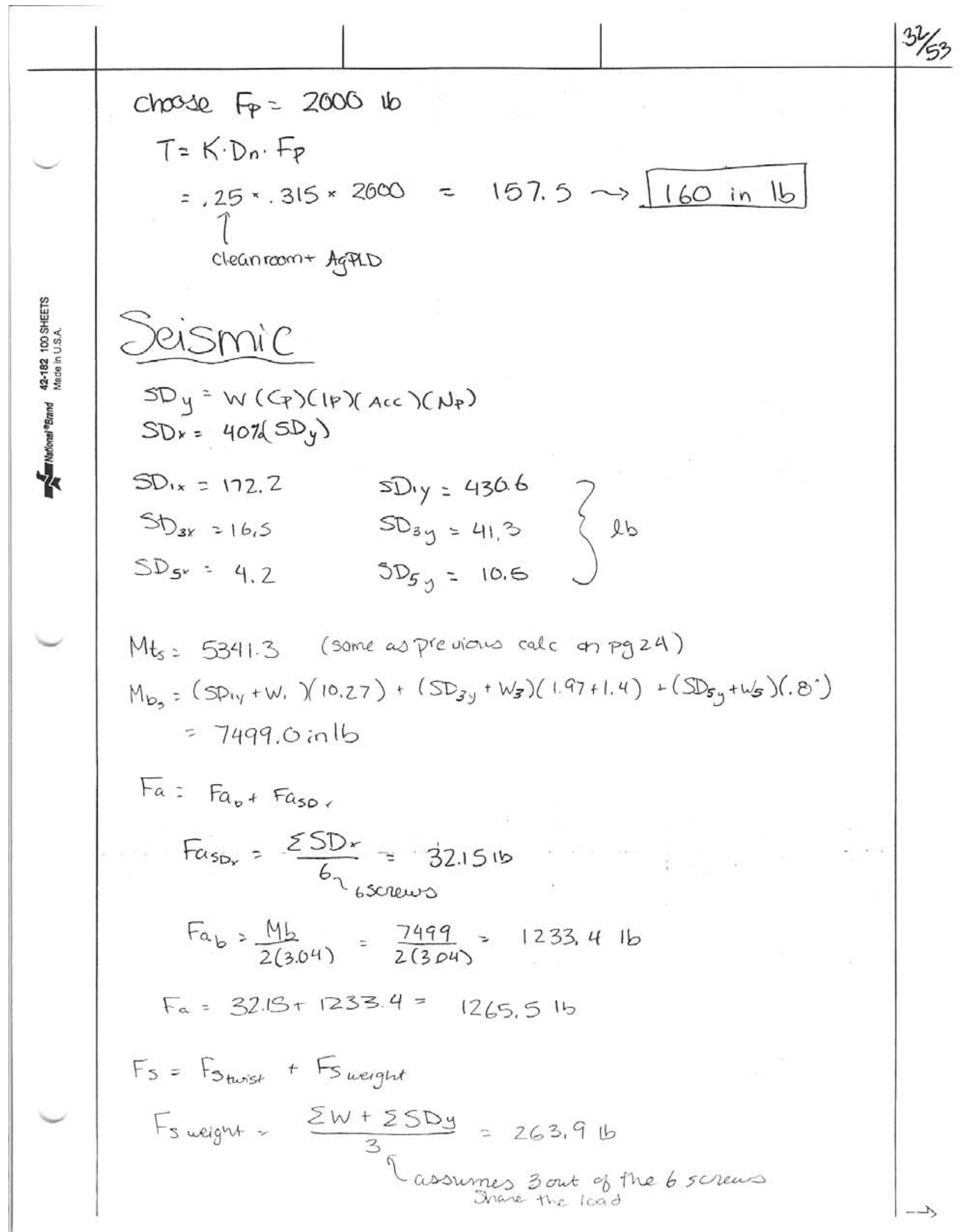




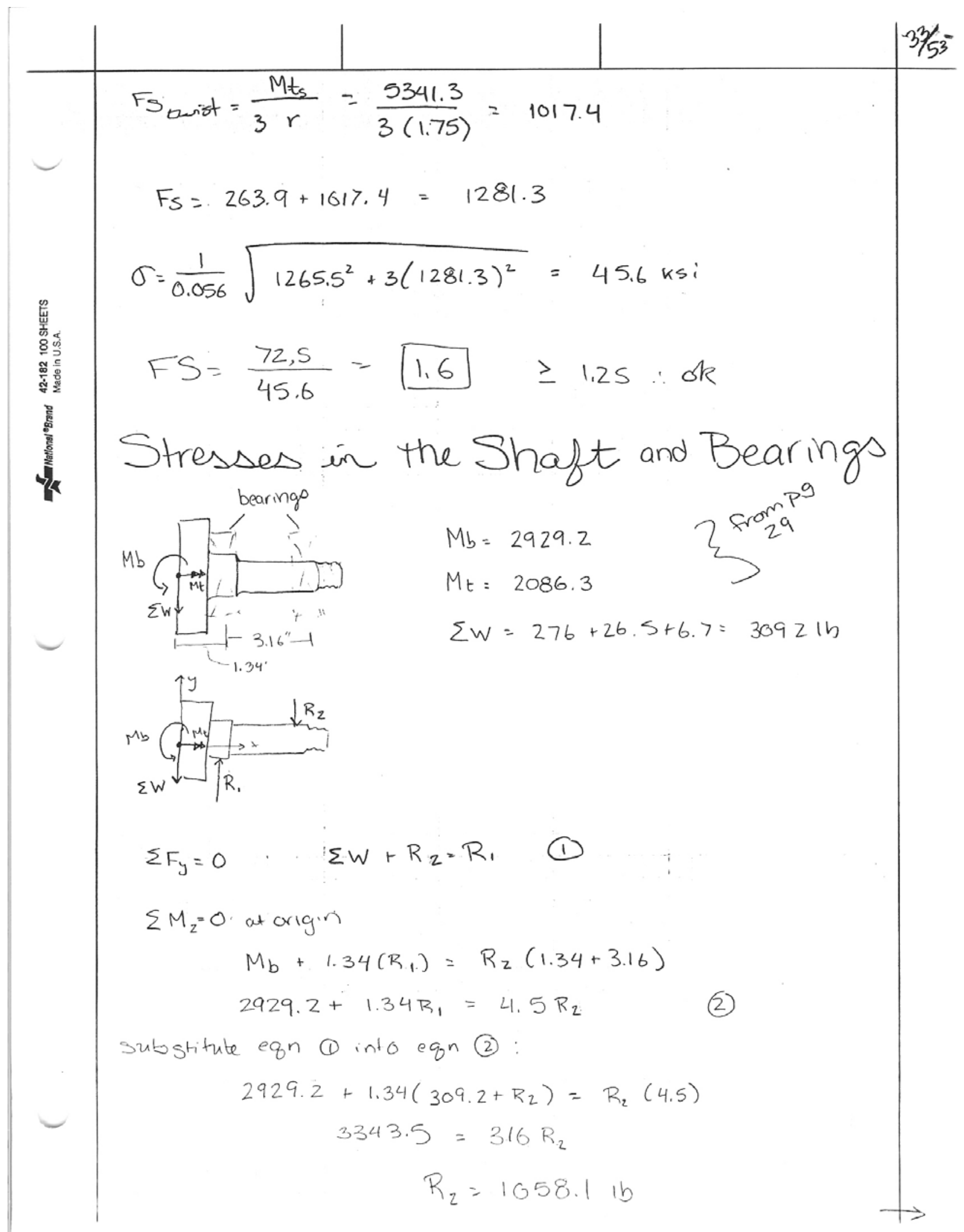




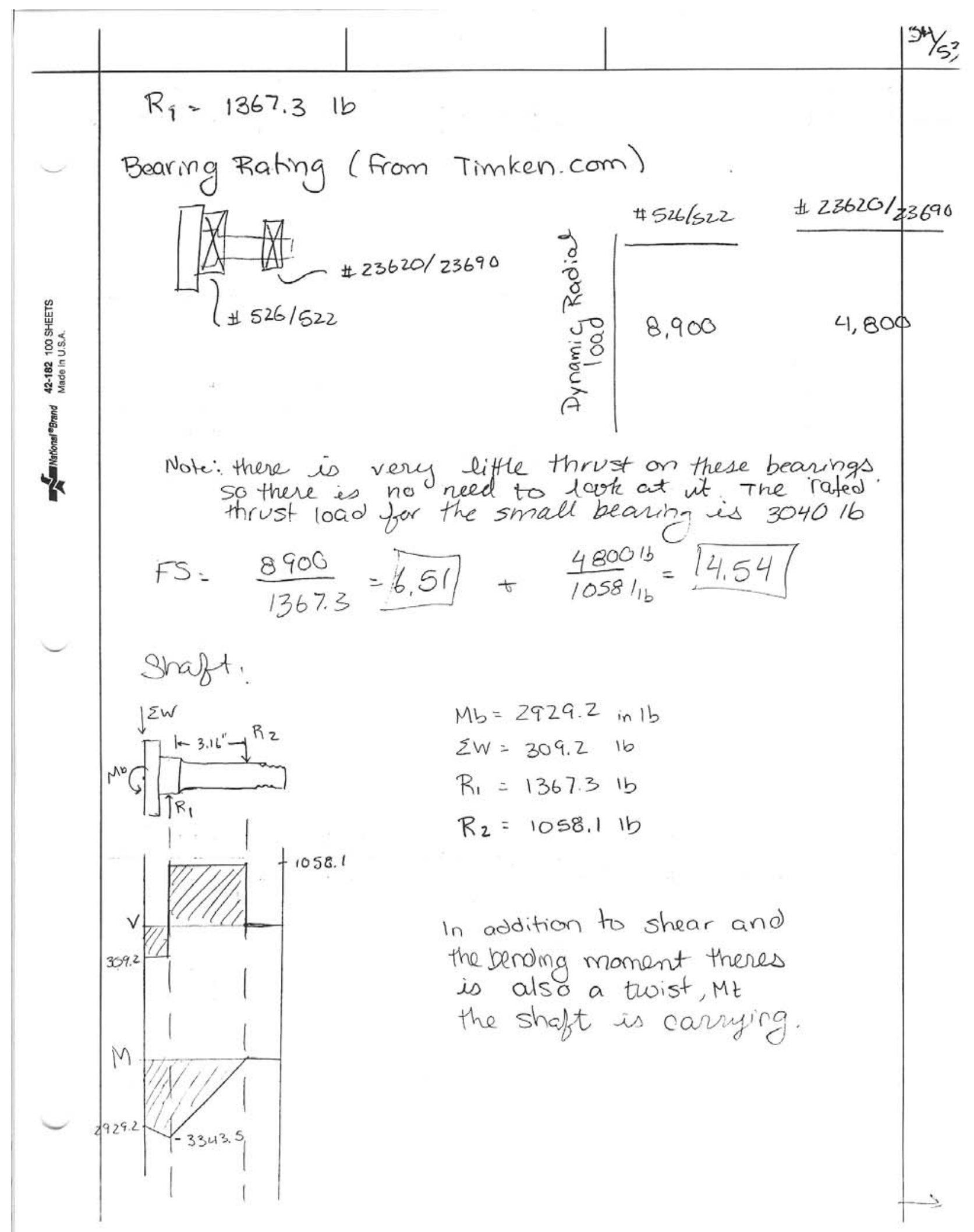




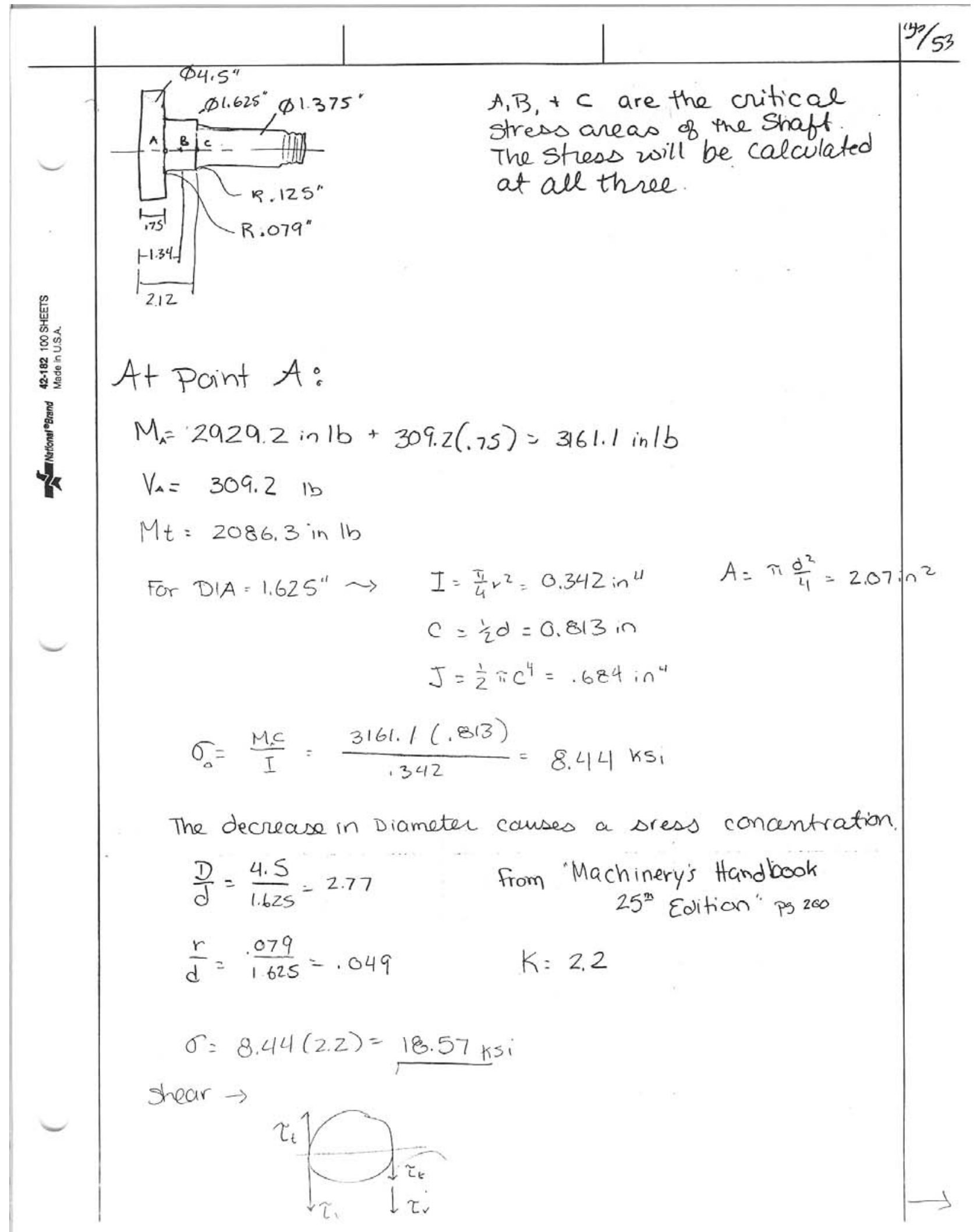




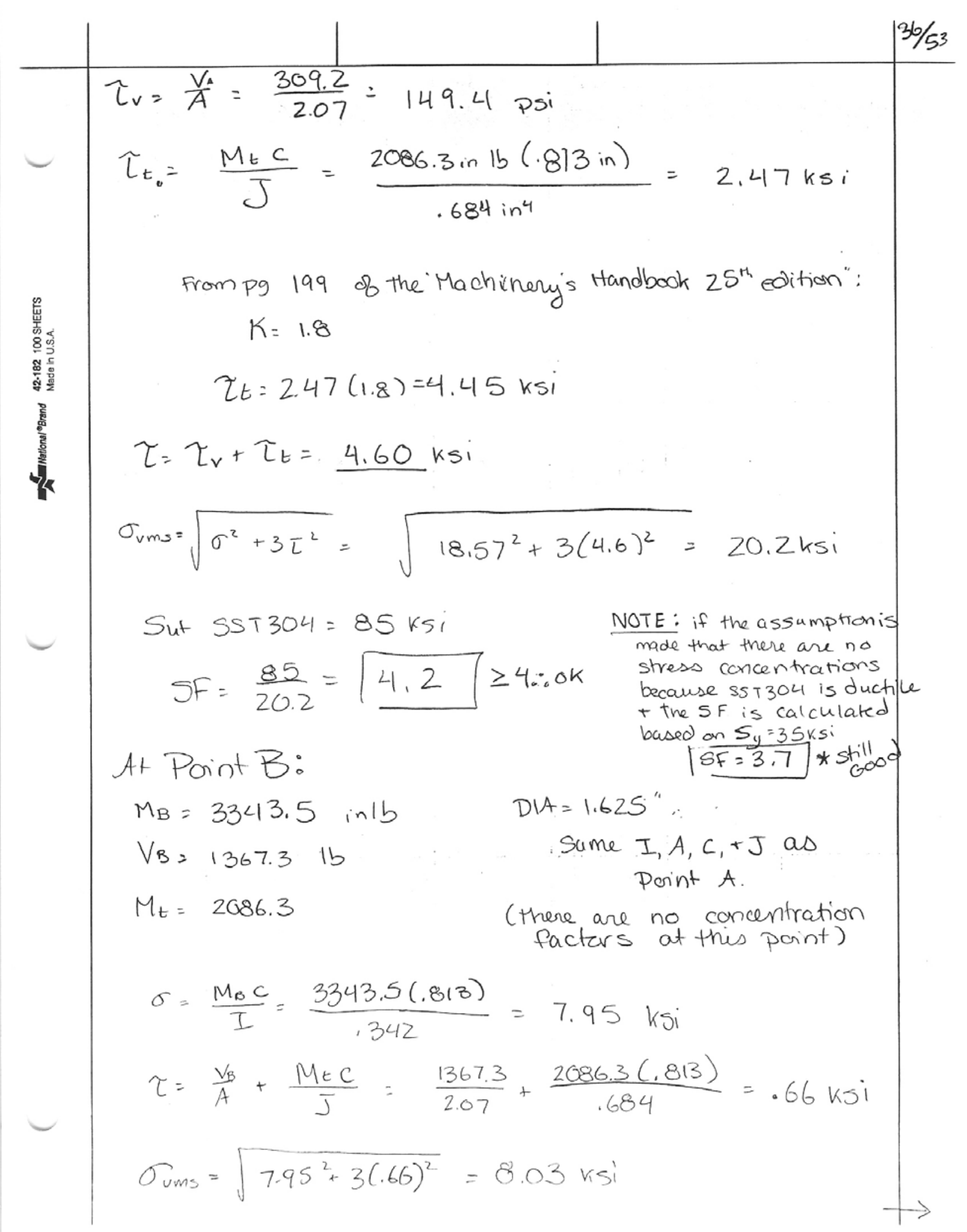




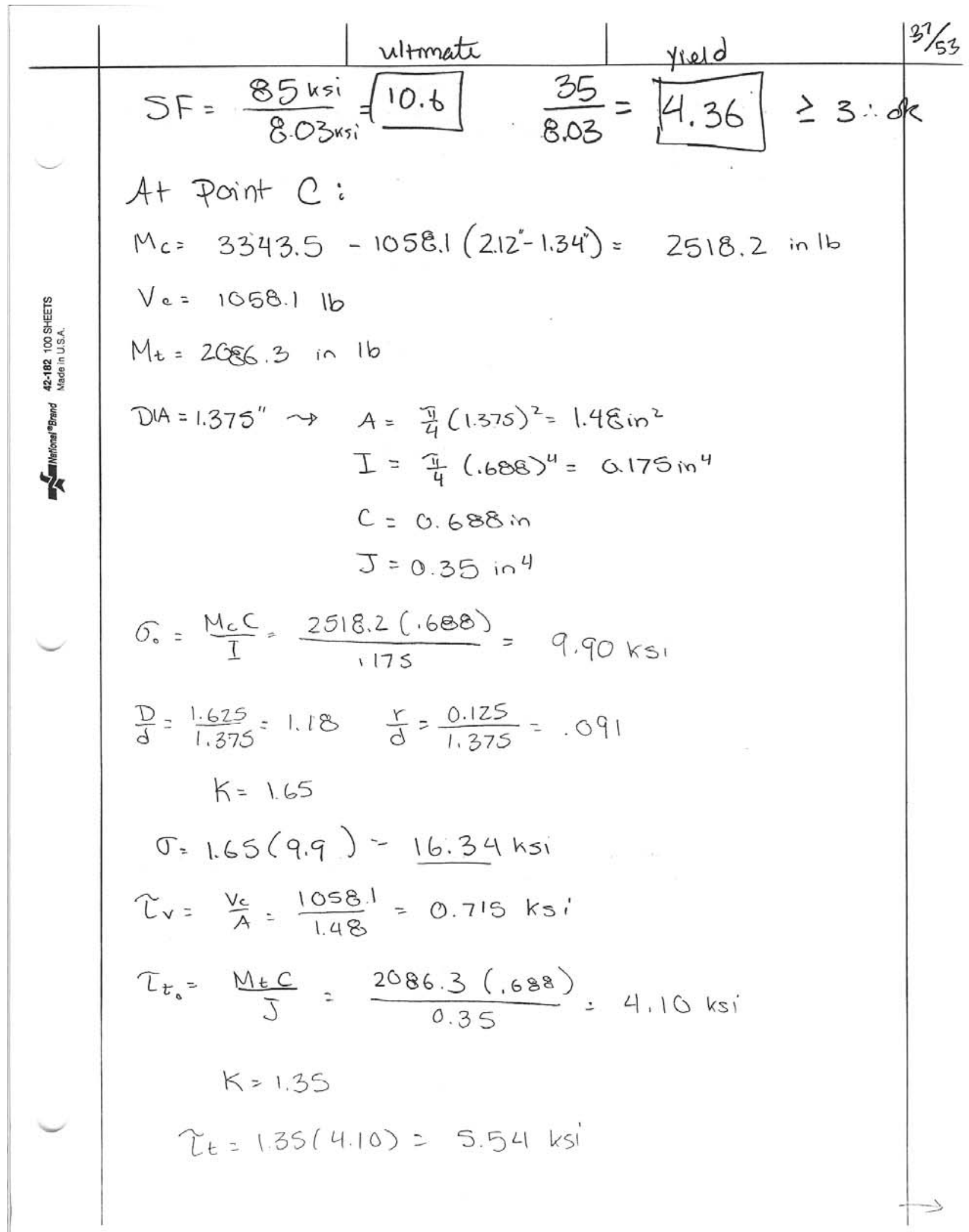




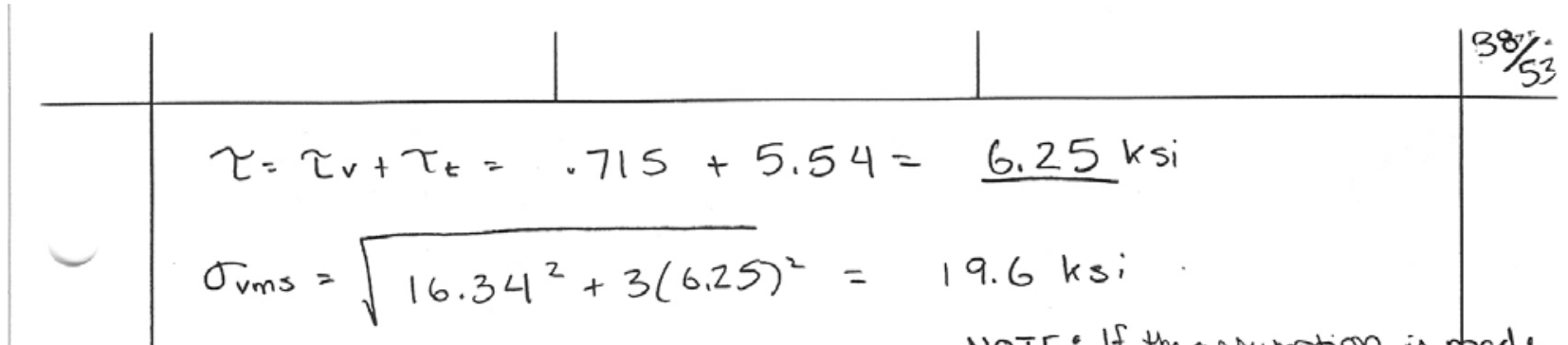

$$
S F=\frac{85}{19.6}=4.3 \geq 4
$$$$
\text { Seismic }
$$

$$
\left.\begin{array}{l}
M_{b_{s}}=7499 \text { in } 1 \mathrm{~b} \\
M_{t_{s}}=5341.3 \text { in } \mathrm{b} \\
\text { Weight }=\sum w_{+}+25 D_{y}=791.7 \mathrm{ib}
\end{array}\right\}
$$

NOTE: If the assumption is node that there are no stress concentrations because SST 304 is ductile t the SF. is calculated based on $S_{y}=35 \mathrm{ksi} F$

(pt, A)

from Pg 32 in the shaft.

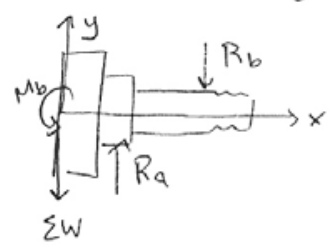

$$
\begin{aligned}
& \rightarrow \times \quad \sum F_{y}=0 \quad 791.7+R b=R_{a} \text { (1) } \\
& \sum M_{z} \text { at origan }=0 \\
& M b_{s}+R_{a}(1.34)=R_{b}(134+3.16)
\end{aligned}
$$$$
7499+1.34 R_{a}=4.5 R b
$$

Substitute eqn (1) into (2)

$$
\begin{gathered}
7499+1.34\left(791.7+R_{b}\right)=4.5 R b \\
R_{b}=2708.8 \mathrm{~b} \\
R_{a}=3500.5 \mathrm{lb}
\end{gathered}
$$

Sha rt Moment Dagainit on next page 


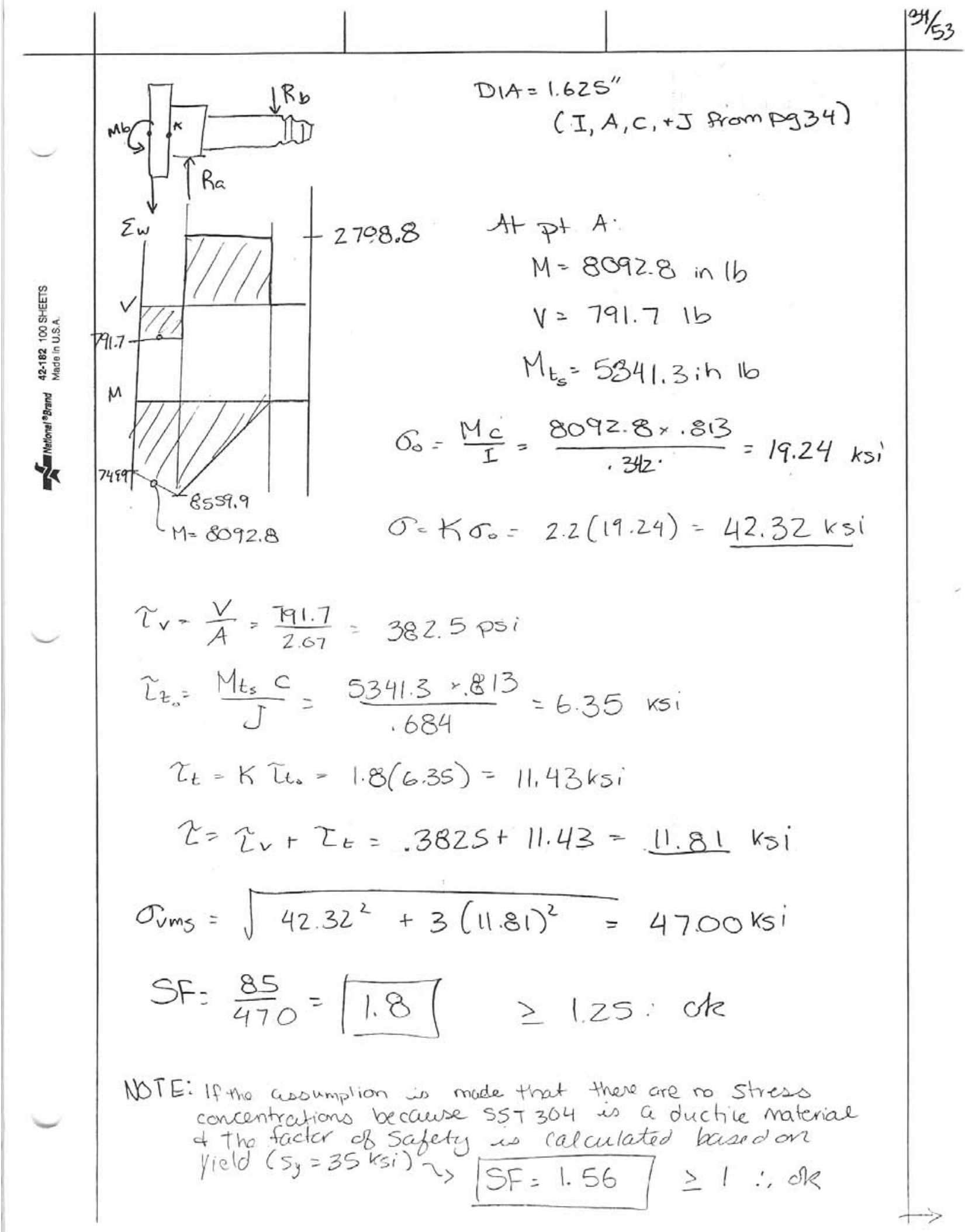




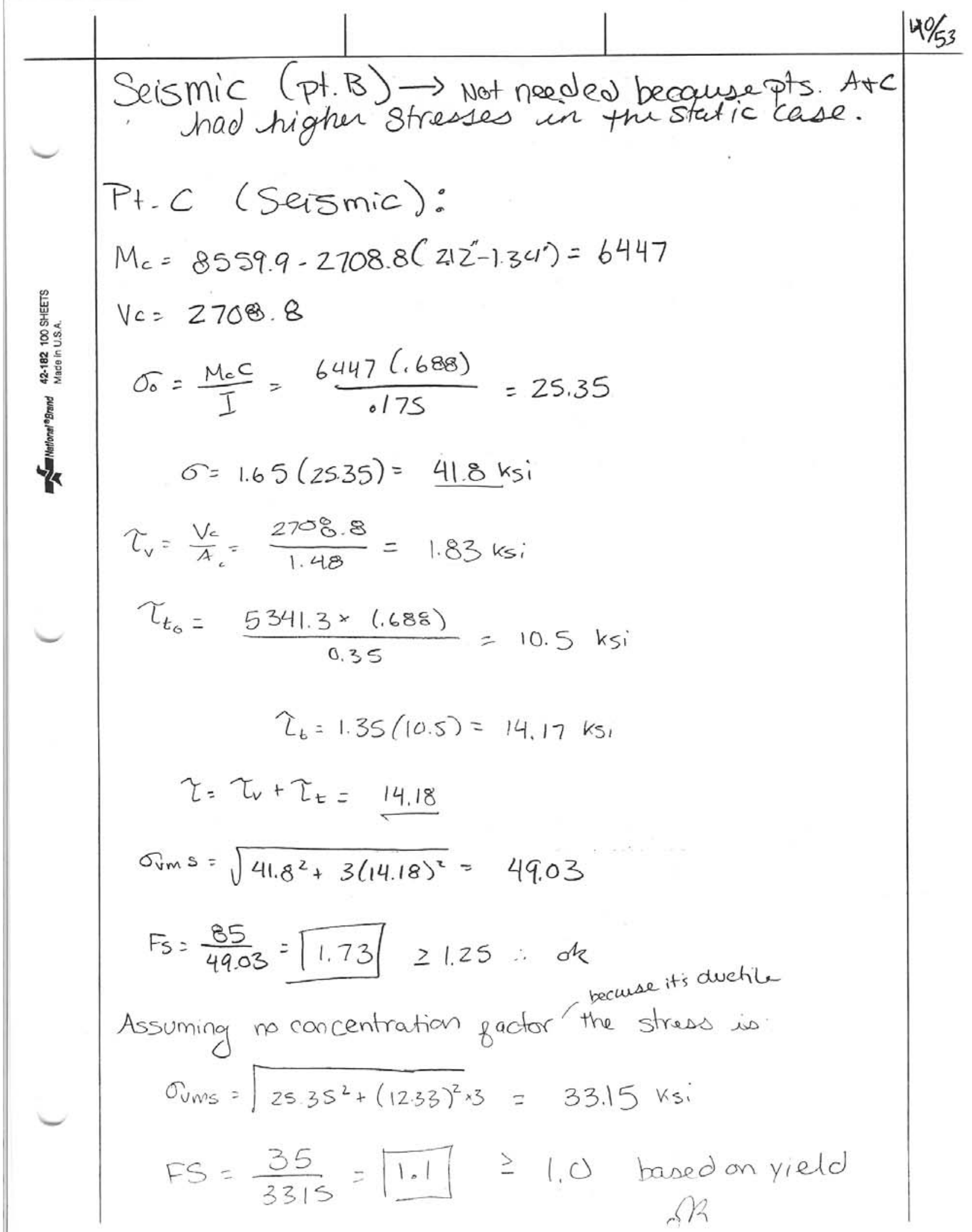




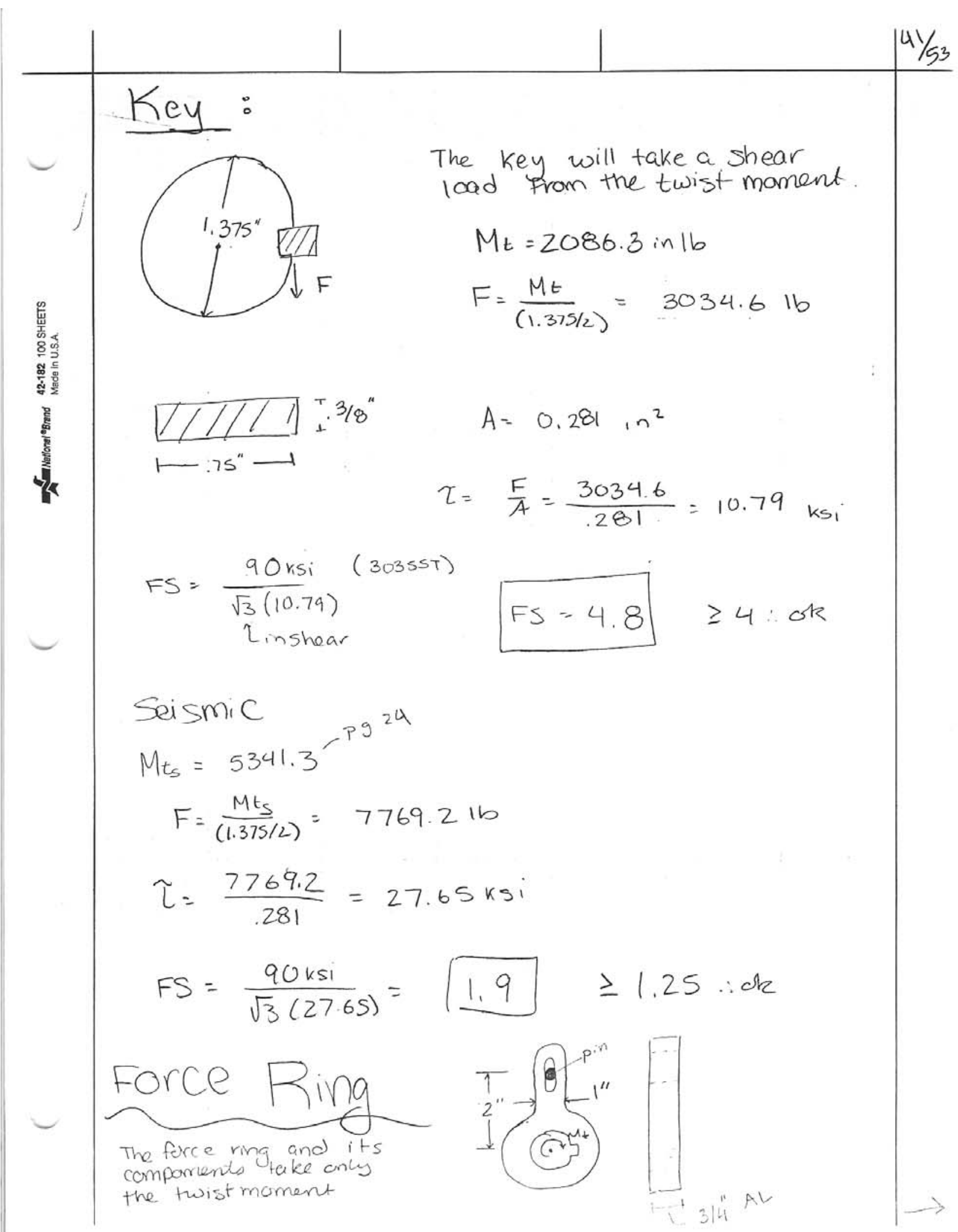




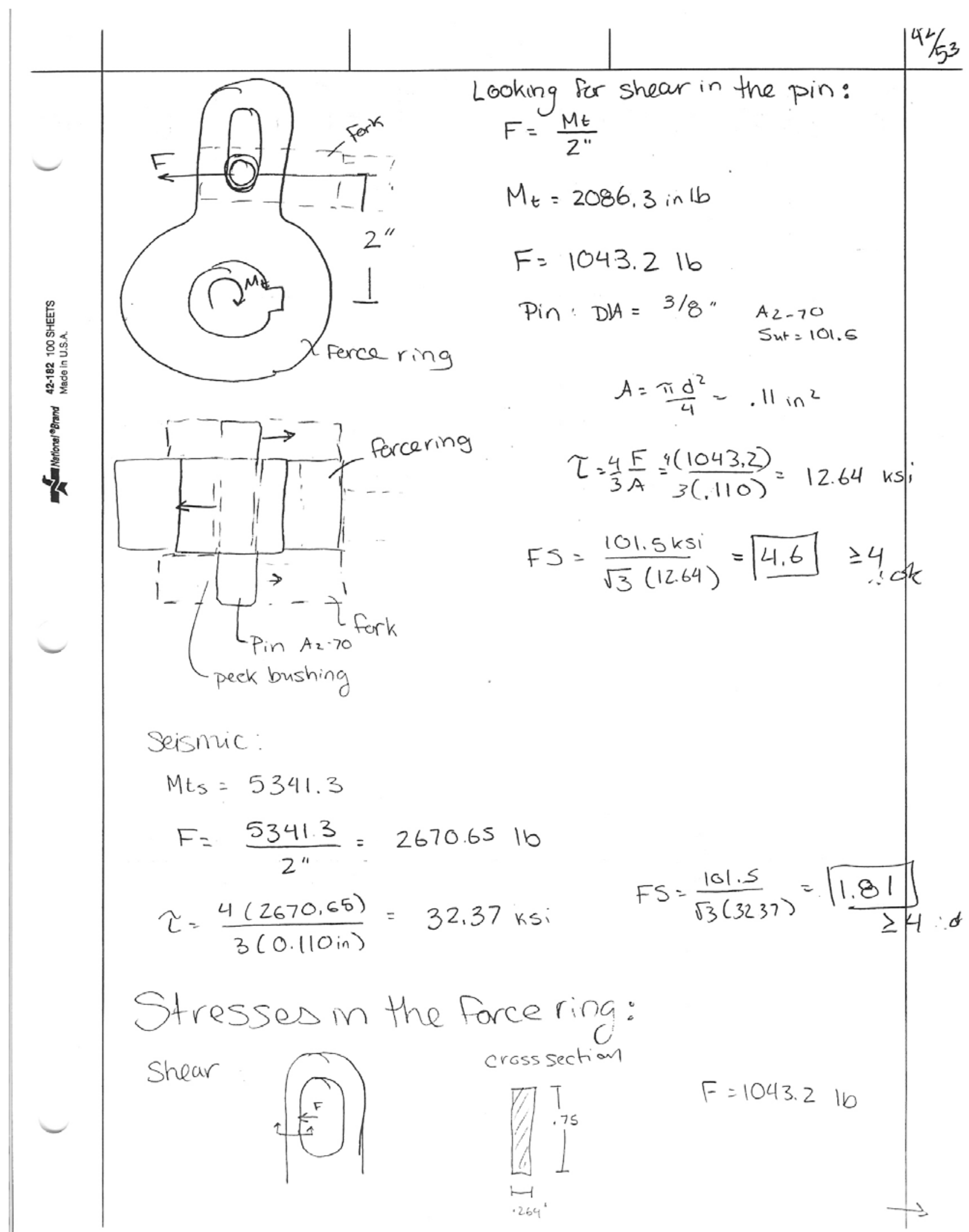




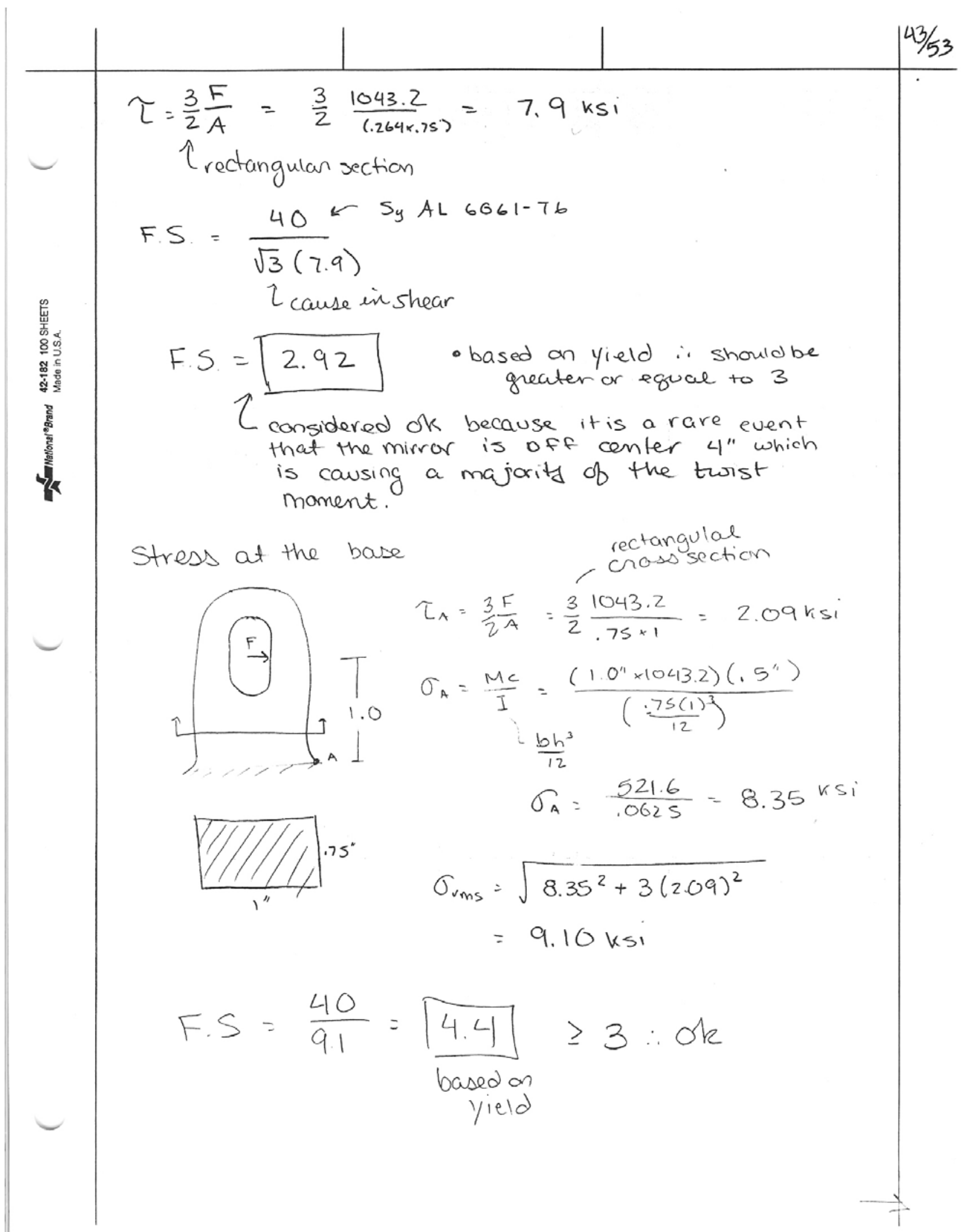




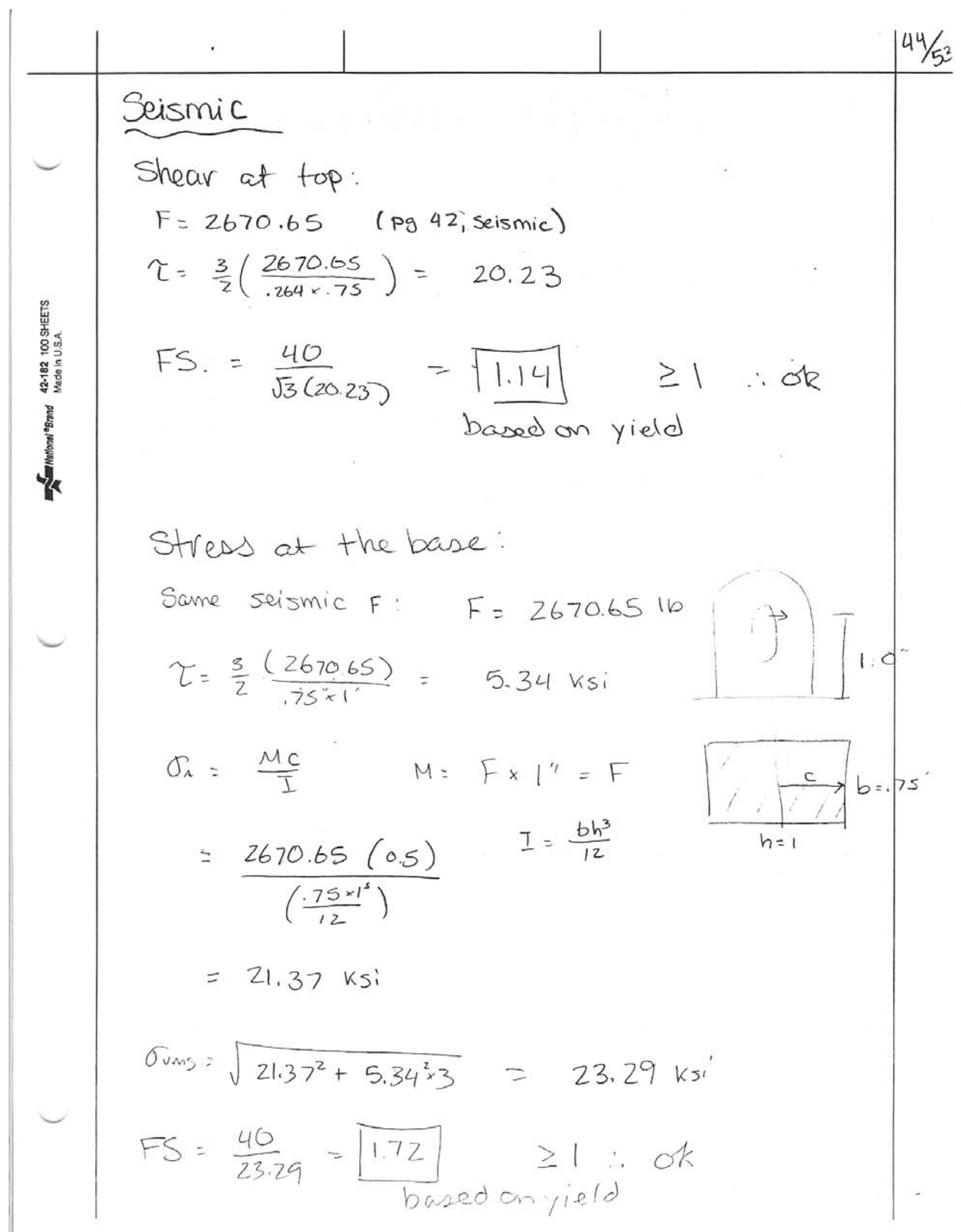




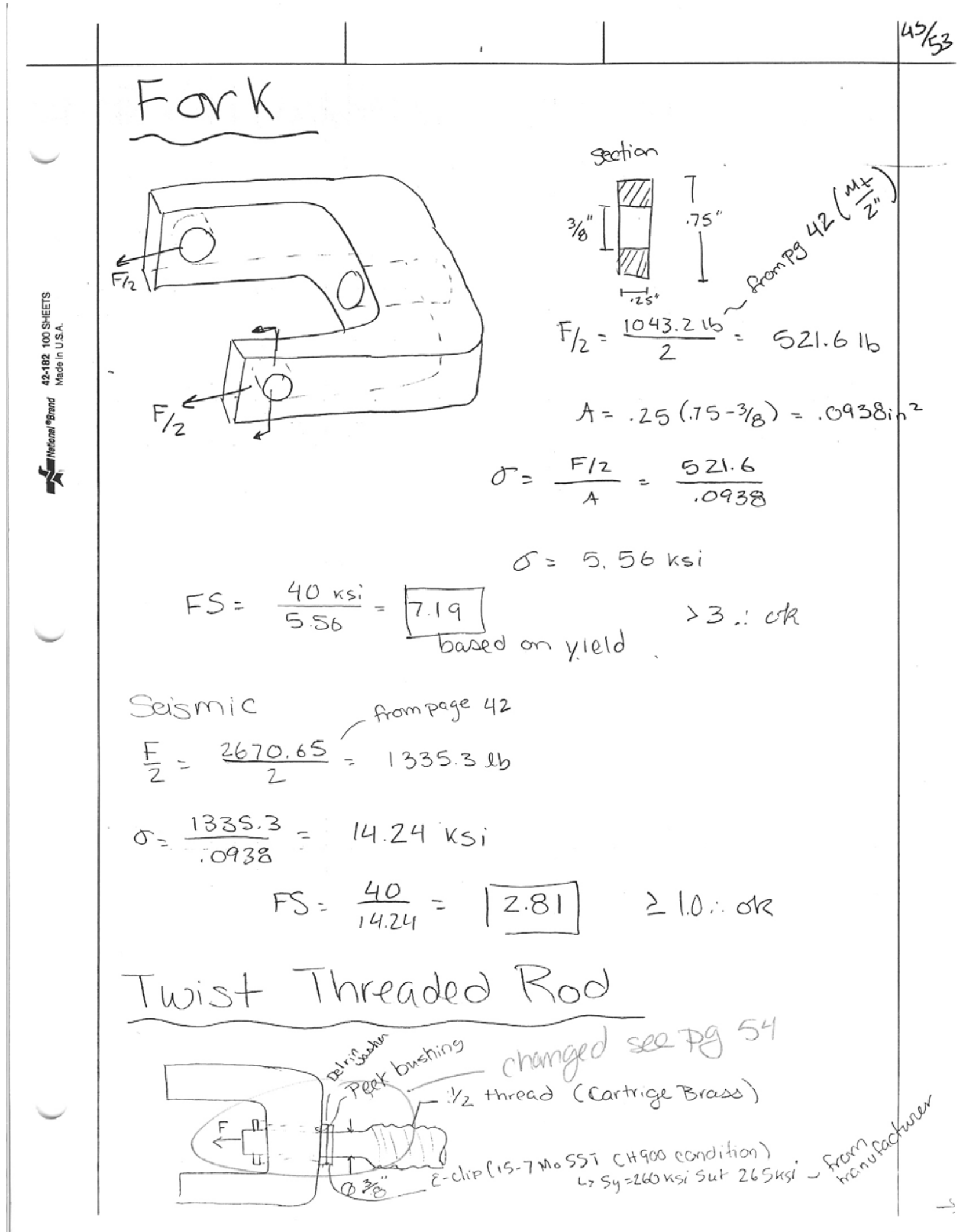




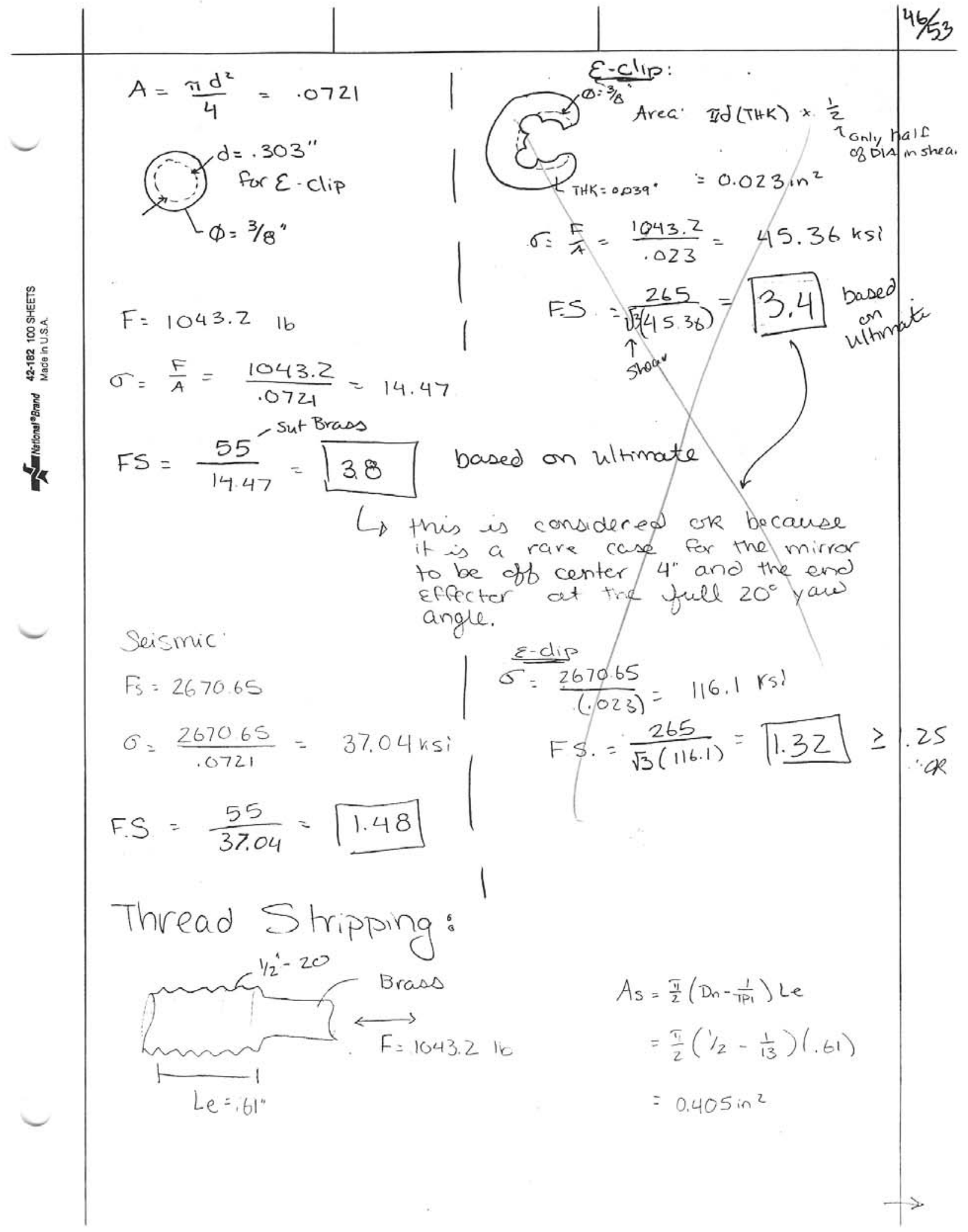




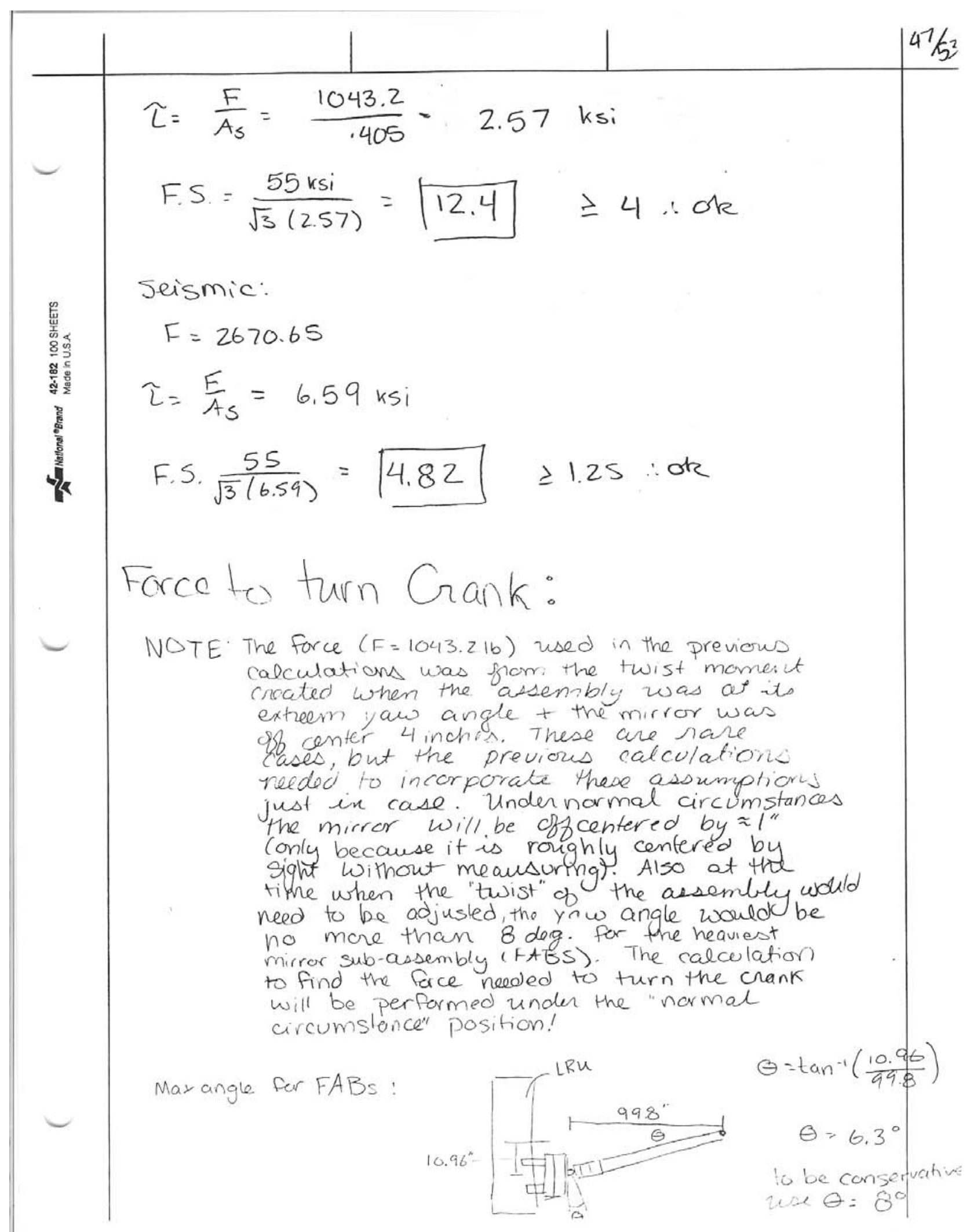




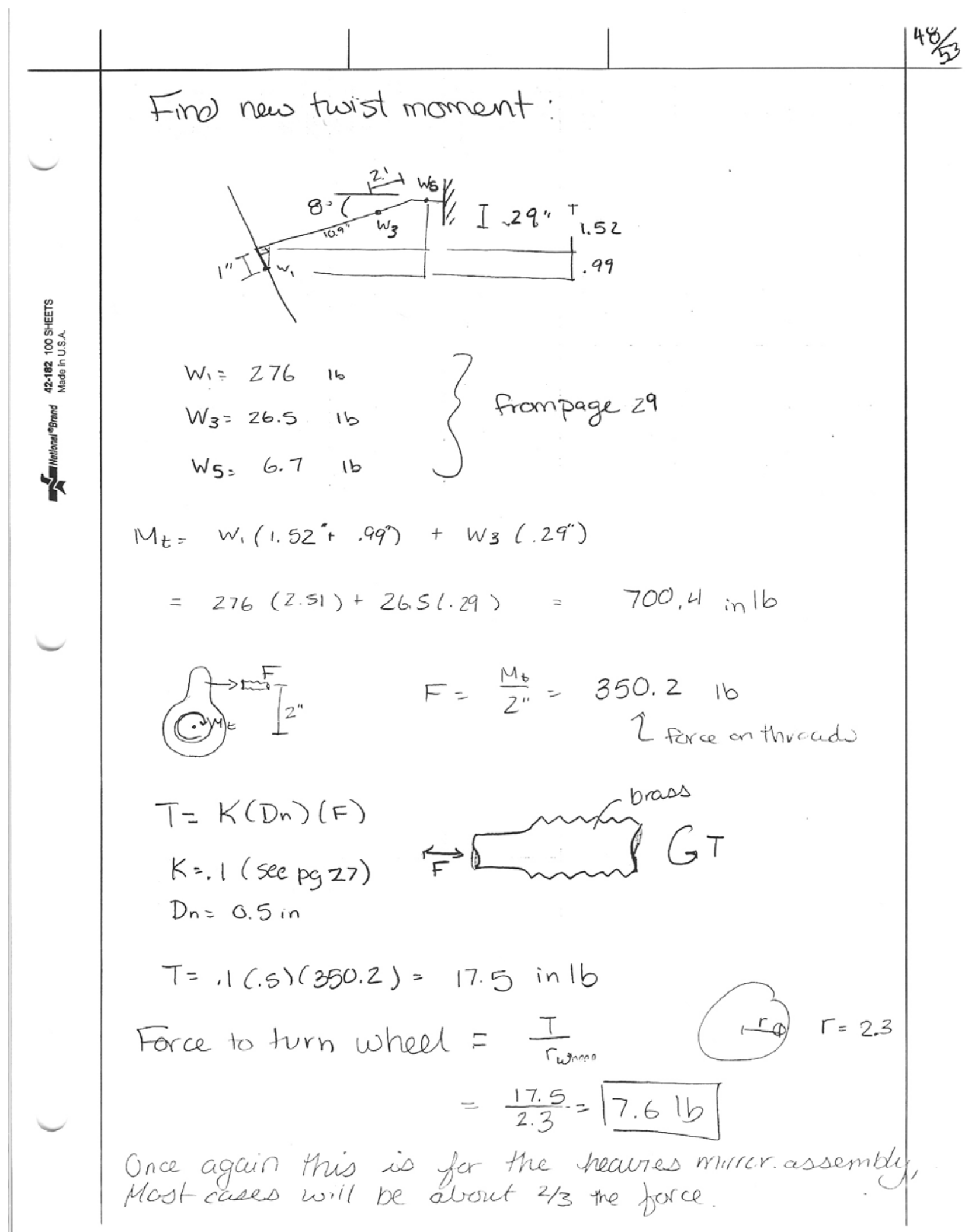




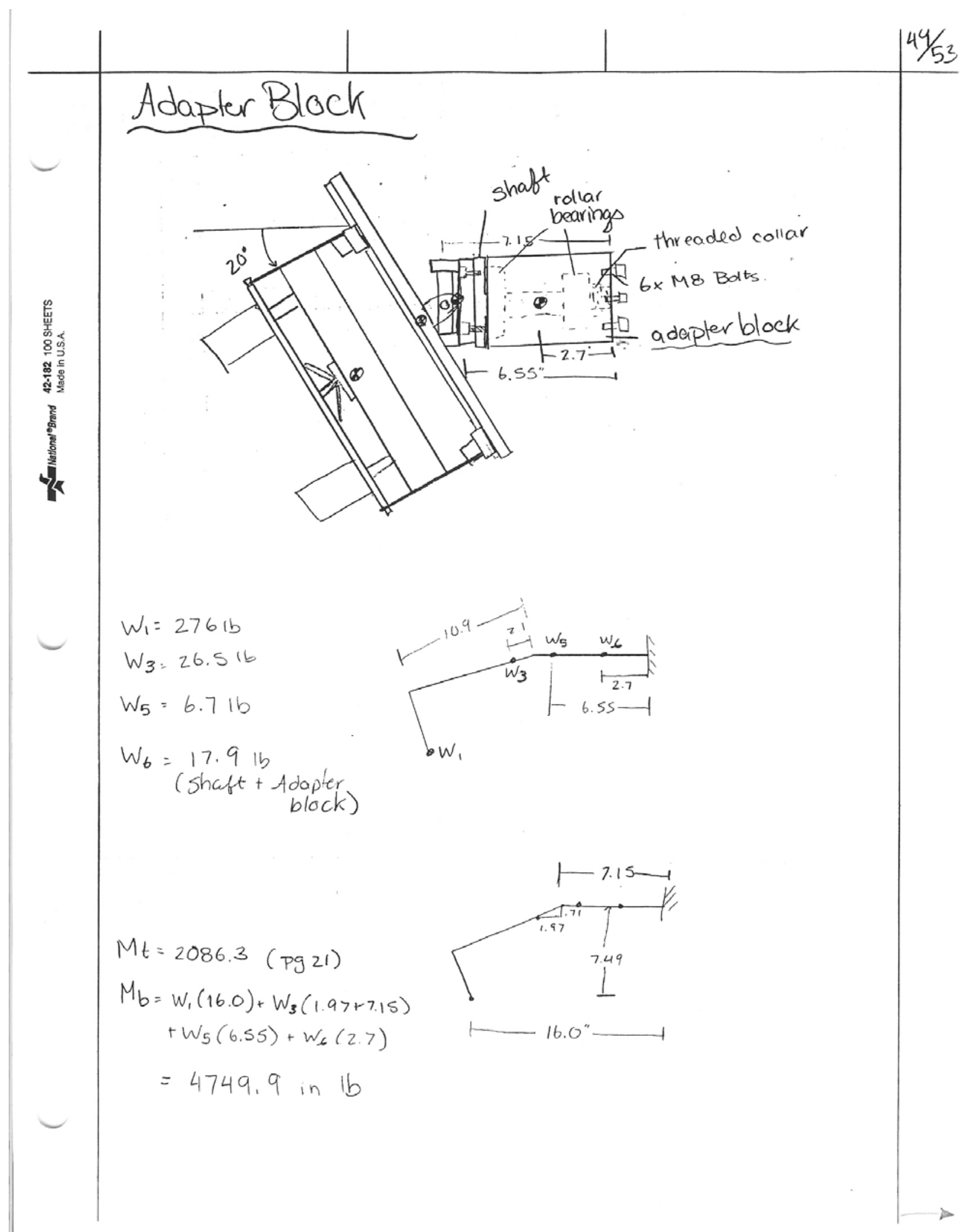




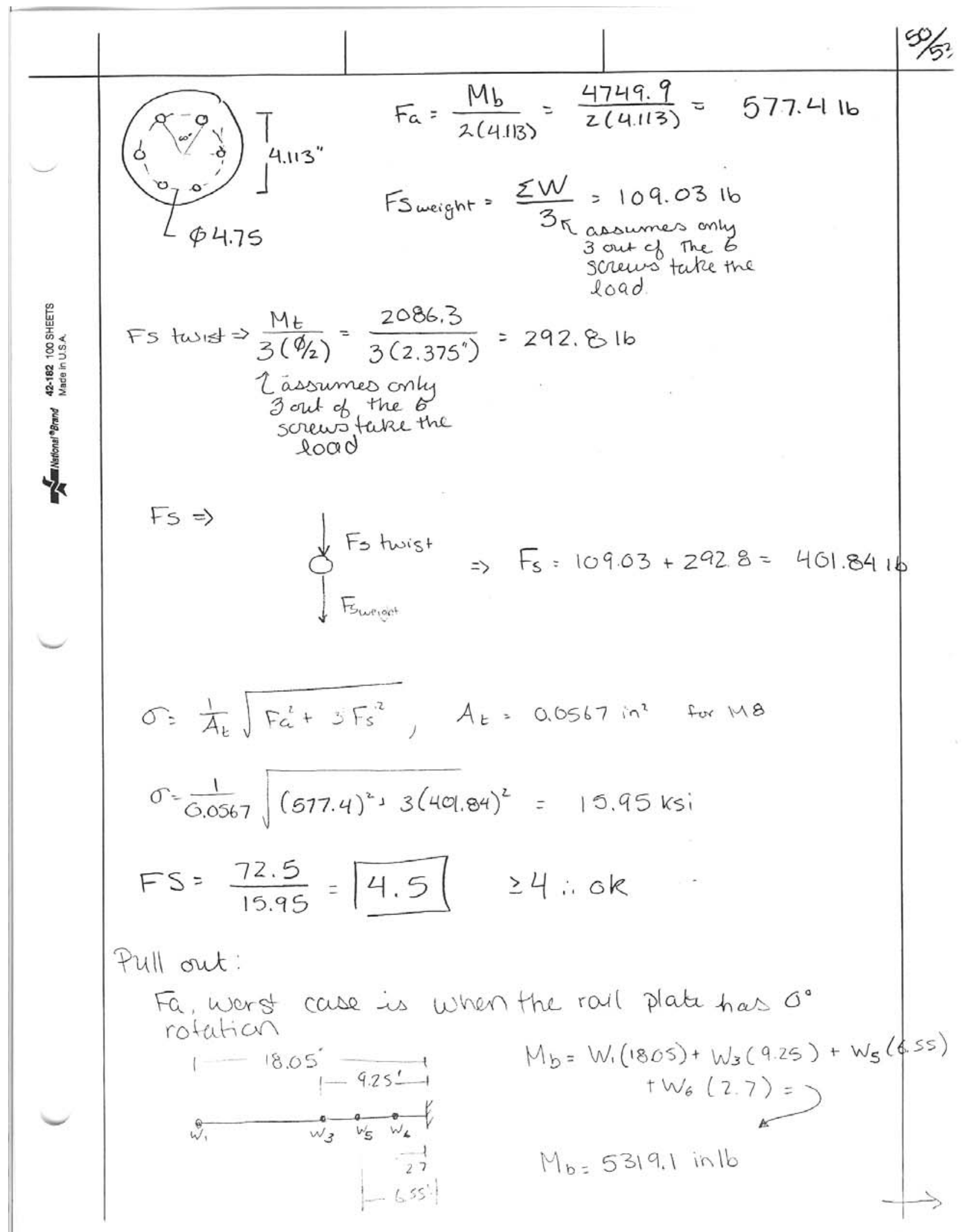




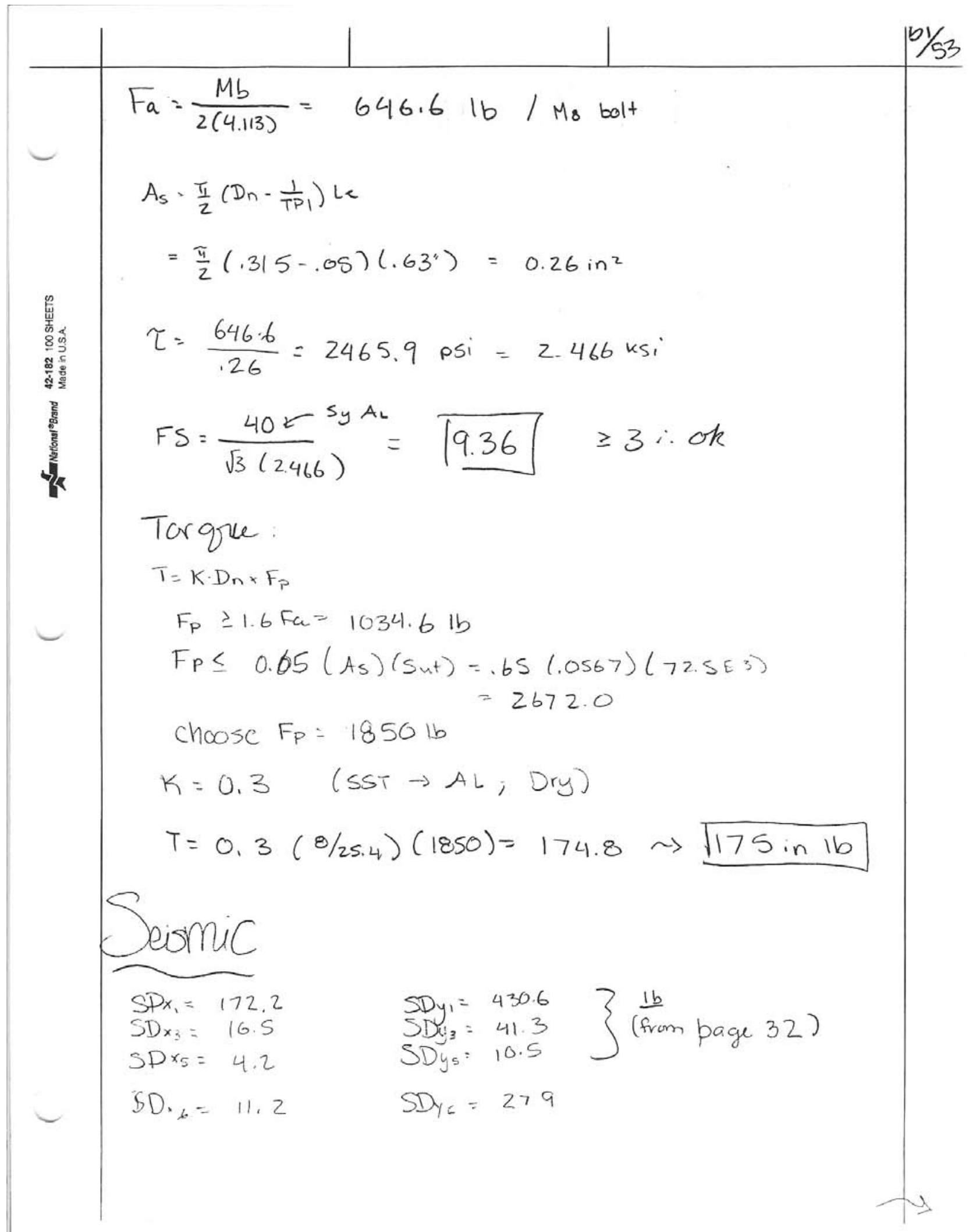




$$
\begin{aligned}
& \begin{array}{l|l|l|l|l}
02 & & 53 \\
\hline
\end{array} \\
& \begin{array}{c}
M_{t}=5341.3 \mathrm{ib}\left(W_{4}\right. \text { does not add to twist, so it's the } \\
\text { Same as on } 9 \text { g } 40 \text { ) }
\end{array} \\
& M_{b_{s}}=\left(W_{1}+S D_{y_{1}}\right)(16)+\left(W_{3}+S D_{y_{3}}\right)(1.97+7.15)+\left(W_{5}+S D_{y_{5}}\right)(6.55) \\
& +\left(W_{6}+\operatorname{SDy}_{6}\right)(2.7) \\
& =12,160 \text { in. } 15
\end{aligned}
$$

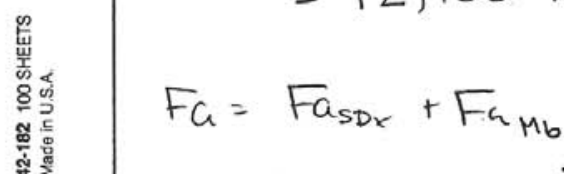

$$
\begin{aligned}
& \text { FasDx }=\frac{\sum S D_{x}}{6}=34.0210 \\
& F_{M_{b}}=\frac{M b}{3\left(4.113^{\prime \prime}\right)}=985.49 \mathrm{lb} \\
& F a=1019.51 b \\
& F_{S}=F_{S \text { twist }}+F_{S} \text { weight } \\
& F_{\text {stwist }}=\frac{M t_{S}}{3(\Phi / 2)}=\frac{5341.3}{3(2.375)}=749.6616 \\
& F_{\text {sweigtt }}=\frac{\sum S D_{y}+\sum W}{3}=279.13 \mathrm{lb} \\
& F=1028.81 \mathrm{~b} \\
& \sigma=\frac{1}{0.0567} \sqrt{(1019.5)^{2}+3(1028.8)^{2}}=36.21 \mathrm{ks} 1 \\
& F S=\frac{72.5}{36.2}=2.0 \quad \therefore .25
\end{aligned}
$$




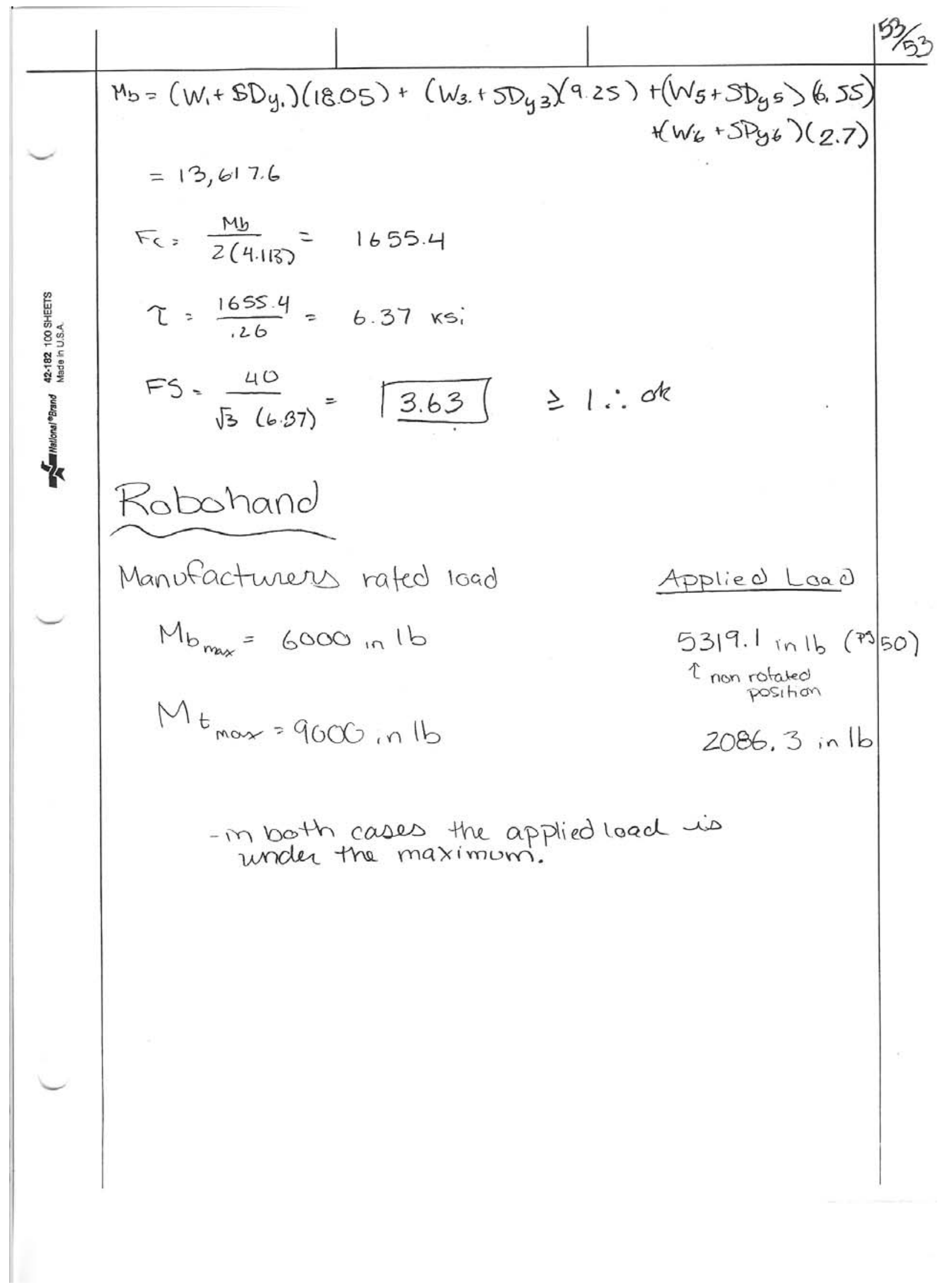

